UNIVERSIDADE DE SÃO PAULO

ESCOLA DE ENGENHARIA DE SÃO CARLOS

FACULDADE DE MEDICINA DE RIBEIRÃO PRETO

INSTITUTO DE QUÍMICA DE SÃO CARLOS

ANA CAROLINA TREVISAN

AVALIAÇÃO DE DIFERENTES MÉTODOS DE RECONSTRUÇÃO DE

IMAGENS NO PROCESSAMENTO DE SPECT CEREBRAL COM SIMULADOR ANTROPOMÓRFICO ESTRIATAL

São Carlos, 


\section{AVALIAÇÃO DE DIFERENTES MÉTODOS DE RECONSTRUÇÃO DE IMAGENS NO PROCESSAMENTO DE SPECT CEREBRAL COM SIMULADOR ANTROPOMÓRFICO ESTRIATAL}

Dissertação de mestrado apresentada ao Programa de Pós-Graduação Interunidades Bioengenharia Escola de Engenharia de São Carlos/Faculdade de Medicina de Ribeirão Preto/Instituto de Química de São Carlos da Universidade de São Paulo como parte dos requisitos para a obtenção do título de mestre em Ciências.

Área de Concentração: Bioengenharia

Orientador: Prof. Dr. Lauro Wichert Ana

\section{Versão corrigida}

São Carlos, 
AUTORIZO A REPRODUÇÃO TOTAL OU PARCIAL DESTE TRABALHO, POR QUALQUER MEIO CONVENCIONAL OU ELETRÔNICO, PARA FINS DE ESTUDO E PESQUISA, DESDE QUE CITADA A FONTE.

Trevisan, Ana Carolina

T814a Avaliação de diferentes métodos de reconstrução de imagens no processamento de SPECT cerebral com simulador antropomórfico estriatal/Ana Carolina Trevisan;

Orientador Lauro Wichert Ana. São Carlos, 2015.

Dissertação (Mestrado) - Programa de Pós-Graduação Interunidades Bioengenharia e Área de Concentração em Bioengenharia - Escola de Engenharia de São Carlos; Faculdade de Medicina de Ribeirão Preto; Instituto de Química de São Carlos, da Universidade de São Paulo, 2015.

1. Reconstrução de imagens. 2. Filtros. 3. SPECT cerebral. 4. Doença de Parkinson. 


\section{AGRADECIMENTOS}

Inicialmente agradeço a Deus, por toda a força, paciência e sabedoria que me proporcionou ao longo desses anos. Tenho certeza de que sem a presença espiritual dele eu não teria alcançado minhas conquistas.

"Tente sempre acreditar e agradecer a Deus nas horas de alegria, pois na tristeza é a única coisa que você terá."

Rodrigo Guedes

Agradeço aos meus pais Carlos Roberto e Maria de Lourdes e ao meu irmão Luís Fernando, pela paciência e apoio em mais esta etapa da minha vida, por acreditar e confiar em mim. Mesmo com a distância, se mostraram sempre presentes. Sem vocês, eu não teria conseguido.

"A educação tem raízes amargas, mas os seus frutos são doces."

Aris tóteles

Ao professor e amigo Lauro Wichert Ana, por ter acreditado e apostado em mim, me instruindo a iniciar este trabalho, pela excelente orientação e total atenção em todas as horas que precisei. Sou eternamente grata.

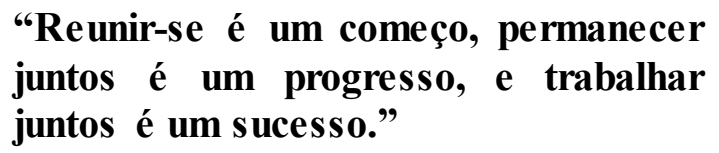

Henry Ford

Ao grupo de pesquisa da Medicina Nuclear, amigos que me ajudaram demais nesta jornada. Carlos, Camila, Emerson, Daniele, Mery e Rafaela. Em especial ao grupo TRODAT, Leonardo e Felipe, que entre tantos tropeços, conseguimos unidos vencer esta batalha.

"A simplicidade é o último degrau da sabedoria."

Kalil Gibran 
A todos os funcionários da Seção de Medicina Nuclear do Hospital das Clínicas da Faculdade de Medicina de Ribeirão Preto - USP. Em especial a Danila Pupolin que, além dos ensinamentos profissionais, se tornou uma grande amiga e passou a fazer parte da minha vida pessoal.

\section{"Não há prazer comparável ao de encontrar um velho amigo, a não ser o de fazer um novo."}

Rudyard Kipling

A professora de português, Maria do Socorro Senne, e a professora de inglês Andreika Lopes, pela correção deste trabalho, com total competência.

Aos professores de estatística, Edson Zangiacomi Martinez e Jorge Alberto Achcar pelo auxilio nas técnicas aplicadas aos dados deste trabalho.

"A aprendizagem é um processo individual, mas ela se torna mais interessante quando temos como nosso guia alguém que sabe como ensianr." 


\section{RESUMO}

TREVISAN, A. C. Avaliação de diferentes métodos de reconstrução de imagens no processamento de SPECT cerebral com simulador antropomórfico estriatal. Dissertação de Mestrado - Escola de Engenharia de São Carlos, Universidade de São Paulo - São Carlos, 2015.

A dopamina (DA) é um neurotransmissor sintetizado nos neurônios dopaminérgicos da substância nigra, possuindo efeito importante sobre o Sistema Nervoso Central (SNC), dentre as quais a sensação de prazer e a motivação. Uma alteração nos transportadores de dopamina (DATs) se caracteriza por uma desordem progressiva do movimento devido à disfunção dos neurônios secretores de dopamina, gerando a Doença de Parkinson (DP). Por ser um distúrbio mais comum entre um espectro de doenças neurológicas, é necessário um estudo mais aprofundado para melhor diagnóstico. Esta dissertação apresenta um estudo do desempenho do filtro butterworth passa-baixa na reconstrução analítica Filtered Backprojection - FBP e reconstrução iterativa Ordered Subsets Expectation Maximization - OSEM, para garantir a qualidade da imagem de SPECT cerebral, adquirida pelo fantoma antropomórfico estriatal. Por avaliação interindividual de quatro especialistas em medicina nuclear, foram aplicadas notas para a análise visual das imagens, garantindo a qualidade da resolução espacial, contraste, ruído e diferenciação anatômica do corpo estriado. Para cada tipo de reconstrução, houve 49 imagens do corpo estriado, variando os valores das covariáveis apresentadas pelos algoritmos (iteração, subsets, ordem e frequência de corte). A fim de resultados consistentes, foram utilizados a regressão linear e o teste T-Student pareado. Os dados coletados demonstraram que é necessário utilizar um intervalo confiável de frequência de corte para FBP $(0,9$ a 1,6) e para $\operatorname{OSEM}(1,2$ a 1,5) e variar a ordem de 0 a 10 que não influenciará a imagem. Para a reconstrução OSEM, ficou comprovado que o valor de iteração (i) e o número de subsets (s) que garantem melhor qualidade foram os mesmos que a empresa do algoritmo utilizado sugeriu (3i 8s). Esta, também, mostrou evidências de melhor qualidade da imagem, quando comparada à reconstrução FBP. Para uma imagem de qualidade, representando uma reconstrução confiável e uma análise visual segura, é necessário utilizar o intervalo de valores encontrados das covariáveis ordem e frequência de corte do filtro butterworth passa-baixa na reconstrução FBP e OSEM. Também é necessário utilizar o valor de iteração e subsets que a empresa sugeriu, e a reconstrução OSEM mostrou superioridade nas imagens comparadas à FBP, mas se o serviço não utilizar ainda este tipo de algoritmo, a imagem com FBP no intervalo proposto também garantirá a qualidade.

Palavras-chave: SPECT cerebral, Doença de Parkinson, Filtros, Reconstrução de imagens. 


\begin{abstract}
TREVISAN, A. C. Evaluation of different methods of image reconstruction in brain SPECT processing with striatal anthropomorphic simulator. Dissertação de Mestrado - Escola de Engenharia de São Carlos, Universidade de São Paulo - São Carlos, 2015.
\end{abstract}

Dopamine is a synthesized neurotransmitter in dopaminergic neurons of the substantia nigra where it has an important effect on the central nervous system (CNS), such as the feeling of pleasure and motivation. A change in the dopamine transporters (DATs) is characterized by a progressive disorder of movement due to a dysfunction of the dopamine secreting neurons, causing Parkinson's Disease (PD). As it is a more common disorder among a spectrum of neurological diseases, further studies are necessary for a better diagnosis. This study presents an investigation on the performance of the lowpass butterworth filter in the Filtered Backprojection analytic reconstruction - FBP and Ordered Subsets Expectation Maximization iterative reconstruction - OSEM to ensure the quality of brain SPECT image, acquired by the anthropomorphic striatal phantom. By individual evaluation of four nuclear medicine specialists, grades were applied to the visual analysis of the images, ensuring the quality of the spatial resolution, contrast, noise and anatomical differentiation striatum. For each type of reconstruction, there were 49 pictures of the striatum, varying the values of covariates submitted by the algorithms (iteration, subsets, order and cutoff frequency). In order to obtain consistent results, we used linear regression and T-Student paired test. The collected data showed that it is necessary to use a reliable interval of cutoff frequency for both the FBP $(0.9$ to 1.6), and OSEM (1.2 to 1.5$)$, and varying the order of 0 to 10 , which does not influence the image. For OSEM reconstruction, it has been verified that the iteration value (i) and the number of subsets (s) ensuring best quality was the same as the company's algorithm suggested (3i 8s). This also showed evidence of better image quality when compared to FBP reconstruction. For an image quality, representing a reliable reconstruction and a safe visual analysis, you must use the range of values found of covariates order and cutoff frequency of the butterworth low-pass filter on the FBP and OSEM reconstruction. You must also use the iteration value and subsets that the company suggested and the OSEM reconstruction showed superiority on the images compared to FBP, but if the service does not use this type of algorithm, the image with FBP in the proposed range, also ensures quality.

Key-words: Brain SPECT, Parkinson's Disease, Filters, Image reconstruction 


\section{LISTA DE FIGURAS}

Figura 1 - Simulador antropomórfico estriatal RS-900T, composto pela concha cerebral e as cavidades de putâmen e núcleo caudado direito/esquerdo. 18 Figura 2 - Componentes de uma gama-câmara, simulando a aquisição de uma imagem cintilográfica. 19

Figura 3 - Matrix 6x6 com contagens armazenadas e organizadas em linhas e colunas (a). Contagens transformadas em número de pixels (b). Pixels conglome rados, sem a presença de linhas e colunas da matriz (c).

Figura 4 - Imagem $f(x, y)$ adquirida pelas coordenadas $(x, y)$, matriz estática e coordenadas (r,s), matriz rotacional (a); Sinograma das projeções adquiridas em um perfil sinusoidal (b).

Figura 5 - Etapa da Simple Backprojection, organizando os dados na matriz desejada.

Figura 6 - Representação do efeito estrela nas projeções adquiridas gama-câmara.

Figura 7 - Imagem do corpo estriado com resolução espacial de qualidade, diferenciando o putâmen e cabeça do núcleo caudado e bordas distinguíveis (a); Imagem do corpo estriado com baixa resolução espacial, impossível distinção das partes (putâmen e núcleo caudado) e bordas indefinidas (b).

Figura 8 - Imagem do corpo estriado com presença de ruído, aspecto visual granuloso, sem distinção das estruturas putâmen e núcleo caudado e exibindo flutuações de contagem além da borda da concha cerebral.

Figura 9 - Representação gráfica da covariável ordem do filtro butterworth passabaixa, variando os valores de $n$ (1 a 4$)$

Figura 10 - Dado no domínio do espaço, passando para o domínio da frequência (espaço-K), nas coordenadas $\left(k_{x}, k_{y}\right)$ e $\left(k_{s}, k_{r}\right)$ no ângulo $\phi$.

Figura 11 - Representação gráfica caracte rística do filtro rampa no sinal.

Figura 12 - Representação gráfica da multiplicação do filtro rampa e butterworth passa-baixa (a) e representação gráfica da multiplicação já aplicada entre os dois filtros (b), uma instrumentação pelo software Image J $\operatorname{com} f_{c}=1$ e $\operatorname{Ordem}=0,36.30$ Figura 13 - Esquematização das etapas realizadas na reconstrução de imagens com o algoritmo iterativo OSEM. 33

Figura 14 - Instrumento de chumbo (canister) com a ampola de ${ }^{99 \mathrm{~m}}$ Tc. 36 
Figura 15 - Papel Whatman 3 MM dentro do tubo de ensaio, contendo o solvente Metanol $85 \%$. Pinça necessária para manipulação do papel. 37

Figura 16 - Análise visual do pH do ${ }^{99} \mathrm{~m}$ Tc através do papel universal de $\mathrm{pH}$ (Merck®), composto por uma escala colorimétrica que resulta nos valores de 0 a 14.

Figura 17 - Peça (parafuso) da cavidade do núcleo caudado direito do fantoma antropomórfico estriatal reproduzida pela oficina do Departamento de Física Médica da FFCLRP - USP. .51

Figura 18 - Material utilizado para o preenchimento das cavidades do fantoma antropomórfico estriatal. (a) Agulhas com $7 \mathrm{~cm}$ e $5 \mathrm{~cm}$ de comprimento, utilizadas para o preenchimento das cavidades do putâmen e do núcleo caudado, respectivamente (b) Pisseta com extremidade de diâmetro de $0,4 \mathrm{~cm}$ foi utilizada para o preenchimento da concha ce rebral. 52 Figura 19 - Gráfico de barras com as médias das notas dos três especialistas para as imagens com dife rentes frequências de corte reconstruídas no algoritmo FBP. 59 Figura 20 - Gráfico de colunas com as médias das notas dos três especialistas designados e as imagens com diferentes ordens reconstruídas no algoritmo FB P. 60 Figura 21 - Gráfico de contorno com as variáveis frequência de corte e ordem. Também composto pelas médias das notas, utilizando o algoritmo FBP.

Figura 22 - Imagens de SPECT cerebral com fantoma antropomórfico estriatal reconstruída com algoritmo analítico FBP no intervalo de 0,9 a 1,6 de frequência de corte, variando a ordem de 0 a 10 . Este intervalo proposto fornece 21 maneiras que categorizam padrão de qualidade na análise visual das imagens. Figura 23 - Análise de regressão, mostrando o p-valor de cada covariável do estudo.

Figura 24 - Gráfico de barras entre as categorias (número de iterações e número de subsets) através de notas $(0$ - 5), por um especialista independente em medicina nuclear. 64 Figura 25 - Imagem de SPECT cerebral adquirido com fantoma antropomórfico estriatal reconstruído com algoritmo iterativo OSEM da gama-câmara PHILIPS, utilizando três iterações e oito subsets. Intervalo que garante qualidade da imagem na primeira etapa da reconstrução OSEM. 
Figura 26 - Imagens reconstruídas com o algoritmo iterativo OSEM, variando as covariáveis iterações ( 2 a 60) e número de subsets $(4,8$ e 16), totalizando 30 imagens.

Figura 27 - Gráfico de barras com as médias das notas dos três especialistas, designadas as imagens com diferentes frequências de corte reconstruídas no algo ritmo OSEM

Figura 28 - Gráfico de barras com as médias das notas dos três especialistas, designadas as imagens com diferentes ordens reconstruídas no algoritmo OSEM.

Figura 29 - Gráfico de contorno com as variáveis frequência de corte, ordem e médias das notas, utilizando o algoritmo OSEM.

Figura 30 - Imagens de SPECT cerebral com fantoma antropomórfico estriatal reconstruída com algoritmo iterativo OSEM no intervalo de 1,2 a 1,5 frequência de corte, variando a ordem de 0,0 a 10,0 . Este intervalo proposto fornece 14 maneiras que categorizam padrão de qualidade nos laudos médicos. 70 Figura 31 - Análise de regressão, mostrando o p-valor de cada covariável do estudo. 71

Figura 32 - Gráfico de barras demonstrando as notas e quantidade de notas atribuídas pelo especialista em medicina nuclear 1, tanto para técnica FBP quanto OSEM. 73

Figura 33 - Gráfico de barras demonstrando as notas e quantidade de notas atribuídas pelo especialista em medicina nuclear 2, tanto para técnica FBP quanto OSEM.

Figura 34 - Gráfico de barras demonstrando as notas e quantidade de notas atribuídas pelo especialista em medicina nuclear 3, tanto para técnica FBP quanto OSEM 75 


\section{LISTA DE TABELAS}

Tabela 1 - Notas da covariável frequência de corte na reconstrução analítica FBP em cada grupo da covariável ordem

Tabela 2 - Notas da covariável frequência de corte na reconstrução iterativa OSEM em cada grupo da covariável ordem 46

Tabela 3 - Grupos que foram analisados para obter a média das notas da covariável ordem, através do conjunto da covariável frequência de corte, na reconstrução analítica $\mathrm{FBP}$ 47

Tabela 4 - Grupos que foram analisados para obter a média das notas da covariável ordem, através do conjunto da covariável frequência de corte, na

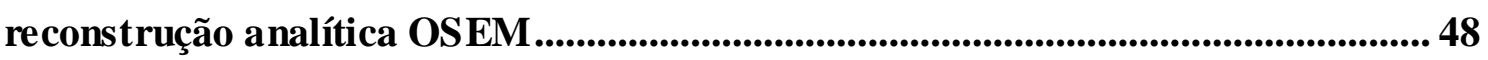
Tabela 5 - Variação da ordem e frequência de corte aplicadas pelo algoritmo FBP, em 49 amostras, categorizadas por notas de 0,0 a 10,0 por três especialistas e a média das notas das três avaliações 55 Tabela 6 - Variação dos números de iterações e subsets utilizados na primeira fase do experimento, usando o algoritmo OSEM, em 30 amostras, categorizadas por notas de 0,0 a 5,0 por um especialista independente. 56 Tabela 7 - Variação da ordem e frequência de corte aplicadas pelo algoritmo OSEM, em 49 amostras, categorizadas por notas de 0,0 a 10,0 por três especialistas e a média das notas. 58

Tabela 8 - Valores estatísticos que o teste t-student pareado proporcional para a análise entre os três especialistas em medicina nuclear. 


\section{LISTA DE FÓRMULAS}

Fórmula 1 - Equações utilizadas para determinar como a radioatividade em um local (x, y) no objeto contribui para o sinal gravado na localização $r$ ou $s$ na projeção adquirida no $\phi$ ângulo ............................................................................................. 20

Fórmula 2 - Fórmula da aplicação do filtro rampa, representado pelo $\left|k_{r}\right| \ldots . . . . . . .29$ Fórmula 3 - Fórmula representativa da Transformada de Fourier inversa, aplicada nos dados durante a reconstrução das imagens cintilográficas ................. 30 Fórmula 4 - Fórmula representativa da aplicação do algoritmo analítico FBP nos dados adquiridos pela gama-câma ra ...................................................................... 30 Fórmula 5 - Fórmula aplicada para transformar a escala dos dados de 0,0 - 10,0

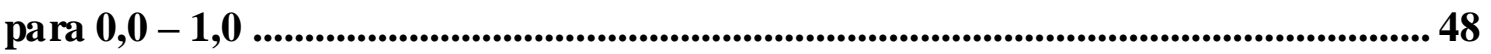

Fórmula 6 - Fórmula aplicada aos dados para a transformação logito ................... 49

Fórmula 7 - Modelo de regressão linear de segunda ordem ..................................... 49 


\section{SUMÁRIO}

1. INTRODUÇÃO......................................................................................................... 16

1.1 Doença de Parkinson ..................................................................................................... 16

1.2 Medicina Nuclear e SPECT ............................................................................ 18

1.2.1 Formação da imagem tomográfica ......................................................................... 19

1.3 Qualidade da imagem................................................................................................................ 22

1.3.1 Resolução espacial ........................................................................................................ 22

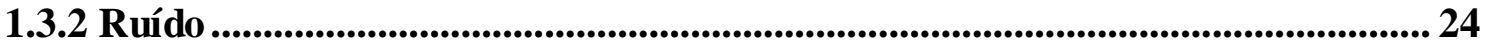

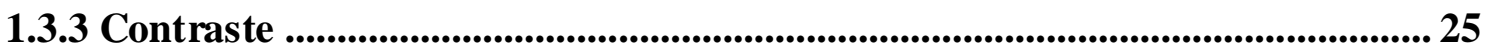

1.4 Algoritmos de reconstrução de imagens tomográficas ..................................... 25

1.4.1 Filtro butterworth passa-baixa..................................................................... 26

1.4.2 Algoritmo ana lítico - Filtered Backprojection (FB P) ........................................ 27

1.4.3 Algoritmo iterativo ................................................................................................................... 31

1.5 Controles de qualidade ........................................................................................... 33

1.5.1 Gama-Câmara ........................................................................................................................... 33

1.5.2 Radioisótopo Tecnécio 99 metaestável - ${ }^{99} \mathrm{~m}$ Tc ................................................... 34

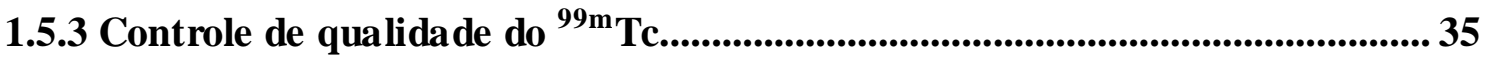

1.5.3.1 Teste de Pureza Radionuclídica do ${ }^{99} \mathrm{~m}_{\mathrm{m}} \mathrm{Tc}$........................................................ 35

1.5.3.2 Teste de Pureza Radioquímica do ${ }^{99 \mathrm{~m}}$ Tc.................................................... 36

1.5.3.3 Teste de pH do ${ }^{99} \mathrm{~m}_{\mathrm{Tc}}$.....................................................................................3 37

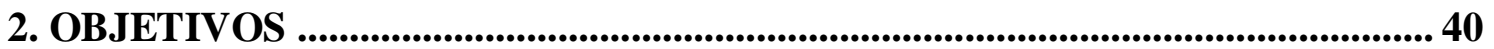

2.1 Objetivos Gerais......................................................................................... 40

2.2 Objetivos Específicos ............................................................................................ 40

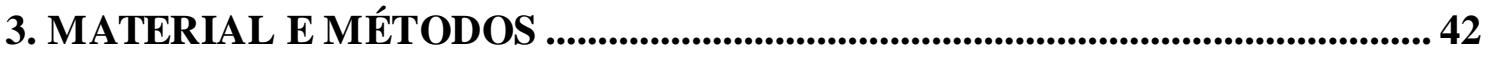

3.1 Eluição do radioisótopo ${ }^{99} \mathrm{~m}_{\mathrm{T}}$ Tc.........................................................................42 42

3.2 Controle de Qualidade do ${ }^{99} \mathrm{~m}^{\mathrm{T}} \mathrm{Tc}$................................................................................ 42

3.2.1 Teste de Pureza Radionuclídica ........................................................................... 42

3.2.2 Teste de Pureza Radioquímica .................................................................................... 42

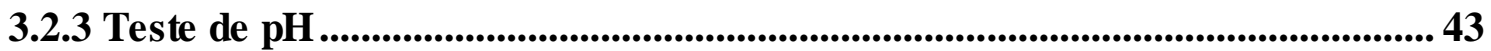

3.3 Aquisições de imagens com fantoma antropomórfico estriatal ............................ 43

3.3.1 Protocolo de aquisição do SPECT cerebral com fantoma antropomórfico estriatal .

3.3.2 Processamentos do SPECT cerebral com fantoma antropomórfico estriatal 44 
3.4 Avaliação dos dados pelos especialistas em medicina nuclear........................... 45

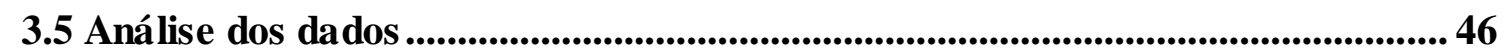

3.5.1 Frequência de corte utilizando FBP e OSEM ................................................. 46

3.5.2 Orde m utilizando FBP e OSEM ......................................................................... 47

3.5.3 Orde me frequência de corte com FBP (Fase 1) e OSEM (Fase 3):................. 48

3.5.4 Iteração e número de subconjuntos (subsets) com OSEM (Fase 2) ................ 50

3.5.5 Teste T-Student Pareado ..............................................................................50

3.6 Limitações e intercorrências do estudo ...............................................................50

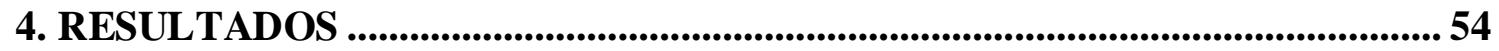

4.1 Casuísticas das imagens ...............................................................................5 54

4.2 Notas atribuídas pelos especialistas em medicina nuclear .................................55

4.2.1 Orde me frequência de corte utilizando o FBP (Fase 1) .................................... 55

4.2.2 Número de iterações e de subsets utilizando o algoritmo OSEM (Fase 2) ..... 56

4.3 Frequência de corte utilizando o algoritmo FBP ...............................................59

4.4 Orde $m$ utilizando o algoritmo FBP ........................................................................ 59

4.5 Variáveis ordem e frequência de corte utilizando o algoritmo FBP (Fase 1).... 60

4.6 Número de iterações e de subsets utilizando o OSEM (Fase 2) ........................... 64

4.7 Frequência de corte utilizando o algoritmo OSEM ........................................... 67

4.8 Orde m utilizando o algo ritmo OSEM........................................................................68 68

4.9 Ordem e frequência de corte utilizando o algoritmo OSEM (Fase 3) ............... 68

4.10 Avaliação comparativa da qualidade das imagens com o algoritmo FBP e

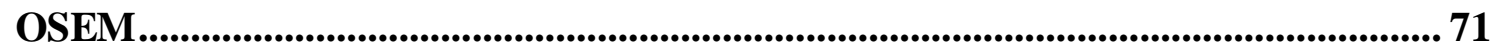

4.10.1 Teste T-Student Pareado com a técnica FBP versus OSEM ............................ 71

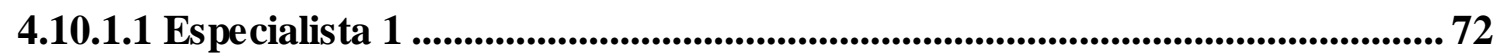

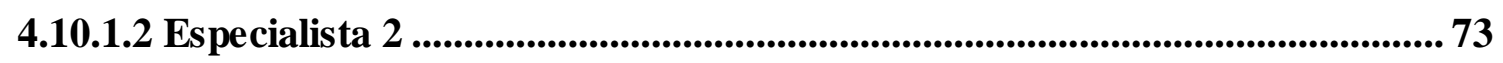

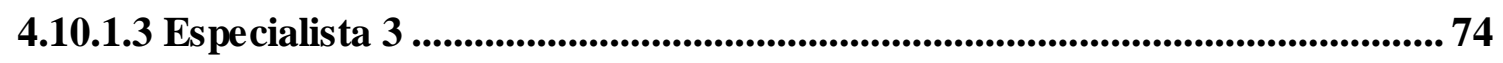

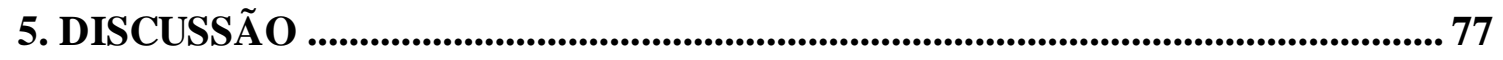

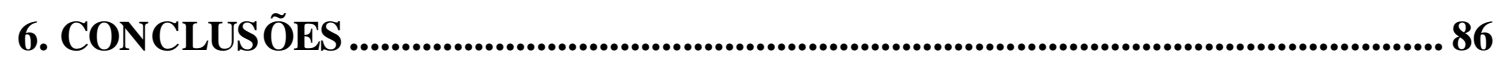

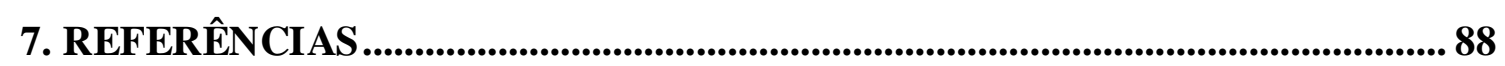

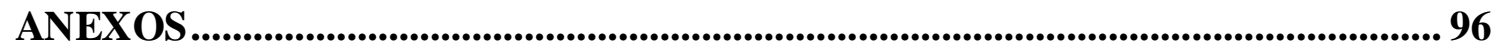

ANEXO 1 - Anatomia do corpo estriado contendo a estrutura do putâmen e

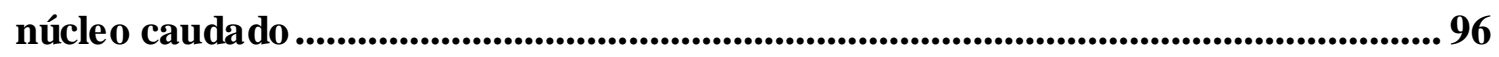

ANEXO 2 - Formulário explicativo para aplicação das notas pelos especialistas em medicina nuclear 


\section{INTRODUÇÃO}

\subsection{Doença de Parkinson}

A Doença de Parkinson (DP), caracterizada pelo distúrbio crônico, progressivo e degenerativo, é a mais comum entre um espectro de doenças neurológicas e apresenta diferentes causas, prognóstico e evolução clínica (KRAEMMER et al., 2014; PELLECCHIA et al., 2015).

Esta doença decorre principalmente da morte dos neurônios dopaminérgicos da substância nigra, afetando os movimentos do ser humano. Sob circunstâncias normais, os neurônios dopaminérgicos da substância nigra emitem axônios que se conectam com outras células do corpo estriado (putâmen núcleo e caudado) e através de sinapses liberam a dopamina nos terminais sinápticos desta região. Muitos neurônios na substância nigra são destruídos em indivíduos com DP, causando lentidão de movimentos, rigidez muscular, tremores, instabilidade postural e sintomas não motores, disfunção cognitiva e características psiquiátricas (SCHERFLER e POEWE, 2011; KRAEMMER et al., 2014; SPRENGER et al., 2015; MARTINO et al., 2015).

No entanto, as alterações não são restritas somente à substância nigra e podem estar presentes em outros núcleos do tronco cerebral (núcleo motor dorsal do vago, córtex cerebral e neurônios periféricos), como os do plexo mioentérico. A presença do processo degenerativo, além do sistema nigroestriatal, pode explicar uma série de sintomas e sinais não motores, como alterações do olfato, distúrbios do sono, hipotensão postural, constipação, mudanças emocionais, depressão, ansiedade, sintomas psicóticos, prejuízos cognitivos e demência (VALLABHAJOSULA, 2009; PELLECCHIA et al., 2015).

O método de diagnóstico da DP é clínico, mas os exames de neuroimagem (SPECT) podem contribuir. Atualmente, o custo dos exames funcionais é elevado, mas aos poucos estão sendo viáveis na rotina clínica e, por isso, desenvolveram o radiofármaco ${ }^{99 \mathrm{~m}} \mathrm{Tc}-\mathrm{TRODAT}-1$, indicado para o diagnóstico desta doença (BORSENG-SHU et al., 2014).

Ao injetar este derivado de tropano via endovenosa, vem se mostrando um radioligante promissor no acúmulo do corpo estriado (putâmen e núcleo caudado). Foi 
confirmado como excelente marcador após 4 horas e com grande facilidade de ultrapassar a Barreira Hematoencefálica (BHE). Seu desenvolvimento apresentou grande valia em relação ao custo-benefício, já que supriu a necessidade desejada, conseguindo identificar as estruturas através do radionuclídeo Tecnécio 99 metaestável $\left({ }^{99 \mathrm{~m}} \mathrm{Tc}\right)$, ignorando a necessidade de radionuclídeos produzidos por cíclotron que custam até dez vezes mais (KUNG et al., 1996; HOEXTER et al., 2006; YIN et al., 2014; HUANG et al., 2015; KORDE et al., 2015).

A lesão da via dopaminérgica nigroestriatal no SPECT cerebral com ${ }^{99 \mathrm{~m}} \mathrm{Tc}$ TRODAT-1 demonstra diminuição da neurotransmissão dopaminérgica no corpo estriado (HOEXTER et al., 2006; KORDE et al., 2015). Esta redução acontece antes do início dos sintomas da doença, e com $40 \%$ a $60 \%$ da estrutura reduzida é que os pacientes começam a ter sintomas. Para saber esta porcentagem, é necessária a imagem de SPECT cerebral. Assim, por este motivo a técnica vem sendo benéfica e muito utilizada no diagnóstico de DP (HOEXTER et al., 2006; HUANG et al., 2015).

Com a evolução dos exames com ${ }^{99 \mathrm{~m}}$ Tc-TRODAT-1, surge a necessidade de protocolos padronizados com métodos de reconstrução de imagens, para a qualidade da imagem e garantindo a reprodutibilidade e confiabilidade dos laudos médicos.

Através da utilização de um fantoma antropomórfico estriatal RS-900T Alderson RSD (Radiological Support Devices, Long Beach, CA) (Figura 1), é possível entender detalhadamente a estrutura do corpo estriado.

O fantoma RS-900T é um objeto físico de representação anatômica real do corpo estriado, composto por cinco compartimentos que podem ser manipulados separadamente, núcleo caudado direito/esquerdo (5,4ml cada), putâmen direito/esquerdo (6,0ml cada) e cavidade referente ao volume encefálico (1260ml) (WENG et al., 2014).

Por possuir as características de absorção ideal dos coeficientes de atenuação do corpo humano, podemos identificar e padronizar melhores métodos de reconstrução de imagens e aplicações de filtros (LEONG; CONNOR; MARAGANORE, 1999; CASSOLA, 2007; WENG et al., 2014).

Para o estudo do corpo estriado, é necessário testá-lo primeiramente em imagens simétricas, caracterizando uma estrutura normal através da simulação da absorção uniforme do radiofármaco ${ }^{99} \mathrm{~m}$ Tc-TRODAT-1 e também, avaliá-lo com diferentes concentrações radioativas, simulando uma estrutura já acometida pela DP (STODILKA et al., 1998). 


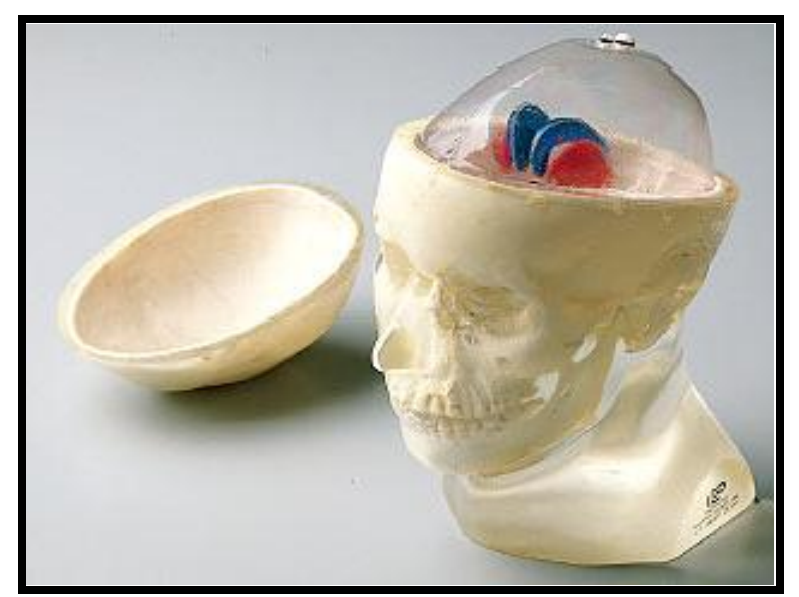

Figura 1 - Simulador antropomórfico estriatal RS-900T, composto pela concha cerebral e as cavidades de putâmen e núcleo caudado direito/esquerdo.

Fonte: http://www.rsdphantoms.com/nm_striatal.htm

\subsection{Medicina Nuclear e SPECT}

A Medicina Nuclear (MN) é uma moderna especialidade médica, capaz de diagnosticar e tratar doenças através da utilização de radiofármacos. Embora haja vários tipos de gama-câmara, a mais utilizada é a Emissão de Fóton Único por Tomografia Computadorizada (SPECT - Single Photon Emission Computed Tomography) com dois detectores, cuja principal função é adquirir múltiplas imagens tomográficas captadas pela rotação de $180^{\circ}$ de cada detector, através da captação da radioatividade do órgão desejado.

O principal método de aquisição tomográfica é a rotação Step \& Shoot. As projeções são adquiridas em sua totalidade na pausa de alguns segundos dos detectores, e assim sucessivamente completando $360^{\circ}$ em torno do paciente (CAO et al., 1996; POWSNER; POWSNER, 2006).

O desempenho de um sistema gama-câmara é determinado pela nitidez e detalhe das imagens adquiridas pela eficiência da detecção a radiação incidente. Os componentes utilizados para este processo são os colimadores absorvem e direcionam os raios gama $(\gamma)$ até os detectores, composto por cristais de Iodeto de Sódio ativado com Tálio $\mathrm{NaI}(\mathrm{Tl})$. Estes cristais absorvem o fóton incidente, transformando-o em fótons de luz que, interligados a fotomultiplicadoras, transformam os fótons incidentes em corrente elétrica. Esta corrente elétrica chega até os amplificadores, impedindo a 
atenuação dos sinais provenientes da fotomultiplicadora, passando esses dados para o software (Figura 2) (CHERRY; SORENSON; PHELPS, 2012).

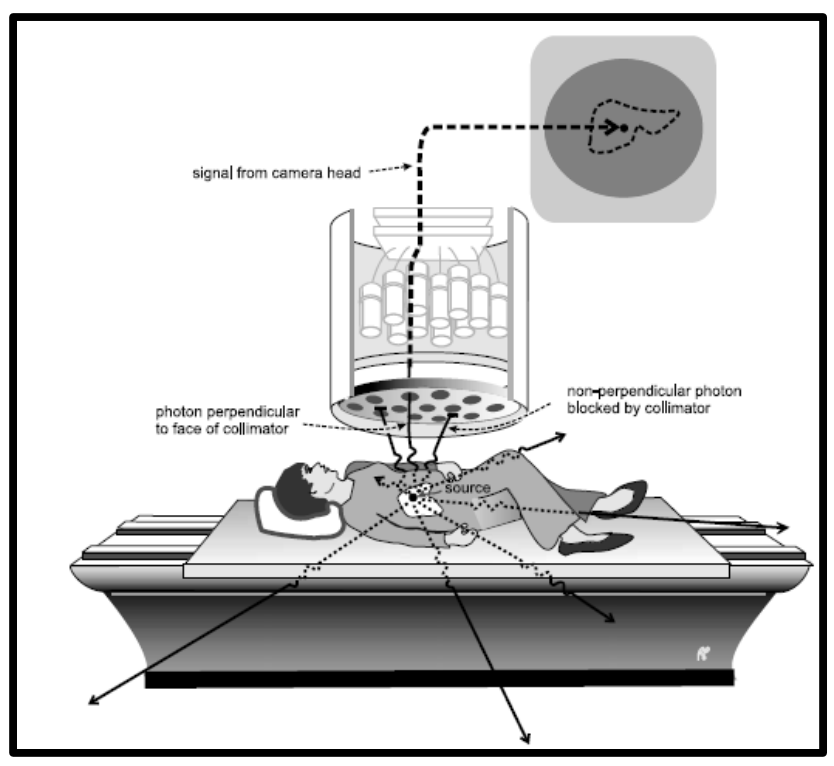

Figura 2 - Componentes de uma gama-câmara, simulando a aquisição de uma imagem cintilográfica.

Fonte: POWSNER; POWSNER, 2006.

\subsubsection{Formação da imagem tomográfica}

As projeções, conjunto de pixels, são adquiridas em matrizes quadradas determinadas pelo operador. Os dados na medicina nuclear podem ser armazenados em matrizes de $64 \times 64,128 \times 128,256 \times 256,512 \times 512$ ou $1024 \times 1024$. Cada pulso captado pelo cristal $\mathrm{NaI}(\mathrm{Tl})$ gera uma contagem armazenada na matriz (Figura 3a). Estas contagens transformadas em pixels são organizadas em linhas e colunas, diferenciandoas na quantidade de pixel em cada ponto da matriz (Figura $3 \mathrm{~b}$ e $3 \mathrm{c}$ ). Quanto maior a quantidade de pixels em um campo de visão, melhor é a resolução da imagem (POWSNER; POWSNER, 2006). 
a

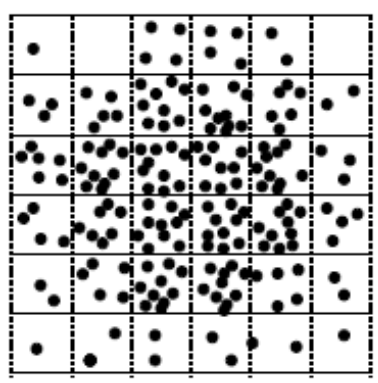

b

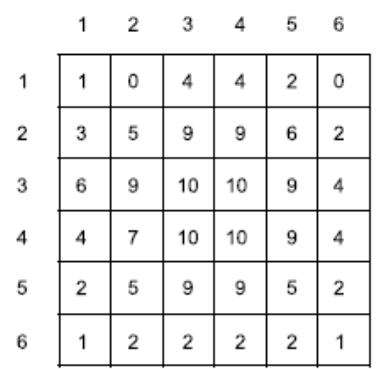

c

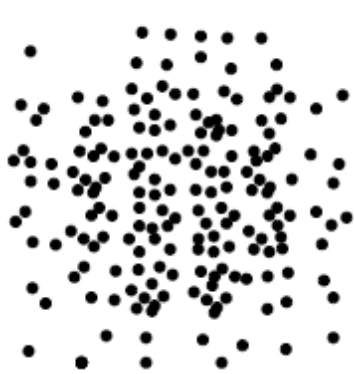

Figura 3 - Matrix 6x6 com contagens armazenadas e organizadas em linhas e colunas (a). Contagens transformadas em número de pixels (b). Pixels conglomerados, sem a presença de linhas e colunas da matriz (c).

Fonte: POWSNER; POWSNER, 2006.

Após todas as projeções adquiridas, é constituído o sinograma das projeções. O sinograma é um conjunto completo dos dados adquiridos durante a realização do exame, ou seja, conjunto das linhas de projeções ao redor de ângulos. Estes ângulos são divididos em eixo $\mathrm{x}, \mathrm{y}$ (matrizes estáticas) e eixo $\mathrm{r}$, $\mathrm{s}$ (matrizes rotacionais) em $\mathrm{n}$ ângulos $\left(0^{\circ}\right.$ a $\left.360^{\circ}\right)$, conforme mencionado na Figura $4 \mathrm{a}$.

Cada corte do sinograma (Figura 4b) consiste em dados de $n$ ângulo e este por completo se caracteriza como uma trajetória sinusoidal. Uma curva sinusoide consiste em uma forma de onda que possui uma equação onde a variável é diretamente proporcional ao seno ou cosseno de uma variável (CHERRY; SORENSON; PHELPS, 2012). Assim, as projeções são adquiridas conforme o princípio da similaridade dos triângulos (Fórmula 1).

$$
\begin{aligned}
& r=x \cos \phi+y \operatorname{sen} \phi \\
& s=y \cos \phi-x \operatorname{sen} \phi
\end{aligned}
$$

Fórmula 1 - Equações utilizadas para determinar como a radioatividade em um local (x, y) no objeto contribui para o sinal gravado na localização $r$ ou $\mathrm{s}$ na projeção adquirida no $\phi$ ângulo.

Fonte: CHERRY; SORENSON; PHELPS, 2012. 


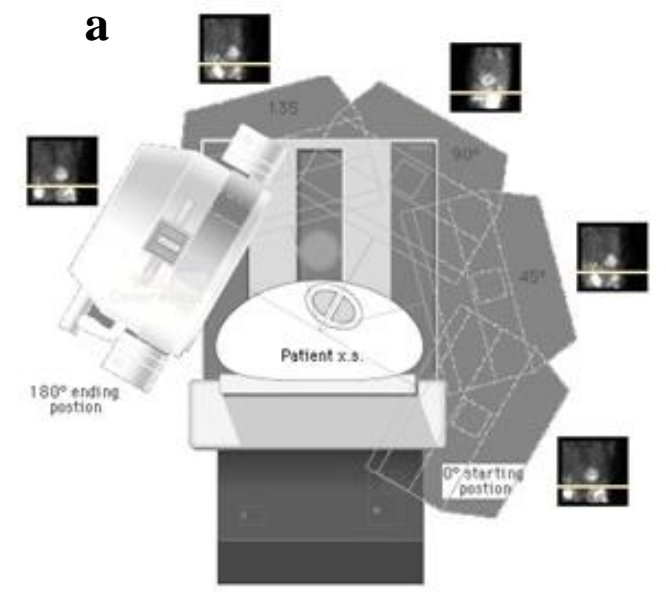

\section{b}

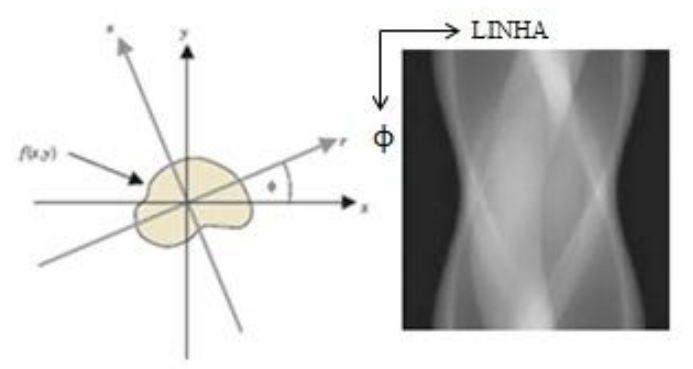

Figura 4 - Imagem $f(\mathrm{x}, \mathrm{y})$ adquirida pelas coordenadas $(\mathrm{x}, \mathrm{y})$, matriz estática e coordenadas $(\mathrm{r}, \mathrm{s})$, matriz rotacional (a); Sinograma das projeções adquiridas em um perfil sinusoidal (b).

Fonte: CHERRY; SORENSON; PHELPS, 2012.

Após a finalização das aquisições, é aplicada a etapa da retroprojeção simples (Simple Backprojection), um algoritmo matemático de reconstrução de imagem que reconstrói os dados do sinograma, distribuindo-os na matriz desejada (Figura 5) (ALESSIO; KINAHAN, 1959; BRUYANT, 2002; POWSNER; POWSNER, 2006; SAHA, 2010; CHERRY; SORENSON; PHELPS, 2012).
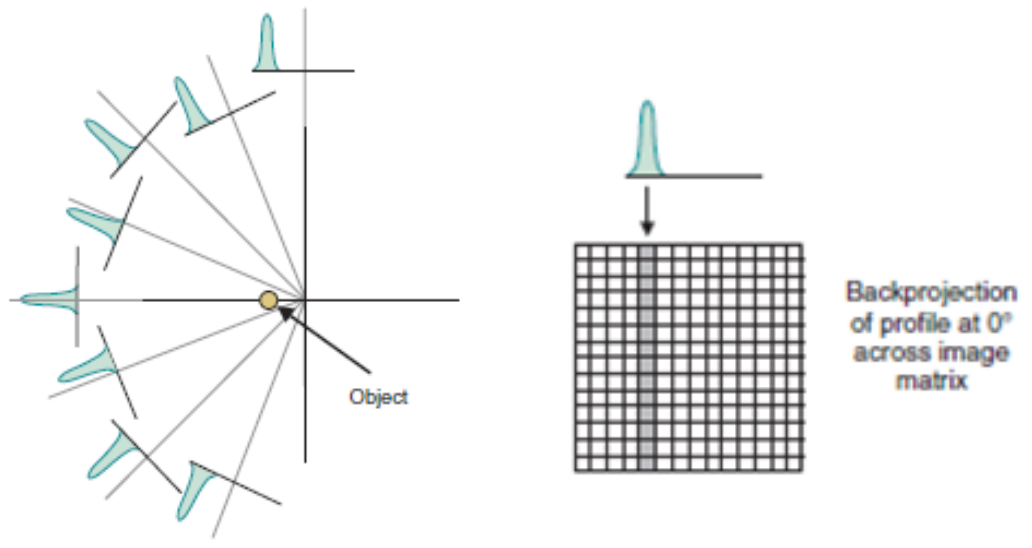

Figura 5 - Etapa da Simple Backprojection, organizando os dados na matriz desejada. Fonte: CHERRY; SORENSON; PHELPS, 2012.

Embora esta etapa seja fundamental para gerar a imagem, ela causa um artefato, conhecido como efeito estrela. Este nome é denominado, pois cada projeção de $n$ ângulo é distribuída na matriz e pode se encontrar em um mesmo ponto, onde há maior número de pixels e assim, causar interferência. Esta interferência desenvolve um ruído através 
das radiações e prejudica a interpretação da imagem. Após a finalização desta etapa, com todas as projeções distribuídas na matriz, o ruído é visto como uma estrela (Figura 6) (ALESSIO; KINAHAN, 1959; BRUYANT, 2002; SAHA, 2010; POWSNER; POWSNER, 2006).

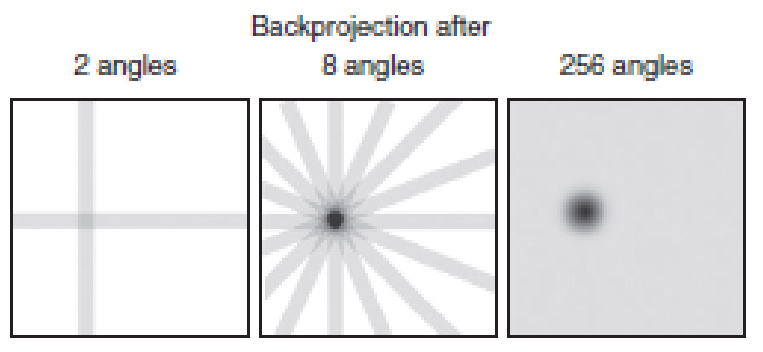

Figura 6 - Representação do efeito estrela nas projeções adquiridas gama-câmara. Fonte: CHERRY; SORENSON; PHELPS, 2012.

\subsection{Qualidade da imagem}

A qualidade da imagem em uma avaliação visual é uma noção subjetiva. Primeiramente, a informação visual deve ser satisfatória, permitindo uma avaliação precisa das estruturas ou funções em questão.

Para um excelente diagnóstico médico, a imagem deve manter a fidelidade das estruturas. Os principais componentes para esta qualidade são resolução espacial, contraste e ruído.

Teoricamente uma imagem eficiente consiste em alto contraste, alta resolução espacial e baixo nível de ruído, no entanto, estes não são itens independentes. Os níveis reais de contraste, resolução espacial e ruído que consigamos aceitar dependem da finalidade desejada da imagem (BOURNE, 2010; GONZALEZ; WOODS, 1992).

\subsubsection{Resolução espacial}

A resolução espacial é uma propriedade que descreve a habilidade de retratar com precisão o objeto (nitidez ou detalhe), nas dimensões espaciais, altura e largura, geralmente com unidade de milímetro e escala de cinza (diferentes intensidades), 
qualificando uma imagem pela menor mudança perceptível dos níveis de cinza (BUSHBERG, et al., 2002).

O conhecimento da resolução espacial é a capacidade da distinção de dois objetos bem próximos em diferentes tamanhos. Quanto mais adjacentes estão estes objetos, resultando ainda em distinção, melhor a resolução espacial, detalhes mais refinados da estrutura. Mas se, em algum ponto, os objetos aparecerem tão perto como um só, há baixa resolução espacial na imagem (BOURNE, 2010; BUSHBERG, et al., 2002).

Segundo Cherry; Sorenson e Phelps (2012), as imagens em medicina nuclear são limitadas à resolução espacial comparada às demais técnicas radiológicas. $\mathrm{O}$ principal fator limitante é a absorção dos fótons pelos colimadores até a chegada ao detector. Os fótons são atenuados em diversos meios, e o fator distância (diâmetro), entre os furos paralelos do colimador e detector, também prejudica o resultado final, fazendo com que a radiação $\gamma$ chegue com baixa contagem no destino final e consequentemente danific ando a resolução espacial (GONZALEZ; WOODS, 2002).

As imagens também podem ser afetadas pelo movimento do paciente durante a aquisição e pela variação de pixels na matriz. O padrão de eficácia são dois pixels por largura à meia altura (FWHM - Full Width at Half Maximum) (POWSNER; POWSNER, 2006; CHERRY; SORENSON; PHELPS, 2012).

Já para análise qualitativa, algumas diferenças visuais são perceptíveis, como a distorção da estrutura anatômica e bordas indefinidas (Figura 7a e 7b) (GONZALEZ; WOODS, 2002).
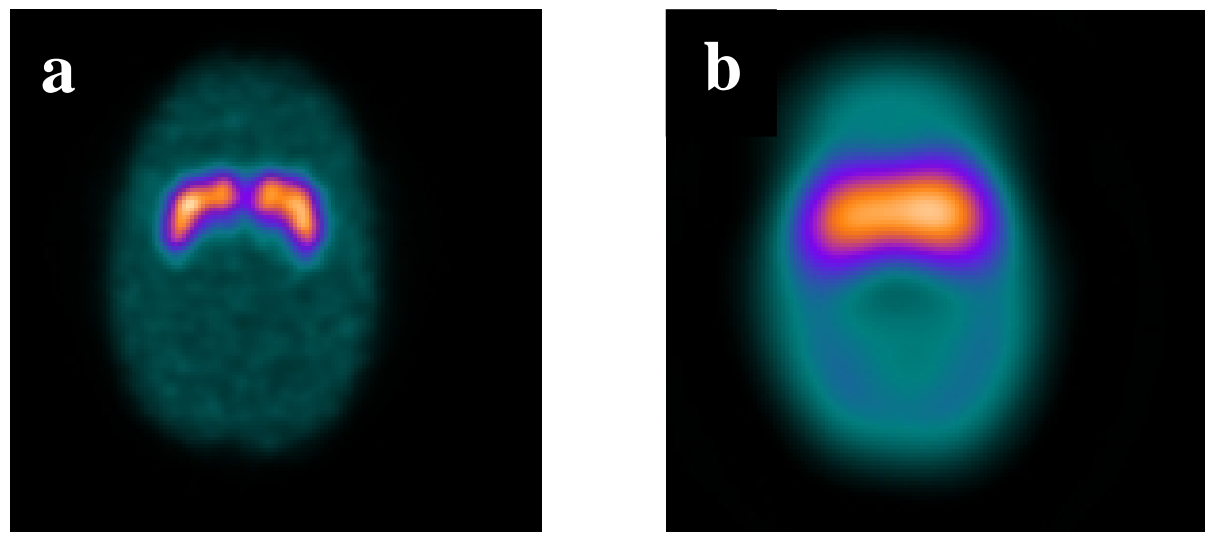

Figura 7 - Imagem do corpo estriado com resolução espacial de qualidade, diferenciando o putâmen e cabeça do núcleo caudado e bordas distinguíveis (a); Imagem do corpo estriado com baixa resolução espacial, impossível distinção das partes (putâmen e núcleo caudado) e bordas indefinidas (b). 


\subsubsection{Ruído}

O ruído em geral pode ser caracterizado como flutuações aleatórias ou estruturadas que se referem a um aspecto granuloso na imagem final (Figura 8). Basicamente, é qualquer intensidade ou flutuações de contagem que dificultam analisar a estrutura desejada.

O ruído estruturado apresenta variações não randômicas/aleatórias na taxa de contagem e interfere na estrutura de interesse. Isto se deve à má distribuição dos radiofármacos ou presença de artefatos, como objetos durante a aquisição das projeções (POWSNER; POWSNER, 2006; CHERRY; SORENSON; PHELPS, 2012).

A relação sinal-ruído representa quanto o ruído prejudica a informação contida em uma imagem. Quanto maior o seu valor, menor a influência prejudicial causada pelo ruído.

Existem vários tipos de ruídos que afetam a imagem final, ruído gaussiano, rayleigh, gama, exponencial, uniforme e impulsivo (sal e pimenta). Todos estes modelos degradam a imagem tanto na aquisição como na transmissão dos dados adquiridos e processamento (GONZALEZ; WOODS, 2002).

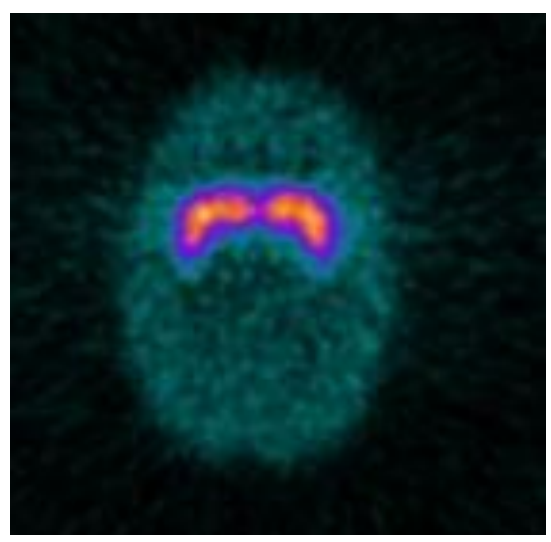

Figura 8 - Imagem do corpo estriado com presença de ruído, aspecto visual granuloso, sem distinção das estruturas putâmen e núcleo caudado e exibindo flutuações de contagem além da borda da concha cerebral. 


\subsubsection{Contraste}

O contraste corresponde a diferenças de tons de cinza nos níveis de captação radioativa no paciente, ou seja, diferença na escala de tons de cinza da imagem em regiões adjacentes. A diferença nesta escala resulta em várias etapas que ocorrem durante a aquisição de um exame e processamento das imagens. Na medicina nuclear, um dos principais elementos que ativa o contraste são as propriedades dos radiofármacos. O radiofármaco utilizado deve conglomerar com eficiência na região desejada do corpo, para então, os colimadores da gama-câmara adquirirem os sinais com eficiência. Caso contrário, os colimadores captam baixa contagem, baixo nível de atividade e também a radiação de fundo - background (BKG), captando incertezas estatísticas através da radiação indesejada sobreposta à atividade de interesse e danificando o resultado final (CHERRY; SORENSON; PHELPS, 2012). Por isso, os controles de qualidades do radioisótopo e radiofármaco são de extrema importância.

Nenhum método de imagem funciona sem contraste e livre de ruído. Se o contraste é baixo e o ruído é evidente, então a variação de intensidade devido a ruídos aleatórios irá torná-lo difícil de detectar visualmente as mudanças de intensidade, devido ao contraste (WENG et al., 2004).

\subsection{Algoritmos de reconstrução de imagens tomográficas}

Com os avanços tecnológicos da informática, os algoritmos de reconstrução de imagens vêm sendo cada vez mais eficazes. Através das projeções adquiridas, os algoritmos reconstroem as imagens em cortes axiais, coronais e sagitais e também fornecem parâmetros para melhorar a qualidade da imagem, como filtros e correção de movimentos. Nos últimos anos, a área tecnológica vem investindo cada vez mais nesses algoritmos, para diminuir o tempo de reconstrução e melhorar a qualidade da imagem (AZEVEDO, 2011).

Estes algoritmos atuam nas frequências das projeções, pois uma imagem reconstruída de SPECT cerebral, com estruturas de vários tamanhos, apresenta várias 
frequências, e a partir delas que a qualidade da imagem é avaliada (ALESSIO; KINAHAN, 1959; BRUYANT, 2002).

\subsubsection{Filtro butterworth passa-baixa}

As aquisições das projeções na medicina nuclear apresentam ruído por diversos fatores. Outro fator importante que afeta a qualidade da imagem são as aplicações errôneas de filtros, durante a reconstrução das imagens. A aplicação de filtros é requisitada para melhorar o contraste e resolução espacial da imagem. Segundo Saha, (2010) e Weng et al. (2004), o filtro mais indicado é o butterworth passa-baixa, pois apresenta melhores resultados na prática clínica com imagens do corpo estriado, utilizando o radiofármaco ${ }^{99 \mathrm{~m}}$ Tc-TRODAT.

Para extrair uma informação mais robusta dos dados, este filtro seleciona as frequências de interesse do sinal no domínio da frequência, eliminando as frequências indesejadas.

Este mecanismo atua em uma faixa de passagem e uma faixa de rejeição, ou seja, as frequências que estão dentro da faixa de passagem são recuperadas com pouca ou nenhuma distorção, já as frequências que estão na faixa de rejeição são atenuadas.

Para categorizar um filtro butterworth passa-baixa ideal, que preserva todas as frequências dentro da faixa de passagem e atenua todas as frequências na faixa de rejeição, é necessário utilizar os parâmetros disponíveis no algoritmo do filtro, a frequência de corte (cutoff) e a ordem (order) (MACCALLUM et al., 2011; BORSENG-SHU et al., 2014; MOZLEY et al., 2014).

A frequência de corte é um intervalo proposto que limita a quantidade de altas frequências que serão atenuadas e a quantidade de baixas frequências que serão aceitas. Quanto menor o valor dessa variável, mais as altas frequências serão atenuadas, havendo perdas na resolução espacial e contraste, visto que a alta frequência controla a definição de bordas. Já quanto maior a frequência de corte, mais as baixas frequências serão aceitas e, assim, resulta em melhor resolução espacial, visto que a baixa frequência controla o desfoque.

Mesmo com a atenuação de frequências indesejáveis, algumas amplitudes acabam passando e afetando a imagem. A frequência utilizada deve ser atenuada pelo 
menos em torno de $70 \%$ das frequências indesejáveis, o que corresponde a uma atenuação de -3dB, para então garantir uma boa filtragem (BRUYANT, 2002; GONZALEZ; WOODS, 2002; LARSSON, et al., 2010).

A ordem atua na inclinação do filtro, ou seja, determina a velocidade em decibéis $(\mathrm{dB})$ com que a atenuação das frequências acontece. Quanto maior a ordem, mais acentuada é a inclinação do filtro, resultando em maior grau de atenuação das frequências indesejáveis, consequentemente, uma imagem mais suavizada (Figura 9) (GONZALEZ; WOODS, 2002; SAHA, 2010).

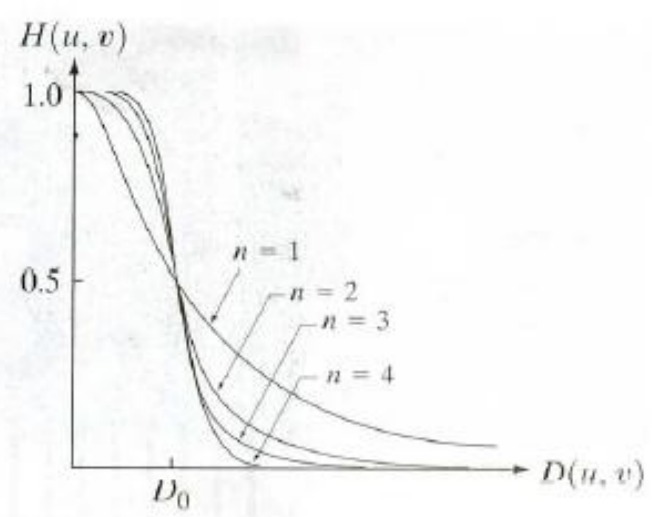

Figura 9 - Representação gráfica da covariável ordem do filtro butterworth passabaixa, variando os valores de n (1 a 4$)$

Fonte: GONZALEZ; WOODS, 2002.

Assim, estas variáveis, frequência de corte e ordem, trabalham em conjunto na aplicação do filtro butterworth passa-baixa, e para finalizar a reconstrução com uma filtragem de qualidade, é necessária a utilização correta desses valores.

\subsubsection{Algoritmo analítico - Filtered Backprojection (FBP)}

Os métodos analíticos baseiam-se no Teorema de Corte da Transformada de Fourier (TF), para então melhorar a reconstrução de cada projeção.

$\mathrm{Na}$ etapa da retroprojeção simples, os dados situam-se no domínio do espaço, ou seja, são os pixels distribuídos na matriz desejada. Assim, na aplicação da retroprojeção filtrada, conhecida com FBP, é necessária a aplicação da TF, atuando em cada projeção no domínio do espaço, passando-a para o domínio da frequência, conhecido como 
espaço-K, onde possibilita a alteração de cada pixel na matriz. Esta etapa é essencial para corrigir os problemas encontrados, durante as aquisições dos dados, e gerar uma imagem de qualidade no resultado final (CHERRY; SORENSON; PHELPS, 2012).

O mecanismo da TF ( $\mathcal{F}$ ) aplicada em uma dada projeção inicia-se no sinal (p) na distância (r) ao longo do ângulo $(\boldsymbol{\phi})$ da matriz no domínio do espaço. Assim, passam-se os dados para o domínio da frequência, resultando um sinal (P) na distância $\left(\boldsymbol{k}_{\mathbf{r}}\right)$ ao longo do ângulo $(\boldsymbol{\phi})$ no espaço-K (Figura 10).

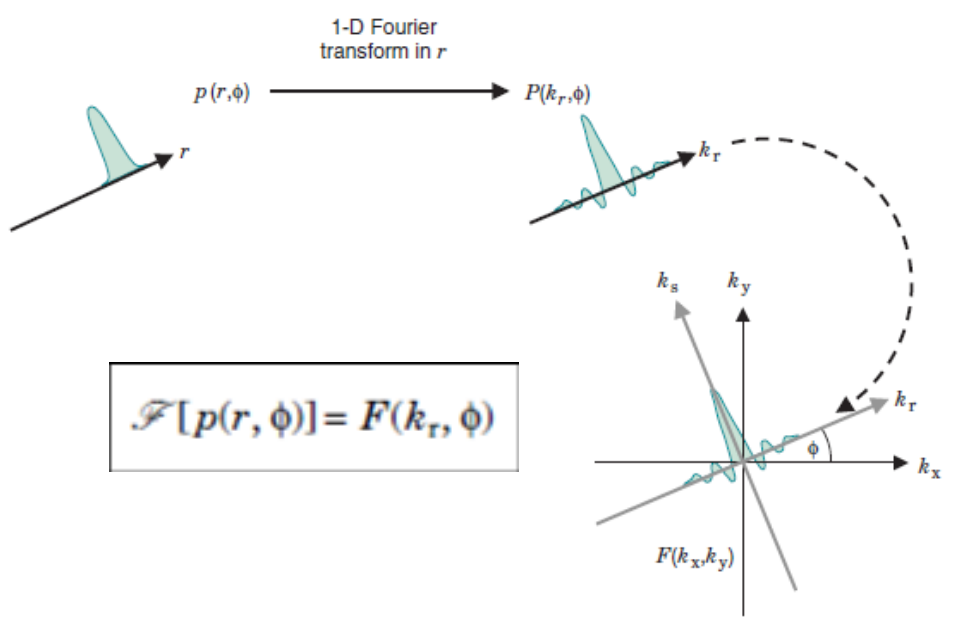

Figura 10 - Dado no domínio do espaço, passando para o domínio da frequência (espaço-K), nas coordenadas $\left(\mathrm{k}_{\mathrm{x}}, \mathrm{k}_{\mathrm{y}}\right) \mathrm{e}\left(\mathrm{k}_{\mathrm{s}}, \mathrm{k}_{\mathrm{r}}\right)$ no ângulo $\phi$.

Fonte: CHERRY; SORENSON; PHELPS, 2012.

Esse domínio da frequência permite corrigir pixel por pixel da matriz da projeção, podendo corrigir os defeitos que afetam a qualidade da imagem na retroprojeção simples. Este procedimento é feito em todas as coordenadas $\left(\boldsymbol{k}_{\mathbf{x}}{ }_{\mathbf{x}}=\boldsymbol{k}_{\mathbf{r}} \cos \right.$ $\phi)$ e $\left(\boldsymbol{k}_{\mathbf{y}}^{\prime}=\boldsymbol{k}_{\mathbf{r}} \cos \boldsymbol{\phi}\right)$. Estando todas as coordenadas no domínio da frequência, é aplicada a etapa de filtragem dos dados por uma operação matemática, conhecida como filtro rampa (GONZALEZ; WOODS, 2002; CHERRY; SORENSON; PHELPS, 2012).

Uma operação matemática aplicada em uma imagem é capaz de atenuar ou enfatizar diferentes frequências, o que permite visualizar melhor as características da imagem, segundo Marques da Silva (1998). A aplicação deste filtro atua matematicamente na multiplicação de cada projeção no domínio da frequência por $|\mathbf{k r}|$ que é o valor absoluto da coordenada radial no espaço-K. É finalizado com a projeção filtrada $\boldsymbol{P}^{\prime}\left(\boldsymbol{k}_{\boldsymbol{r}}, \boldsymbol{\Phi}\right)$ (Fórmula 2), cuja representação gráfica característica do filtro rampa 
no sinal filtrado é demonstrada na Figura 11 (ALESSIO; KINAHAN, 1959; CHERRY; SORENSON; PHELPS, 2012).

$$
P^{\prime}\left(k_{\mathrm{r}}, \phi\right)=\left|k_{\mathrm{r}}\right| P\left(k_{\mathrm{r}}, \phi\right)
$$

Fórmula 2 - Fórmula da aplicação do filtro rampa, representado pelo $\left|k_{r}\right|$. Fonte: CHERRY; SORENSON; PHELPS, 2012.

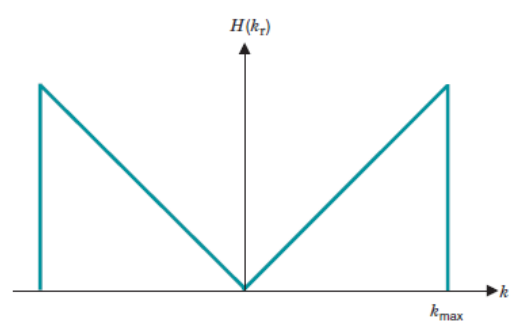

Figura 11 - Representação gráfica característica do filtro rampa no sinal. Fonte: CHERRY; SORENSON; PHELPS, 2012.

A característica deste filtro é reduzir o borramento das projeções, ou seja, aumentar as altas frequências e reduzir as baixas frequências (BRUYANT, 2002). Isto resulta na eliminação do principal artefato causado pela retroprojeção simples, o efeito estrela, mencionado no item 1.2.1 (ALESSIO; KINAHAN, 1959; BRUYANT, 2002; POWSNER; POWSNER, 2006; SAHA, 2010).

Embora o filtro rampa aperfeiçoe as altas frequências, ele resulta também na amplificação de ruído, havendo a necessidade da aplicação de outro filtro para corrigir este problema, o filtro butterworth passa-baixa, conforme mencionado no item 1.4.1.

Portanto, a aplicação dos dois filtros, nos dados do domínio da frequência, categoriza na multiplicação de ambos, demonstrado na Figura 12a, com representação gráfica final conforme a Figura $12 \mathrm{~b}$. 
$\mathbf{a}$

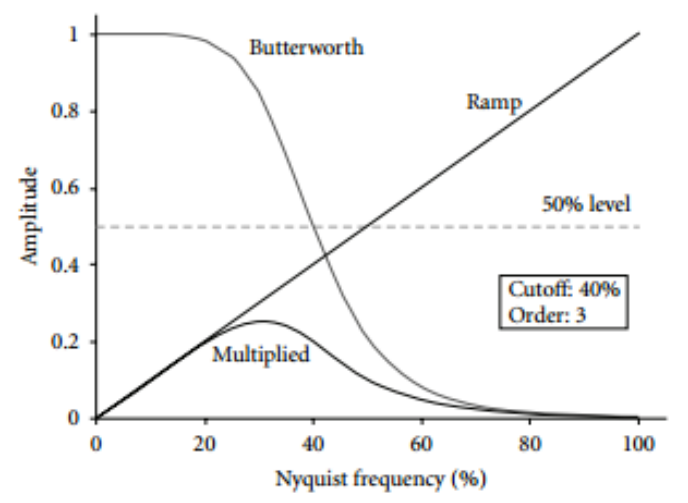

b

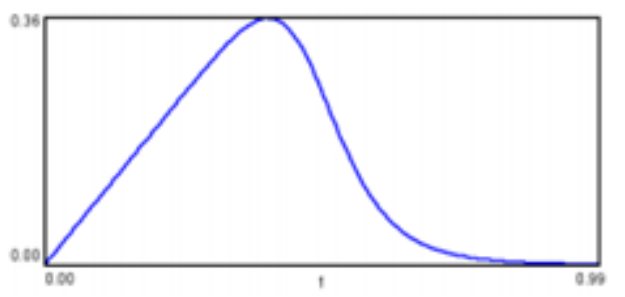

Figura 12 - Representação gráfica da multiplicação do filtro rampa e butterworth passa-baixa (a) e representação gráfica da multiplicação já aplicada entre os dois filtros

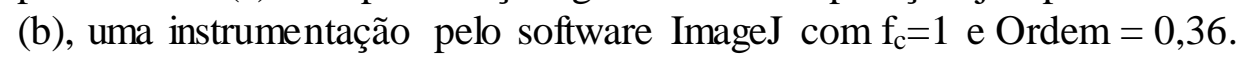

Fonte: http://www.pucrs.br/fisica/pesquisas/nimed/nucnovo/arquivos/manualNucMed.pdf

Após a finalização da aplicação dos filtros, tentando corrigir o máximo dos dados, é necessário fazer a $\mathrm{TF}$ inversa $\left(\mathcal{F}^{-1}\right)$, para obter os dados filtrados de volta ao domínio do espaço [p'(r, ф)], ou seja, os dados voltam à etapa da retroprojeção simples, com os dados processados (Fórmula 3).

$$
\begin{aligned}
p^{\prime}(r, \phi) & =\mathscr{F}^{-1}\left[P^{\prime}\left(k_{\mathrm{r}}, \phi\right)\right] \\
& =\mathscr{F}^{-1}\left[\left|k_{\mathrm{r}}\right| P\left(k_{\mathrm{r}}, \phi\right)\right]
\end{aligned}
$$

Fórmula 3 - Fórmula representativa da Transformada de Fourier inversa, aplicada nos dados durante a reconstrução das imagens cintilográficas.

Fonte: CHERRY; SORENSON; PHELPS, 2012.

Assim, são aplicadas essas etapas em todos os $\mathrm{n}$ ângulos das projeções (Fórmula 4), resultando em uma imagem final, totalmente filtrada (SAHA, 2010; CHERRY; SORENSON; PHELPS, 2012).

$$
f(x, y)=\frac{1}{N} \sum_{i=1}^{N} p^{\prime}\left(x \cos \phi_{i}+y \sin \phi_{i}, \phi_{i}\right)
$$

Fórmula 4 - Fórmula representativa da aplicação do algoritmo analítico FBP nos dados adquiridos pela gama-câmara.

Fonte: CHERRY; SORENSON; PHELPS, 2012. 


\subsubsection{Algoritmo iterativo}

O algoritmo iterativo visa a soluções numéricas para melhorar a qualidade da imagem. São aplicados métodos estatísticos através de sucessivas estimativas das projeções reais $f(\mathrm{x}, \mathrm{y})$, comparando com medidas de uma projeção estimada $f^{\prime}(\mathrm{x}, \mathrm{y})$ (CHERRY; SORENSON; PHELPS, 2012).

Após todas as aquisições adquiridas, é realizada a seleção de um conjunto de projeções do sinograma (retroprojeção simples), categorizando-a como uma projeção inicial arbitrária. Através da etapa da projeção direta (Forward Projections), baseandose na distribuição das contagens da projeção inicial, é formada uma projeção estimada.

Com essa projeção estimada, é realizada a comparação de ambas através dos valores dos pixels. Se neste processo, os dados entre as duas projeções não forem aceitos pelo algoritmo, é aplicado um fator de correção que é multiplicado pela estimativa da projeção inicial e dividido por um termo de ponderação com base no modelo do algoritmo. Este processo é chamado iteração e repete-se até os dados da projeção estimada se aproximarem da solução de máxima verossimilhança da projeção inicial ou quantas iterações o operador mencionar no software (ALESSIO; KINAHAN, 1959; CHERRY; SORENSON; PHELPS, 2012).

Esse método é realizado no algoritmo MLEM (Maximum Likelihood Expectation Maximization), onde geralmente há necessidade de diversas iterações para chegar a uma reconstrução adequada, ocasionando um tempo considerável no processo (ALESSIO; KINAHAN, 1959; KOCH et al., 2011; SOWA-STASZCZAK et al., 2013).

Esse algoritmo exibe melhora na qualidade da imagem através de fatores físicos, mas o único problema visível na imagem é que com o aumento das iterações, há um aumento de ruído (MARQUES DA SILVA, 1998; ANDRADE, 2007; CHERRY; SORENSON; PHELPS, 2012; ALEXANDRE; FARIA, 2013). Assim, para minimizar estes ruídos, foi desenvolvido o algoritmo OSEM (Ordered Subset Expectation Maximization). Conhecido como um MLEM ajustado, o OSEM se diferencia na diminuição do tempo computacional da reconstrução das imagens e melhora a qualidade da reconstrução (ALESSIO; KINAHAN, 1959; BRUYANT, 2002; SAHA, 2010; XU; CHEN, [s.d.]).

Isso ocorre através dos números de subsets (subconjuntos de ângulos) selecionados no software. Estes subconjuntos consistem em agrupamentos de vários 
ângulos da projeção, e a reconstrução é aplicada em cada agrupamento, subset, ao invés de ser aplicado em cada projeção, que se caracteriza em 1 subset (MLEM).

Por exemplo, uma aquisição com 64 projeções, divididos em 16 subconjuntos, contém quatro projeções em cada subset (ALESSIO; KINAHAN, 1959; BRUYANT, 2002; ZENG, 2009; XU; CHEN, [s.d.]).

Subset 1: Projeções 1, 17, 33 e 49

Subset 2: Projeções 2, 18, 34 e 50

Subset 15: Projeções 15, 31, 47 e 63

Subset 16: Projeções 16, 32, 48 e 64

A comparação dos dados, durante a reconstrução, é realizada entre todos os subsets da aquisição, finalizando o processo da iteração. Este processo se repete até a projeção estimada chegar à verossimilhança, ou até realizar o número de iteração sugerido pelo operador da reconstrução, já que são extremamente necessários a combinação de iterações e o número de subsets para a reconstrução acontecer. Caso contrário, é estimada outra imagem já com as correções aplicadas na etapa da iteração anterior, repetindo novamente o processo.

Esse tipo de reconstrução resulta em menor tempo de aplicação geral do processo, minimizando o ruído e caracterizando uma imagem mais refinada. Conforme a Figura 13, segue a esquematização do algoritmo OSEM (POWSNER; POWSNER, 2006; CHERRY; SORENSON; PHELPS, 2012). 


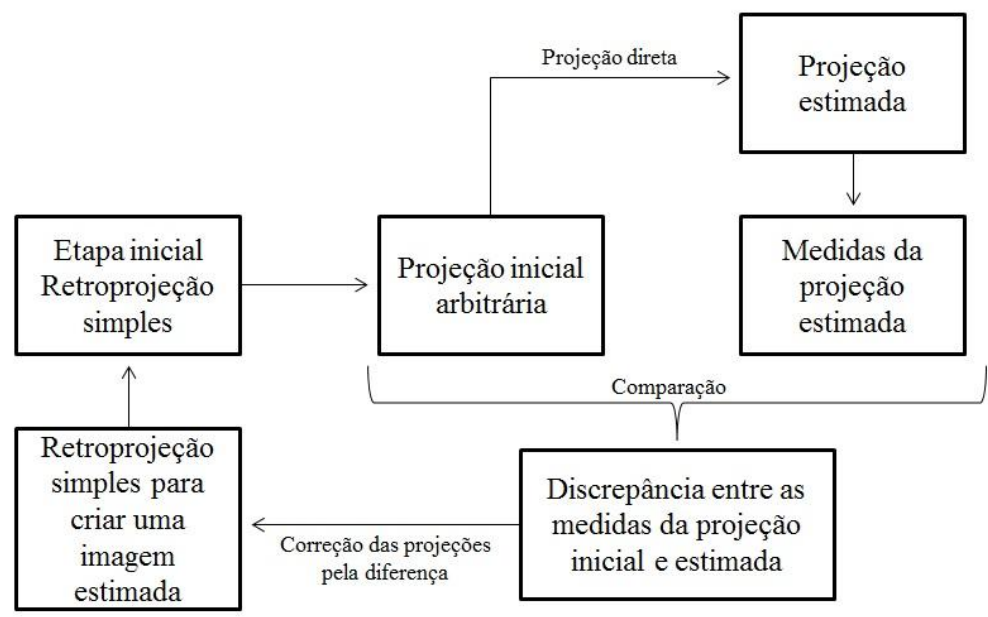

Figura 13 - Esquematização das etapas realizadas na reconstrução de imagens com o algoritmo iterativo OSEM.

Durante a reconstrução, também há aplicação de filtros para diminuir o ruído da imagem, e o mais utilizado é novamente o filtro butterworth passa-baixa, partindo do mesmo princípio da aplicação na reconstrução FBP, ou seja, combinação da frequência de corte e ordem. Este filtro é aplicado em cada etapa da iteração, nas projeções analisadas.

Segundo Powsner e Powsner (2006), o algoritmo OSEM está substituindo o FBP na rotina clínica de vários serviços de medicina nuclear, por apresentar imagens com menos artefatos e com aplicação mais rápida, acelerando a reconstrução da imagem na rotina de diagnóstico clínico.

\subsection{Controles de qualidade}

\subsubsection{Gama-Câmara}

Toda a atividade de controle de qualidade abrange as matérias que, individualmente ou coletivamente, podem influenciar a qualidade do produto. Assim o controle visa a garantir a qualidade necessária para o uso do produto. Para implantar o controle de qualidade de todas as atividades na medicina nuclear, devemos seguir as 
regras de acordo com a Comissão Nacional de Energia Nuclear (CNEN) e a International Atomic Energy Agency (IAEA) (CNEN-NN.3.05, 2013; IAEA,2009).

Todos os testes descritos na resolução da NORMA CNEN NN 3.05 devem ser realizados antes de os equipamentos de diagnóstico entrarem em operação no serviço de medicina nuclear (CNEN-NN.3.05, 2013).

O objetivo do controle de qualidade do SPECT é garantir a sensibilidade adequada da detecção do radionuclídeo, evitando mudanças no desempenho da reconstrução das imagens. O critério utilizado para avaliar o resultado da rotina de controle de qualidade é a comparação dos valores, conforme mencionado pelo fabricante do equipamento (NEMA, 2001).

$\mathrm{Na}$ Seção de Medicina Nuclear do Hospital das Clínicas da Faculdade de Medicina de Ribeirão Preto/Universidade de São Paulo - HCFMRP/USP, os testes aplicados na BrightView XCT - Philips são teste diário de uniformidade e teste mensal de resolução espacial, linearidade e centro de rotação.

Esses parâmetros são testes rotineiros para garantir que o equipamento está operando dentro das especificações do fabricante, resultando consequentemente em uma imagem de qualidade na etapa final (CHERRY; SORENSON; PHELPS, 2012).

\subsubsection{Radioisótopo Tecnécio 99 metaestável - ${ }^{99 m}$ Tc}

$\mathrm{O}$ crescimento da medicina nuclear foi principalmente devido à disponibilidade e facilidade da produção do radioisótopo ${ }^{99 \mathrm{~m}} \mathrm{Tc}$ e custo-benefício aos setores médicos hospitalares. Este isótopo é usado em mais de $80 \%$ de todos os procedimentos de diagnóstico da área. Seu desenvolvimento é na radiofarmácia hospitalar através do gerador Molibdênio-99/Tecnécio-99m ( $\left.{ }^{99} \mathrm{Mo} /{ }^{99 \mathrm{~m}} \mathrm{Tc}\right)$.

O gerador é composto por uma coluna cromatográfica com óxido de alumínio $\left(\mathrm{Al}_{2} \mathrm{O}_{3}\right)$ e Molibdato $\left({ }^{99} \mathrm{MoO}_{4}^{2-}\right)$ em seu interior. Através da absorção da salina ( $\left.\mathrm{NaCl}\right)$ dentro desta coluna, é liberado o radionuclídeo PAI ${ }^{99} \mathrm{MoO}_{4}^{2-}$, que por transição isomérica decai para o radionuclídeo FILHO ${ }^{99} \mathrm{~m} \mathrm{TcO}_{4}^{-}$(Tecnécio 99 - Metaestável) e sucessivamente decai para o isômero ${ }^{99} \mathrm{TcO}_{4}^{-}$(BOERMAN; OYEN; CORSTENS, 2000; FICHNA; JANECKA, 2003; IAEA,2009). 
$\mathrm{O}$ elevado índice da utilização do ${ }^{99 \mathrm{~m}} \mathrm{TcO}_{4}^{-}$é o resultado das propriedades físicas e químicas, composto por meia-vida física de 6,02 horas, longa para a síntese da energia no tecido biológico do paciente e emissão de fótons de $140 \mathrm{keV}$, suficientes para aquisição de imagens (SANTOS, 2007).

\subsubsection{Controle de qualidade $\mathrm{do}^{99 m} \mathrm{Tc}$}

Os controles de qualidade do radioisótopo ${ }^{99 \mathrm{~m}} \mathrm{Tc}$ visam a minimizar ou eliminar os efeitos indesejáveis no resultado final do processo, a imagem. Problemas no processo de eluição podem gerar impurezas radioquímicas no produto final. Assim, os parâmetros fundamentais analisados são determinar a eficiência da eluição e captar impurezas como excesso de Alumina $\left(\mathrm{Al}^{3+}\right)$ no composto, antes de acoplá-lo ao fármaco ou injetar no corpo humano. Estes controles são denominados Teste de Pureza Radionuclídica, Pureza Radioquímica e Teste de Potencial Hidrogeniônico (pH) (ZOLLE, 2007; DASH; KNAPP; PILLAI, 2013).

\subsubsection{Teste de Pureza Radionuclídica do ${ }^{99 m} \mathrm{Tc}$}

A impureza radionuclídica é indesejável, podendo expor o paciente a uma dose extra de radiação. A quantidade de molibdênio $99\left({ }^{99} \mathrm{Mo}\right)$ no radionuclídio ${ }^{99 \mathrm{~m}} \mathrm{Tc}$ está estipulada pela Nuclear Regulatory Commission (NCR), necessitando ser testado a cada eluição (MARQUES et al., 2001). O limite aceitável de ${ }^{99}$ Mo é de $0,1 \%$ do total da atividade do eluato. Se esta porcentagem for maior, o eluato não é admissível para uso (ZOLLE, 2007; LOPES, 2009; ANDRADE; LIMA, 2010). Este teste é feito através de medições no calibrador de dose, canister e a ampola com o ${ }^{99 \mathrm{~m}}$ Tc eluído (Figura 14). 


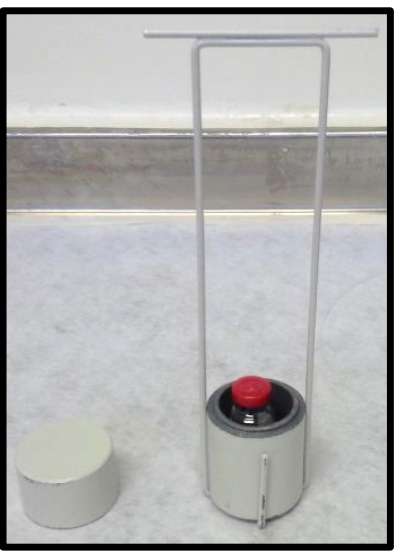

Figura 14 - Instrumento de chumbo (canister) com a ampola de ${ }^{99 \mathrm{~m}} \mathrm{Tc}$.

\subsubsection{Teste de Pureza Radioquímica do ${ }^{99 m} \mathrm{Tc}$}

O teste de pureza radioquímica é utilizado para verificar a existência de impurezas no eluato, baseando na diferença de deslocamento das substâncias químicas presentes na solução. $O$ teste é realizado pela técnica de cromatografia com papéis cromatográficos específicos (Papel Whatman 3MM e Silica Gel) e solventes. Para o ${ }^{99} \mathrm{~m} \mathrm{Tc}$, esta técnica identifica se há pertecnetato $\left(\mathrm{TcO}^{-}\right)$ou tecnécio livre $(\mathrm{TcO} 2)$, através da migração do (TcO4-) de forma conjunta ao solvente adequado no papel Whatman 3MM (Figura 15), enquanto o ${ }^{99 \mathrm{~m}}$ Tc interage fracamente com esta solução, permanecendo na origem do papel. Este procedimento permite a avaliação individualizada de cada uma das partes da tira de papel Whatman 3MM pelo calibrador de dose. O valor aceito de impurezas é de, no máximo, 5\%, ou seja, 95\% de eficiência da eluição do radionuclídeo (ZOLLE, 2007; LOPES, 2009; ANDRADE; LIMA, 2010). 


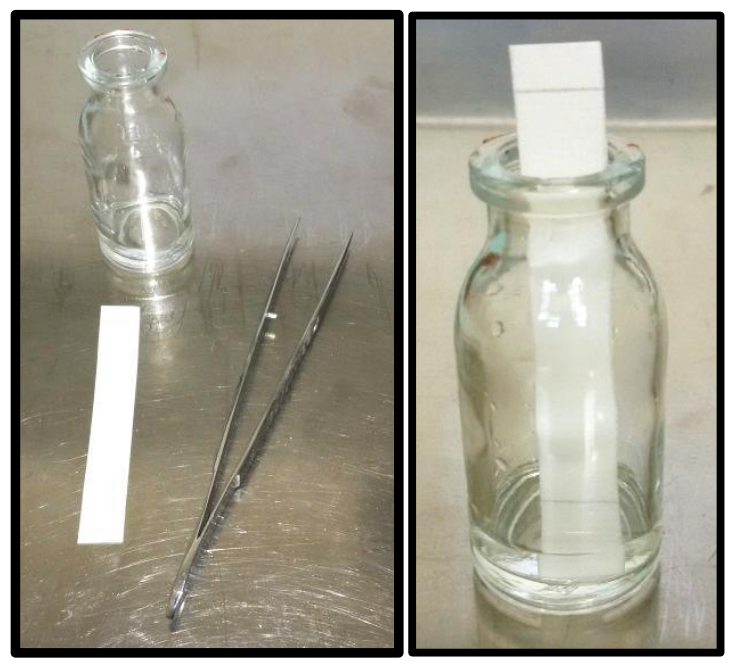

Figura 15 - Papel Whatman 3 MM dentro do tubo de ensaio, contendo o solvente Metanol $85 \%$. Pinça necessária para manipulação do papel.

\subsubsection{Teste de $\mathrm{pH} \mathrm{do}{ }^{99 m} \mathrm{Tc}$}

$\mathrm{O}$ pH é a concentração de íons hidrogênio determinada por uma escala logarítmica que mede o grau de acidez, neutralidade ou alcalinidade presentes em uma solução. Este varia de acordo com a temperatura e a composição de cada substância e a escala envolve valores de 0 a 14 , sendo que o 7 é considerado neutro ou alcalino. $\mathrm{O}$ zero representa a acidez máxima e o 14, neutro ou alcalino. Através de um papel universal de pH (Merck®), os valores são analisados visualmente através da comparação de cores entre uma tabela-padrão (Figura 16) e o resultado do radionuclídeo ${ }^{99 \mathrm{~m}} \mathrm{Tc}$ é entre 5,5 7,0. Se a solução indicar valor menor ou maior do seu valor específico, este não é injetado no paciente (ZOLLE, 2007; ANDRADE; LIMA, 2010; CREPALDI et al., 2010; FERREIRA; PETERLINI; GON, 2012). 


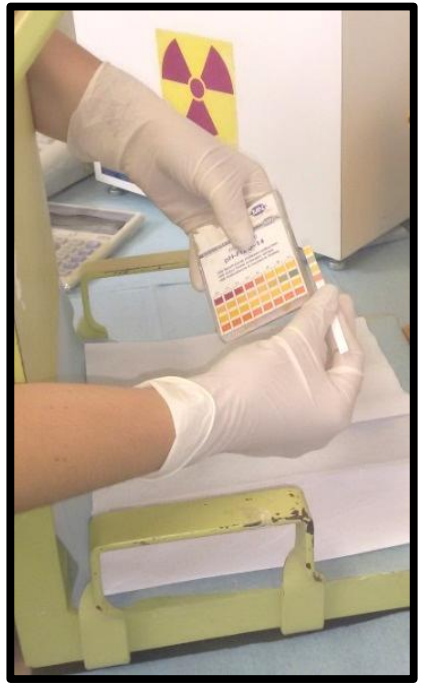

Figura 16 - Análise visual do $\mathrm{pH}$ do ${ }^{99 \mathrm{~m}} \mathrm{Tc}$ através do papel universal de $\mathrm{pH}$ (Merck®), composto por uma escala colorimétrica que resulta nos valores de 0 a 14 . 
2. OBJETIVOS 


\section{OBJETIVOS}

\subsection{Objetivos Gerais}

2.1.1 Avaliar as técnicas de reconstrução de imagens do corpo estriado através de um simulador antropomórfico estriatal, para determinar o melhor protocolo de processamento das imagens a ser futuramente validado na rotina diagnóstica de pacientes com doença de Parkinson.

\subsection{Objetivos Específicos}

2.2.1 Determinar a ordem e frequência de corte do filtro butterworth passabaixa que resulta na melhor representatividade anatômica do corpo estriado, na reconstrução analítica FBP (Fase 1);

2.2.2 Determinar a iteração e número de subsets que resultam na melhor representatividade anatômica do corpo estriado, na reconstrução iterativa OSEM (Fase 2);

2.2.3 Determinar a ordem e frequência de corte do filtro butterworth passabaixa que resulta na melhor representatividade anatômica do corpo estriado na reconstrução iterativa OSEM, através da utilização dos valores padronizados de iteração e número de subsets da Fase 2 (Fase 3);

2.2.4 Determinar qual dos dois métodos de reconstrução utilizados, ie., reconstrução iterativa OSEM versus reconstrução analítica FBP, resulta na melhor qualidade visual e na melhor representatividade anatômica do corpo estriado em um SPECT cerebral utilizando um fantoma antropomórfico estriatal. (Fase 4). 


\section{MATERIAL E MÉTODOS}

\subsection{Eluição do radioisótopo ${ }^{99} \mathrm{~m} / \mathrm{T}$}

Para manter a esterilidade do produto, foi necessário destacar as tampas do frasco a vácuo e frasco de $\mathrm{NaCl}$ e realizar a assepsia da parte superior com álcool etilico $70 \%$. Colocamos o frasco a vácuo adequadamente dentro da blindagem de chumbo. Inserindo junto à agulha do gerador de ${ }^{99} \mathrm{Mo} /{ }^{99 \mathrm{~m}} \mathrm{Tc}$ e a agulha do gerador de ${ }^{99} \mathrm{Mo} /{ }^{99 \mathrm{~m}} \mathrm{Tc}$ o frasco de $\mathrm{NaCl}(6 \mathrm{ml})$, aguardar 3 minutos e o produto final está pronto. Etiquetamos o frasco com as informações "nome do radionuclídeo, atividade total, concentração radioativa e hora de calibração". Retirmos as doses conforme o peso corporal do paciente, evitando a entrada de ar durante o manuseio do frasco.

\subsection{Controle de Qualidade do ${ }^{99 m}$ Tc}

\subsubsection{Teste de Pureza Radionuclídica}

Este teste foi realizado através da inserção de um canister vazio no calibrador de dose. Ao realizar a medição de vazamento de ${ }^{99} \mathrm{Mo}$, anotamos os valores da pureza em $\mu \mathrm{Ci} / \mathrm{mCi}$. Após isto foi avaliado se o valor da pureza está adequado para os procedimentos junto ao radionuclídeo.

\subsubsection{Teste de Pureza Radioquímica}

Teste de pureza radioquímica foi realizado através de uma placa $(6,5 \mathrm{~cm} \mathrm{x}$ $1,0 \mathrm{~cm})$ de papel Whatman 3MM. 
Ao adicionar duas gotas do radionuclídeo ${ }^{99 \mathrm{~m}} \mathrm{Tc}$ na PLACA 1 (papel Whatman 3MM) e coloca-la em um tubo de ensaio, contendo a solução Metanol 85\%, Aguardar o tempo necessário até que o solvente migre até a linha superior da placa. Ao cortar $1,5 \mathrm{~cm}$ a partir do ponto de aplicação, foi calculada a eficiência de marcação, resultando em $\geq 90 \%$ de eficiência.

\subsubsection{Teste de pH}

Para a realização do teste de $\mathrm{pH}$, com o papel universal de $\mathrm{pH}$ (Merck®), foi aplicado uma amostra do ${ }^{99 \mathrm{~m}} \mathrm{Tc}$ sobre e após aguardar 30 segundos, houve a comparação qualitativamente a cor adquirida pela fita com os parâmetros existentes na caixa de $\mathrm{pH}$. O valor padrão deveria estar entre 5,5 e 7,0.

\subsection{Aquisições de imagens com fantoma antropomónfico estriatal}

Admitindo-se uma imagem simétrica como padrão de todo o estudo, cada cavidade foi preenchida com o radioisótopo ${ }^{99} \mathrm{~m} \mathrm{Tc}$, simulando o respectivo acúmulo de ${ }^{99 \mathrm{~m}}$ Tc-TRODAT-1 quando injetado in vivo e foi adquirida junto ao protocolo de SPECT cerebral.

Através do conhecimento exato da volumetria do simulador, foi adquirida uma imagem cintilográfica a partir do preenchimento de cada uma das quatro cavidades independentes (núcleo caudado direito e esquerdo, putâmen direito e esquerdo), contendo $17 \mu \mathrm{Ci} / \mathrm{ml}$ de ${ }^{99 \mathrm{~m}} \mathrm{Tc}$ e água deionizada da solução tanto para a cavidade direita (10,1 ml: putâmen + núcleo caudado) e cavidade esquerda $(10,8 \mathrm{ml}$ : putâmen + núcleo caudado). Já na cavidade de volume encefálico (brain shell), foram utilizados 1,59

$\mu \mathrm{Ci} / \mathrm{ml}$ de ${ }^{99} \mathrm{~m} \mathrm{Tc}$ e água deionizada $(1226 \mathrm{ml})$. Conseguinte, a radioatividade no simulador foi monitorada, antes e após a aquisição das imagens. Ao total, a imagem cintilográfica registrou 9.966 .896 contagens, com média de 77 kctg por projeção. 


\subsubsection{Protocolo de aquisição do SPECT cerebral com fantoma} antropomórfico estriatal

Foi realizada uma imagem cintilográfica do simulador antropomórfico estriatal contendo atividades radioativas simétricas contralateralmente, e entre putâmen e núcleo caudado ipsilateralmente. Foram adquiridas 128 projeções ao redor de $360^{\circ}$, em matriz 128x128, com janela de energia $20 \%$ sobre o fotopico de $140 \mathrm{keV}$, em órbita circular, com movimentos "Step \& Shoot" e colimador Low Energy High Resolution (LEHR). O tempo de aquisição foi de 30 segundos por frame (Frames $=64 /$ Detector), contagem de $70 \mathrm{kcts}$, tamanho do voxel $2,133 \mathrm{~mm}$ e fator de zoom de 1,0 .

\subsubsection{Processamentos do SPECT cerebral com fantoma antropomórfico} estriatal

Com a aquisição da imagem cintilográfica simétrica do simulador estriatal, foi realizado o procedimento de reconstrução pelo Software NM Aplication Suite através do aplicativo AutoSPECT Pro, da Estação de Trabalho EBW (Extended Brilliance TM Workspace) - Philips Healthcare, Cleveland, EUA.

Para eliminar áreas espúrias da imagem e que não são de interesse para o processamento, foram demarcados os limites superior (Start) e inferior (End) do volume cerebral, adicionado da delimitação de um plano médio passando pelo eixo principal e transversal da estrutura de interesse, que neste caso, foi a estrutura do corpo estriado.

$\mathrm{Na}$ fase 1, aplicamos o método de reconstrução analítica FBP e na fase 3, o método de reconstrução iterativa OSEM, variando os valores do filtro butterworth passa-baixa. Estes valores foram escolhidos baseados na literatura de Koch et al.,2005; Seret e Forthomme, 2009; Kock; Suessmair; Tatsch, 2011; Knoll et al., 2012 e Winz et al., 2012, adequando aos valores extremos disponibilizados pelo algoritmo de processamento da EBW. Assim, processamos a partir da escolha de sete ordens $(0,0$; $1,0 ; 2,0 ; 4,0 ; 6,0 ; 8,0$ e 10,0$)$ e sete frequências de corte $(0,1 ; 0,3 ; 0,5 ; 0,7 ; 1,0 ; 1,5$ e 2,0), resultando em 49 imagens para cada reconstrução. Em seguida, foram encontrados 
os melhores ângulos, para deixar a estrutura do corpo estriado perfeita na orientação X, Y e Z.

Na fase 2, aplicamos o método de reconstrução OSEM, variando os valores de iterações (i) e número de subsets (s). Estes valores também foram escolhidos baseados em artigos que analisaram os mesmos parâmetros (ALZIMANI et al., 2008; KOCH et al., 2012; KNOLL et al., 2011; CERIANI et al., 2010 e DUARTE et al., 2012), também se adequando aos valores extremos disponibilizados pelo algoritmo de processamento da EBW e incluindo os valores padronizados pelo equipamento (3i e 8s). Assim, processamos com dez valores de iterações $(2,0 ; 3,0 ; 4,0 ; 6,0 ; 8,0 ; 10,0 ; 12,0 ; 16,0 ; 32,0$ e 60,0) e três números de subsets $(4,0 ; 8,0$ e 16,0), resultando em 30 imagens. Também foram encontrados os melhores ângulos, para deixar a estrutura do corpo estriado perfeita na orientação $\mathrm{X}, \mathrm{Y}$ e Z

\subsection{Avaliação dos dados pelos especialistas em medicina nuclear}

Ordem e frequência de corte com FBP (Fase 1) e OSEM (Fase 3): Avaliação interindividual da qualidade visual da imagem tanto na reconstrução FBP como OSEM. Foi aplicado um mapa de calibração anatômica para o treinamento dos olhos (ANEXO 1). Três especialistas em medicina nuclear deram notas de 1,0 a 10,0 (1,0 a 2,0: Muito ruim, 3,0 a 4,0: Ruim, 5,0: Médio, 6,0 a 7,0: Bom e 8,0 a 10,0: Muito bom), baseandose em um formulário sobre análise da distinção da cabeça do putâmen e núcleo caudado e resolução espacial, contraste e ruído (ANEXO 2).

Iteração e número de subconjuntos (subsets) com OSEM (Fase 2): Avaliação interindividual da qualidade visual da imagem por um especialista em medicina nuclear categorizado como independente na análise. Também foi aplicado um mapa de calibração anatômica para o treinamento dos olhos (ANEXO 1). As notas aplicadas às diferentes reconstruções foram delimitadas em: 1,0 (Muito Ruim), 2,0 (Ruim), 3,0 (Média), 4,0 (Boa) e 5,0 (Muito Boa) através do mesmo formulário das outras fases (ANEXO 2). 


\subsection{Análise dos dados}

\subsubsection{Frequência de corte utilizando FBP e OSEM}

Foi plotada em um gráfico de colunas, para a análise visual dos resultados, a média das notas aplicadas pelos três especialistas em medicina nuclear. Através da nota de cada frequência de corte com todas as ordens utilizadas, foi gerada uma média para esta covariável para FBP (Tabela 1) e OSEM (Tabela 2).

Tabela 1 - Notas da covariável frequência de corte na reconstrução analítica FBP em cada grupo da covariável ordem.

\section{FREQUÊNCIA DE CORTE - FBP}

\begin{tabular}{cccccccc}
\cline { 2 - 7 } ORDEM & $\mathbf{0 , 1}$ & $\mathbf{0 , 3}$ & $\mathbf{0 , 5}$ & $\mathbf{0 , 7}$ & $\mathbf{1 , 0}$ & $\mathbf{1 , 5}$ & $\mathbf{2 , 0}$ \\
\hline $\mathbf{0}$ & 6,0 & 6,0 & 6,7 & 6,3 & 6,0 & 5,0 & 6,3 \\
$\mathbf{1}$ & 1,0 & 4,3 & 6,7 & 6,3 & 5,7 & 5,0 & 4,7 \\
$\mathbf{2}$ & 1,0 & 5,7 & 7,0 & 6,3 & 5,3 & 5,7 & 6,3 \\
$\mathbf{4}$ & 1,0 & 5,0 & 6,7 & 6,3 & 6,3 & 6,0 & 5,7 \\
$\mathbf{6}$ & 1,0 & 5,0 & 7,3 & 6,0 & 4,3 & 5,7 & 5,3 \\
$\mathbf{8}$ & 1,0 & 5,3 & 6,3 & 5,3 & 4,7 & 4,7 & 5,0 \\
$\mathbf{1 0}$ & 1,0 & 6,3 & 7,0 & 5,7 & 3,7 & 5,0 & 5,7 \\
\hline MEDIA & & & & & \\
DAS & & & & & \\
NOTAS & & & & & \\
\hline
\end{tabular}

Tabela 2 - Notas da covariável frequência de corte na reconstrução iterativa OSEM em cada grupo da covariável ordem.

FREQUÊNCIA DE CORTE - OSEM

ORDEM

\begin{tabular}{lllllll}
\hline 0,1 & 0,3 & 0,5 & 0,7 & 1,0 & 1,5 & 2,0
\end{tabular}




\begin{tabular}{rrrrrrrr}
\hline $\mathbf{0}$ & 8,3 & 8,0 & 7,3 & 7,7 & 7,7 & 7,7 & 7,7 \\
$\mathbf{1}$ & 1,0 & 4,0 & 5,3 & 6,3 & 7,0 & 8,0 & 7,3 \\
$\mathbf{2}$ & 3,3 & 4,3 & 6,7 & 7,3 & 8,0 & 8,0 & 7,3 \\
$\mathbf{4}$ & 1,0 & 5,0 & 7,0 & 7,0 & 7,3 & 7,3 & 7,7 \\
$\mathbf{6}$ & 1,0 & 4,7 & 6,7 & 7,7 & 7,7 & 6,7 & 7,7 \\
$\mathbf{8}$ & 1,0 & 4,7 & 7,0 & 8,0 & 8,0 & 8,3 & 8,0 \\
$\mathbf{1 0}$ & 1,0 & 5,0 & 7,0 & 7,7 & 8,3 & 7,7 & 7,7
\end{tabular}

\section{MÉDIA}

DAS

Mencionado nos resultados, item 4.7

NOTAS

\subsubsection{Ordem utilizando FBP e OSEM}

A média foi plotada em um gráfico de colunas, para a análise visual dos resultados, a média das notas aplicadas pelos três especialistas em medicina nuclear. Através da nota de cada grupo de ordem, foi gerada uma média para esta covariável para FBP (Tabela 3) e OSEM (Tabela 4).

Tabela 3 - Grupos que foram analisados para obter a média das notas da covariável ordem, através do conjunto da covariável frequência de corte, na reconstrução analítica FBP

ORDEM - FBP

FREQUÊNCIA DE

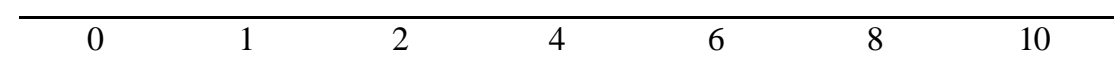

CORTE 
Tabela 4 - Grupos que foram analisados para obter a média das notas da covariável ordem, através do conjunto da covariável frequência de corte, na reconstrução analítica OSEM

\section{ORDEM - OSEM}

FREQUÊNCIA DE

$\begin{array}{lllll}0 & 1 & 2 & 4 & 6\end{array}$

$8 \quad 10$

CORTE

Média das notas, mencionada nos resultados, item 4.8

3.5.3 Ordem e frequência de corte com FBP (Fase 1) e OSEM (Fase 3):

Apresentamos o método de análise dos resultados das notas atribuídas pelos três especialistas para as imagens obtidas com diferentes ordens e frequências de corte, tanto na reconstrução FBP quanto OSEM.

As médias das notas emitidas pelos três especialistas foram analisadas por meio de modelos de regressão linear múltipla que relacionaram uma variável (resposta) a um conjunto de covariáveis. Esse modelo tem como pressuposto que seus resíduos (diferença entre o valor observado e o estimado) tenham distribuição normal com média 0 e variância constante. Como a distribuição dos resíduos não foi satisfatória, houve a aplicação da transformação logito na variável resposta em todos os modelos.

Primeiramente, os dados que estavam na escala original $\mathrm{Y}=(0,0-10,0)$ foram transformados para a escala $Z=(0,0-1,0)$, através da fórmula 5 :

$$
Z=\frac{Y}{10}
$$

Fórmula 5 - Fórmula aplicada para transformar a escala dos dados de 0,0 - 10,0 para $0,0-1,0$.

A transformação logito (W) é dada pela Fórmula 6: 


$$
\mathrm{W}=\log \left(\frac{\mathrm{z}}{1-\mathrm{z}}\right)
$$

Fórmula 6 - Fórmula aplicada aos dados para a transformação logito.

Para a obtenção de resultados preliminares e indicação de um modelo estatístico apropriado para obter inferências e encontrar regiões ótimas de interesse, foi considerada uma análise preliminar com os dados originais e transformados; por essa análise preliminar ter mostrado tendências curvilíneas, introduzimos efeitos quadráticos além de efeitos lineares no modelo de regressão linear múltipla.

Dessa forma, com a inclusão dos termos que medem a curvatura e a interação entre as duas covariáveis do estudo (frequência de corte e ordem), além dos termos lineares, foi considerado um modelo de regressão linear de segunda ordem, utilizado para obter inferências de interesse e também para encontrar regiões ótimas das covariáveis que maximizam a resposta. Esse modelo é dado pela Fórmula 7.

$$
\begin{aligned}
\mathrm{W}=\operatorname{logito}(\mathrm{Z})= & \beta_{0}+\beta_{1} \text { order }+\beta_{2} \text { cutoff }+\beta_{3}(\text { order })^{2}+\beta_{4}(\text { cutoff })^{2} \\
& +\beta_{5}(\text { order }) \times(\text { cutoff })
\end{aligned}
$$

Fórmula 7 - Modelo de regressão linear de segunda ordem.

Em que $\beta_{j}, j=0,1,2,3,4,5$ são coeficientes de regressão relacionados com cada covariável.

Os estimadores dos coeficientes de regressão $\beta_{\mathrm{j}}, \mathrm{j}=0,1,2,3,4,5$ do modelo de regressão linear múltiplo de segunda ordem foram estimados pelo método de mínimos quadrados, utilizando o software MINITAB.

O resultado da região ótima, estimada pela regressão múltipla, é demonstrado através do gráfico de contorno.

Além de estimar a região ótima, também é de interesse verificar as hipóteses do estudo. Em que,

Qual covariável é importante na reconstrução da imagem de SPECT cerebral com fantoma antropomórfico estriatal?

Assim consideramos o teste de hipótese com um nível de significância de 5\%:

$$
\begin{aligned}
& \mathbf{H}_{0}=\boldsymbol{\beta}_{\mathrm{j}}=\mathbf{0} \\
& \mathbf{H}_{\mathbf{l}}=\boldsymbol{\beta}_{\mathrm{j}} \neq \mathbf{0}
\end{aligned}
$$


em que $\mathrm{H}_{0}$ é a hipótese de nulidade (parâmetro de regressão $\beta_{\mathrm{j}}$ associado à j-ésima covariável ser igual a zero) e $\mathrm{H}_{1}$ é a hipótese alternativa (parâmetro de regressão $\beta_{\mathrm{j}}$ associado à j-ésima covariável ser diferente de zero).

\subsubsection{Iteração e número de subconjuntos (subsets) com OSEM (Fase 2)}

As notas adquiridas por um especialista independente foram plotadas em um gráfico de colunas, para a análise visual dos resultados.

\subsubsection{Teste T-Student Pareado}

Este teste é um processo de inferência estatística, considerando uma medida de posição (média), cujo objetivo é evidenciar alguma característica das variáveis através das informações de uma amostra.

É um teste pareado, pois as unidades de observações (imagens) foram avaliadas por um mesmo especialista em duas técnicas diferentes (FBP e OSEM).

Consideramos o teste de hipótese com um nível de significância de 5\%:

$$
\begin{aligned}
& \mathbf{H}_{0}: \mu_{1}-\mu_{2}=0 \\
& \mathbf{H}_{1}: \mu_{1}-\mu_{2} \neq 0
\end{aligned}
$$

Em que, os índices 1 e 2 se referem às técnicas FBP e OSEM respectivamente.

$\mathrm{H}_{0}$ é a hipótese de nulidade (Não há evidências de que as médias das notas da técnica OSEM e FBP diferem) e $\mathrm{H}_{1}$ é a hipótese alternativa do estudo (Há evidências de que as médias das notas da técnica OSEM e FBP diferem).

\subsection{Limitações e intercorrências do estudo}

Houve algumas intercorrências com horários disponíveis na agenda clínica do setor de medicina nuclear do HCFMRP-USP, justificando o retardamento de captação 
dos dados. Houve também a quebra de uma das peças do fantoma antropomórfico estriatal, um parafuso da cavidade do núcleo caudado direito, mostrando a fragilidade do produto.

Contatamos a empresa fornecedora do produto e encomendamos outra peça, mas por ser importado, o processo iria ser demasiado, além dos custos de importação. Assim, levamos a peça danificada ao Departamento de Física da FFCLRP (Faculdade de Filosofia, Ciências e Letras - USP/Ribeirão Preto), especializado em construção de fantomas, o qual aceitou a nossa demanda e conseguiu produzir satisfatoriamente uma réplica da peça (Figura 17$)$.

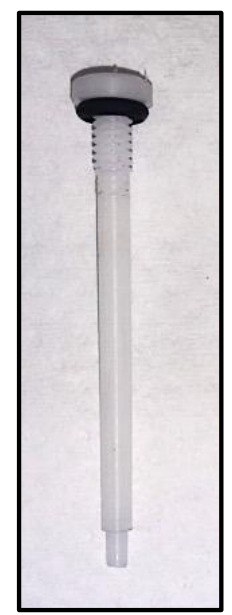

Figura 17 - Peça (parafuso) da cavidade do núcleo caudado direito do fantoma antropomórfico estriatal reproduzida pela oficina do Departamento de Física Médica da FFCLRP - USP.

Apresentou-se também a dificuldade para o preenchimento das cavidades do fantoma antropomórfico estriatal. Foi necessário adaptar agulhas descartáveis de punção liquórica, destinadas ao preenchimento das cavidades. Manualmente, cortamos as extremidades das agulhas de modo a produzir um par de agulhas com comprimento de 5 $\mathrm{cm}$ e outro par com comprimento de $7 \mathrm{~cm}$ (Figura 18a). Para o preenchimento da concha cerebral do fantoma, também foi adaptada uma pisseta (Figura 18b) cuja extremidade possui $0,4 \mathrm{~cm}$ de diâmetro, medida esta necessária para o acoplamento do orifício de preenchimento do fantoma. 


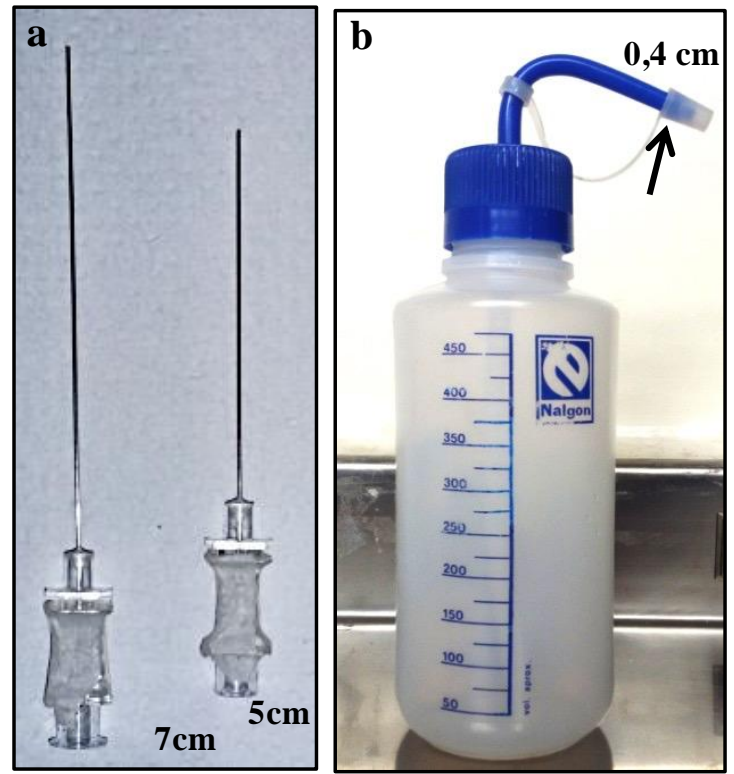

Figura 18 - Material utilizado para o preenchimento das cavidades do fantoma antropomórfico estriatal. (a) Agulhas com $7 \mathrm{~cm}$ e $5 \mathrm{~cm}$ de comprimento, utilizadas para o preenchimento das cavidades do putâmen e do núcleo caudado, respectivamente (b) Pisseta com extremidade de diâmetro de $0,4 \mathrm{~cm}$ foi utilizada para o preenchimento da concha cerebral. 
4. RESULTADOS 


\section{RESULTADOS}

\subsection{Casuísticas das imagens}

Para a realização de todos os experimentos com o fantoma antropomórfico estriatal, foram realizados um treinamento prévio e a análise das técnicas de preenchimento das cavidades independentes e referentes tanto ao corpo estriado quanto ao restante do encéfalo. Este treinamento foi realizado para evitar contaminações externas do fantoma, assim como contaminações de superfície no laboratório de radiofarmácia da Seção de Medicina Nuclear do HCFMRP/USP.

Após o preenchimento bilateral (direito e esquerdo) das cavidades putâmen e núcleo caudado e da concha cerebral, foram realizadas quatro aquisições com o fantoma antropomórfico estriatal, com atividades radioativas homogêneas nas quatro cavidades do corpo estriado, tentando com isto simular uma imagem mais próxima de uma pessoa neurologicamente normal. Estas aquisições foram feitas em quatro dias diferentes devido à necessidade de decaimento da atividade radioativa do radionuclídeo inserido nas cavidades. Para o decaimento total, e também por medida de radioproteção, a concha cerebral ficou isolada na sala de rejeitos radioativos por 72 horas.

Das quatro imagens homogêneas adquiridas, utilizamos a primeira aquisição, pois esta apresentou a melhor homogeneidade da atividade utilizada e permitiu uma distinção visual das estruturas avaliadas.

Ainda que a partir do terceiro dia a concha já pudesse ser novamente utilizada, as aquisições foram realizadas em três meses, por eventuais problemas encontrados, conforme mencionado no item 3.6. 


\subsection{Notas atribuídas pelos especialistas em medicina nuclear}

\subsubsection{Ordem e frequência de corte utilizando o FBP (Fase 1)}

A variação da ordem e frequência de corte aplicadas pelo algoritmo FBP nas 49 imagens reconstruídas estão descritas na Tabela 5. Pode-se observar que as médias das notas dos especialistas foram próximas umas das outras. A média das notas do especialista um foi 4,5 e dos especialistas dois e três foram 5,4. As médias das notas pelos três especialistas para cada imagem, também está descrita na Tabela 5. A média total de nota, de todos os especialistas, e para todas as imagens foi de 5,1.

Tabela 5 - Variação da ordem e frequência de corte aplicadas pelo algoritmo FBP, em 49 amostras, categorizadas por notas de 0,0 a 10,0 por três especialistas e a média das notas das três avaliações. Continua.

\begin{tabular}{|c|c|c|c|c|c|c|}
\hline IMAGENS & Ordem & $\begin{array}{l}\text { Frequência } \\
\text { de corte }\end{array}$ & $\begin{array}{c}\text { Especialista } \\
1\end{array}$ & $\begin{array}{c}\text { Especialista } \\
2\end{array}$ & $\begin{array}{c}\text { Especialista } \\
3\end{array}$ & $\begin{array}{l}\text { Média das } \\
\text { notas }\end{array}$ \\
\hline 1 & 0 & 0,1 & 5,0 & 6,0 & 7,0 & 6,0 \\
\hline 2 & 0 & 0,3 & 5,0 & 6,0 & 7,0 & 6,0 \\
\hline 3 & 0 & 0,5 & 5,0 & 6,0 & 9,0 & 6,7 \\
\hline 4 & 0 & 0,7 & 5,0 & 6,0 & 8,0 & 6,3 \\
\hline 5 & 0 & 1,0 & 5,0 & 6,0 & 7,0 & 6,0 \\
\hline 6 & 0 & 1,5 & 5,0 & 6,0 & 4,0 & 5,0 \\
\hline 7 & 0 & 2,0 & 6,0 & 6,0 & 4,0 & 5,3 \\
\hline 8 & 1 & 0,1 & 1,0 & 1,0 & 1,0 & 1,0 \\
\hline 9 & 1 & 0,3 & 3,0 & 6,0 & 4,0 & 4,3 \\
\hline 10 & 1 & 0,5 & 5,0 & 6,0 & 9,0 & 6,7 \\
\hline 11 & 1 & 0,7 & 6,0 & 6,0 & 7,0 & 6,3 \\
\hline 12 & 1 & 1,0 & 6,0 & 6,0 & 5,0 & 5,7 \\
\hline 13 & 1 & 1,5 & 5,0 & 6,0 & 4,0 & 5,0 \\
\hline 14 & 1 & 2,0 & 4,0 & 6,0 & 4,0 & 4,7 \\
\hline 15 & 2 & 0,1 & 1,0 & 1,0 & 1,0 & 1,0 \\
\hline 16 & 2 & 0,3 & 4,0 & 6,0 & 7,0 & 5,7 \\
\hline 17 & 2 & 0,5 & 6,0 & 6,0 & 9,0 & 7,0 \\
\hline 18 & 2 & 0,7 & 6,0 & 6,0 & 7,0 & 6,3 \\
\hline 19 & 2 & 1,0 & 5,0 & 6,0 & 5,0 & 5,3 \\
\hline 20 & 2 & 1,5 & 6,0 & 6,0 & 5,0 & 5,7 \\
\hline 21 & 2 & 2,0 & 6,0 & 6,0 & 7,0 & 6,3 \\
\hline 22 & 4 & 0,1 & 1,0 & 1,0 & 1,0 & 1,0 \\
\hline 23 & 4 & 0,3 & 3,0 & 7,0 & 5,0 & 5,0 \\
\hline 24 & 4 & 0,5 & 5,0 & 6,0 & 9,0 & 6,7 \\
\hline 25 & 4 & 0,7 & 6,0 & 6,0 & 7,0 & 6,3 \\
\hline 26 & 4 & 1,0 & 5,0 & 6,0 & 8,0 & 6,3 \\
\hline 27 & 4 & 1,5 & 5,0 & 6,0 & 7,0 & 6,0 \\
\hline 28 & 4 & 2,0 & 5,0 & 6,0 & 6,0 & 5,7 \\
\hline 29 & 6 & 0,1 & 1,0 & 1,0 & 1,0 & 1,0 \\
\hline 30 & 6 & 0,3 & 3,0 & 7,0 & 5,0 & 5,0 \\
\hline 31 & 6 & 0,5 & 6,0 & 7,0 & 9,0 & 7,3 \\
\hline
\end{tabular}


Tabela 5 - Variação da ordem e frequência de corte aplicadas pelo algoritmo FBP, em 49 amostras, categorizadas por notas de 0,0 a 10,0 por três especialistas e a média das notas das três avaliações. Conclusão.

\begin{tabular}{ccccccc} 
IMAGENS & Ordem & $\begin{array}{c}\text { Frequência } \\
\text { de corte }\end{array}$ & $\begin{array}{c}\text { Especialista } \\
\mathbf{1}\end{array}$ & $\begin{array}{c}\text { Especialista } \\
\mathbf{2}\end{array}$ & $\begin{array}{c}\text { Especialista } \\
\mathbf{3}\end{array}$ & $\begin{array}{c}\text { Média das } \\
\text { notas }\end{array}$ \\
\hline $\mathbf{3 2}$ & 6 & 0,7 & 5,0 & 6,0 & 7,0 & 6,0 \\
$\mathbf{3 3}$ & 6 & 1,0 & 6,0 & 4,0 & 3,0 & 4,3 \\
$\mathbf{3 4}$ & 6 & 1,5 & 7,0 & 6,0 & 4,0 & 5,7 \\
$\mathbf{3 5}$ & 6 & 2,0 & 6,0 & 6,0 & 4,0 & 5,3 \\
$\mathbf{3 6}$ & 8 & 0,1 & 1,0 & 1,0 & 1,0 & 1,0 \\
$\mathbf{3 7}$ & 8 & 0,3 & 3,0 & 7,0 & 6,0 & 5,3 \\
$\mathbf{3 8}$ & 8 & 0,5 & 5,0 & 7,0 & 7,0 & 6,3 \\
$\mathbf{3 9}$ & 8 & 0,7 & 5,0 & 6,0 & 5,0 & 5,3 \\
$\mathbf{4 0}$ & 8 & 1,0 & 5,0 & 6,0 & 3,0 & 4,7 \\
$\mathbf{4 1}$ & 8 & 1,5 & 5,0 & 6,0 & 3,0 & 4,7 \\
$\mathbf{4 2}$ & 8 & 2,0 & 5,0 & 6,0 & 4,0 & 5,0 \\
$\mathbf{4 3}$ & 10 & 0,1 & 1,0 & 1,0 & 1,0 & 1,0 \\
$\mathbf{4 4}$ & 10 & 0,3 & 4,0 & 7,0 & 8,0 & 6,3 \\
$\mathbf{4 5}$ & 10 & 0,5 & 5,0 & 9,0 & 7,0 & 7,0 \\
$\mathbf{4 6}$ & 10 & 0,7 & 5,0 & 6,0 & 6,0 & 5,7 \\
$\mathbf{4 7}$ & 10 & 1,0 & 3,0 & 4,0 & 4,0 & 3,7 \\
$\mathbf{4 8}$ & 10 & 1,5 & 5,0 & 4,0 & 6,0 & 5,0 \\
$\mathbf{4 9}$ & 10 & 2,0 & 5,0 & 6,0 & 6,0 & 5,7 \\
\hline M|FDIAS & & & $\mathbf{4 , 5}$ & $\mathbf{5 , 4}$ & $\mathbf{5 , 4}$ & $\mathbf{5 , 1}$ \\
\hline
\end{tabular}

\subsubsection{Número de iterações e de subsets utilizando o algoritmo OSEM}

(Fase 2)

A variação da ordem e frequência de corte aplicadas pelo algoritmo OSEM nas 30 imagens reconstruídas estão descritas na Tabela 6. A média das notas do especialista independente foi 2,0 .

Tabela 6 - Variação dos números de iterações e subsets utilizados na primeira fase do experimento, usando o algoritmo OSEM, em 30 amostras, categorizadas por notas de 0,0 a 5,0 por um especialista independente. Continua.

\begin{tabular}{cccc}
\hline IMAGENS & $\begin{array}{c}\text { Número de } \\
\text { iterações }\end{array}$ & $\begin{array}{c}\text { Número de } \\
\text { subsets }\end{array}$ & $\begin{array}{c}\text { Notas atribuídas por } \\
\text { um especialis ta } \\
\text { independente }\end{array}$ \\
\hline $\mathbf{1}$ & 2 & 4 & 3,0 \\
$\mathbf{2}$ & 2 & 8 & 4,0 \\
$\mathbf{3}$ & 2 & 16 & 3,0 \\
$\mathbf{4}$ & 3 & 4 & 4,0 \\
$\mathbf{5}$ & 3 & 8 & 5,0 \\
$\mathbf{6}$ & 3 & 16 & 2,0 \\
$\mathbf{7}$ & 4 & 4 & 4,0 \\
$\mathbf{8}$ & 4 & 8 & 3,0
\end{tabular}


Tabela 6 - Variação dos números de iterações e subsets utilizados na primeira fase do experimento, usando o algoritmo OSEM, em 30 amostras, categorizadas por notas de 0,0 a 5,0 por um especialista independente. Conclusão.

\begin{tabular}{cccc} 
IMAGENS & $\begin{array}{c}\text { Número de } \\
\text { iteraçôes }\end{array}$ & $\begin{array}{c}\text { Número de } \\
\text { subsets }\end{array}$ & $\begin{array}{c}\text { Notas atribuídas por } \\
\text { um especialista } \\
\text { independente }\end{array}$ \\
\hline $\mathbf{9}$ & 4 & 16 & 2,0 \\
$\mathbf{1 0}$ & 6 & 4 & 4,0 \\
$\mathbf{1 1}$ & 6 & 8 & 2,0 \\
$\mathbf{1 2}$ & 6 & 16 & 1,0 \\
$\mathbf{1 3}$ & 8 & 4 & 3,0 \\
$\mathbf{1 4}$ & 8 & 8 & 2,0 \\
$\mathbf{1 5}$ & 8 & 16 & 1,0 \\
$\mathbf{1 6}$ & 10 & 4 & 3,0 \\
$\mathbf{1 7}$ & 10 & 8 & 2,0 \\
$\mathbf{1 8}$ & 10 & 16 & 1,0 \\
$\mathbf{1 9}$ & 12 & 8 & 2,0 \\
$\mathbf{2 0}$ & 12 & 16 & 1,0 \\
$\mathbf{2 1}$ & 12 & 4 & 1,0 \\
$\mathbf{2 2}$ & 16 & 8 & 2,0 \\
$\mathbf{2 3}$ & 16 & 16 & 1,0 \\
$\mathbf{2 4}$ & 16 & 4 & 1,0 \\
$\mathbf{2 5}$ & 16 & 8 & 1,0 \\
$\mathbf{2 6}$ & 32 & 16 & 1,0 \\
$\mathbf{2 7}$ & 32 & 4 & 1,0 \\
$\mathbf{2 8}$ & 32 & 8 & 1,0 \\
$\mathbf{2 9}$ & 60 & 16 & 1,0 \\
$\mathbf{3 0}$ & 60 & & 1,0 \\
\hline Mf́1. & 60 & &
\end{tabular}

\subsubsection{Ordem e frequência de corte utilizando o OSEM(Fase 3)}

A variação da ordem e frequência de corte aplicadas pelo algoritmo OSEM nas 49 imagens reconstruídas estão descritas na Tabela 7. A média das notas do especialista um foi 5,8; do especialista dois foi 7,0 e do especialista três foi 6,4. As médias das notas pelos três especialistas para cada imagem, também está descrita na Tabela 7. A média total de nota, de todos os especialistas, e para todas as imagens foi de 6,4 . 
Tabela 7 - Variação da ordem e frequência de corte aplicadas pelo algoritmo OSEM, em 49 amostras, categorizadas por notas de 0,0 a 10,0 por três especialistas e a média das notas.

\begin{tabular}{|c|c|c|c|c|c|c|}
\hline IMAGENS & Ordem & $\begin{array}{l}\text { Frequência } \\
\text { de corte }\end{array}$ & $\begin{array}{c}\text { Especialista } \\
1\end{array}$ & $\begin{array}{c}\text { Especialista } \\
2\end{array}$ & $\begin{array}{c}\text { Especialista } \\
\mathbf{3}\end{array}$ & $\begin{array}{c}\text { Média das } \\
\text { notas }\end{array}$ \\
\hline 1 & 0 & 0,1 & 8,0 & 8,0 & 9,0 & 8,3 \\
\hline 2 & 0 & 0,3 & 7,0 & 8,0 & 9,0 & 8,0 \\
\hline 3 & 0 & 0,5 & 6,0 & 8,0 & 8,0 & 7,3 \\
\hline 4 & 0 & 0,7 & 7,0 & 8,0 & 8,0 & 7,7 \\
\hline 5 & 0 & 1,0 & 7,0 & 8,0 & 8,0 & 7,7 \\
\hline 6 & 0 & 1,5 & 8,0 & 8,0 & 7,0 & 7,7 \\
\hline 7 & 0 & 2,0 & 8,0 & 8,0 & 7,0 & 7,7 \\
\hline 8 & 1 & 0,1 & 1,0 & 1,0 & 1,0 & 1,0 \\
\hline 9 & 1 & 0,3 & 3,0 & 6,0 & 3,0 & 4,0 \\
\hline 10 & 1 & 0,5 & 5,0 & 6,0 & 5,0 & 5,3 \\
\hline 11 & 1 & 0,7 & 6,0 & 6,0 & 7,0 & 6,3 \\
\hline 12 & 1 & 1,0 & 6,0 & 8,0 & 7,0 & 7,0 \\
\hline 13 & 1 & 1,5 & 8,0 & 8,0 & 8,0 & 8,0 \\
\hline 14 & 1 & 2,0 & 7,0 & 8,0 & 7,0 & 7,3 \\
\hline 15 & 2 & 0,1 & 1,0 & 8,0 & 1,0 & 3,3 \\
\hline 16 & 2 & 0,3 & 4,0 & 6,0 & 3,0 & 4,3 \\
\hline 17 & 2 & 0,5 & 6,0 & 8,0 & 6,0 & 6,7 \\
\hline 18 & 2 & 0,7 & 6,0 & 8,0 & 8,0 & 7,3 \\
\hline 19 & 2 & 1,0 & 7,0 & 8,0 & 9,0 & 8,0 \\
\hline 20 & 2 & 1,5 & 7,0 & 8,0 & 9,0 & 8,0 \\
\hline 21 & 2 & 2,0 & 6,0 & 8,0 & 8,0 & 7,3 \\
\hline 22 & 4 & 0,1 & 1,0 & 1,0 & 1,0 & 1,0 \\
\hline 23 & 4 & 0,3 & 4,0 & 9,0 & 5,0 & 5,0 \\
\hline 24 & 4 & 0,5 & 6,0 & 8,0 & 7,0 & 7,0 \\
\hline 25 & 4 & 0,7 & 6,0 & 8,0 & 7,0 & 7,0 \\
\hline 26 & 4 & 1,0 & 7,0 & 8,0 & 7,0 & 7,3 \\
\hline 27 & 4 & 1,5 & 6,0 & 8,0 & 8,0 & 7,3 \\
\hline 28 & 4 & 2,0 & 7,0 & 8,0 & 8,0 & 7,7 \\
\hline 29 & 6 & 0,1 & 1,0 & 1,0 & 1,0 & 1,0 \\
\hline 30 & 6 & 0,3 & 3,0 & 6,0 & 5,0 & 4,7 \\
\hline 31 & 6 & 0,5 & 6,0 & 8,0 & 6,0 & 6,7 \\
\hline 32 & 6 & 0,7 & 7,0 & 8,0 & 8,0 & 7,7 \\
\hline 33 & 6 & 1,0 & 8,0 & 8,0 & 7,0 & 7,7 \\
\hline 34 & 6 & 1,5 & 7,0 & 9,0 & 7,0 & 6,7 \\
\hline 35 & 6 & 2,0 & 7,0 & 8,0 & 8,0 & 7,7 \\
\hline 36 & 8 & 0,1 & 1,0 & 1,0 & 1,0 & 1,0 \\
\hline 37 & 8 & 0,3 & 4,0 & 6,0 & 4,0 & 4,7 \\
\hline 38 & 8 & 0,5 & 6,0 & 8,0 & 7,0 & 7,0 \\
\hline 39 & 8 & 0,7 & 8,0 & 8,0 & 8,0 & 8,0 \\
\hline 40 & 8 & 1,0 & 9,0 & 6,0 & 9,0 & 8,0 \\
\hline 41 & 8 & 1,5 & 8,0 & 8,0 & 9,0 & 8,3 \\
\hline 42 & 8 & 2,0 & 7,0 & 8,0 & 9,0 & 8,0 \\
\hline 43 & 10 & 0,1 & 1,0 & 1,0 & 1,0 & 1,0 \\
\hline 44 & 10 & 0,3 & 5,0 & 6,0 & 4,0 & 5,0 \\
\hline 45 & 10 & 0,5 & 6,0 & 8,0 & 7,0 & 7,0 \\
\hline 46 & 10 & 0,7 & 7,0 & 8,0 & 8,0 & 7,7 \\
\hline 47 & 10 & 1,0 & 8,0 & 8,0 & 9,0 & 8,3 \\
\hline 48 & 10 & 1,5 & 8,0 & 8,0 & 7,0 & 7,7 \\
\hline 49 & 10 & 2,0 & 6,0 & 8,0 & 9,0 & 7,7 \\
\hline MÉDIA & & & 5,8 & 7,0 & 6,4 & 6,4 \\
\hline
\end{tabular}




\subsection{Frequência de corte utilizando o algoritmo FBP}

A Figura 19 apresenta as notas designadas pelos três especialistas para as imagens processadas com FBP, variando-se as frequências de corte de 0,1 a 2,0. No gráfico de barras, observamos que a melhor frequência de corte avaliada (nota 6,8) é a de 0,5 ciclos/pixel.

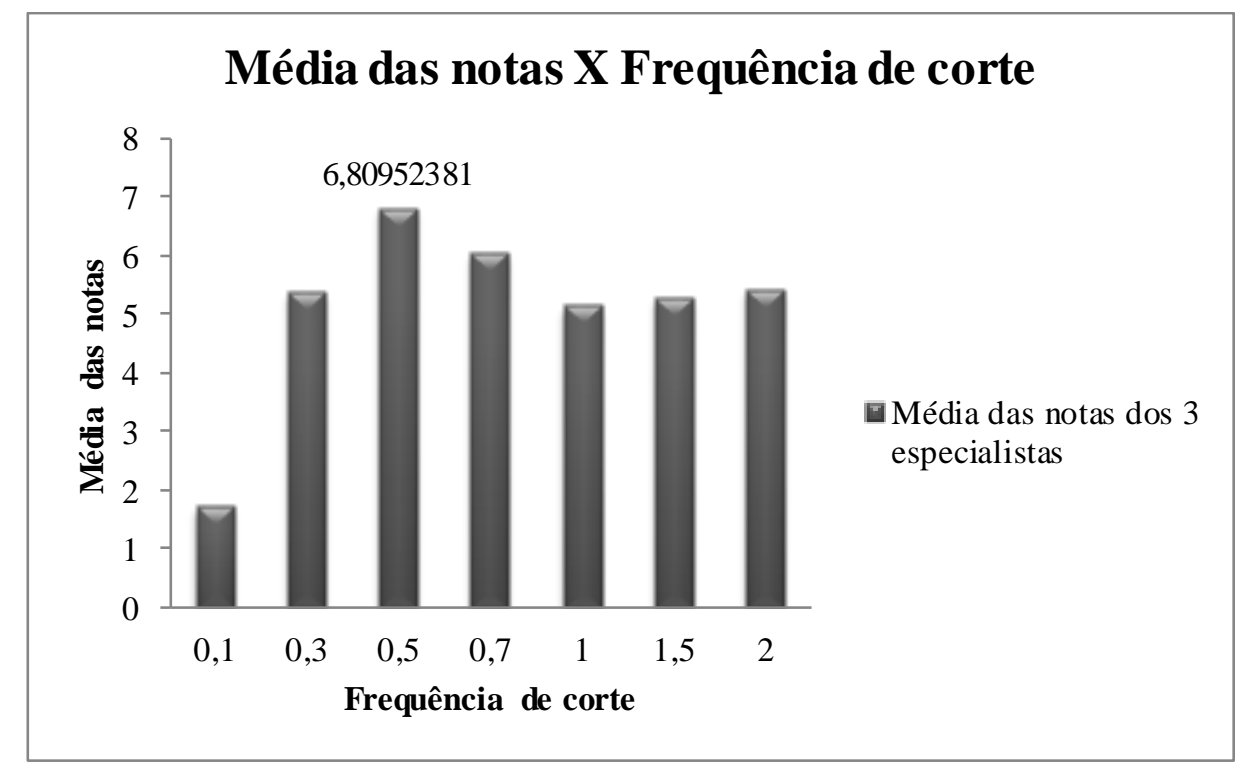

Figura 19 - Gráfico de barras com as médias das notas dos três especialistas para as imagens com diferentes frequências de corte reconstruídas no algoritmo FBP.

\subsection{Ordem utilizando o algoritmo FBP}

A Figura 20 apresenta as médias das notas designadas pelos três especialistas para as imagens processadas com FBP, variando-se as ordens de 0 a 10 . No gráfico de barras, observamos que a melhor ordem avaliada (nota 5,9) é a ordem 0. 


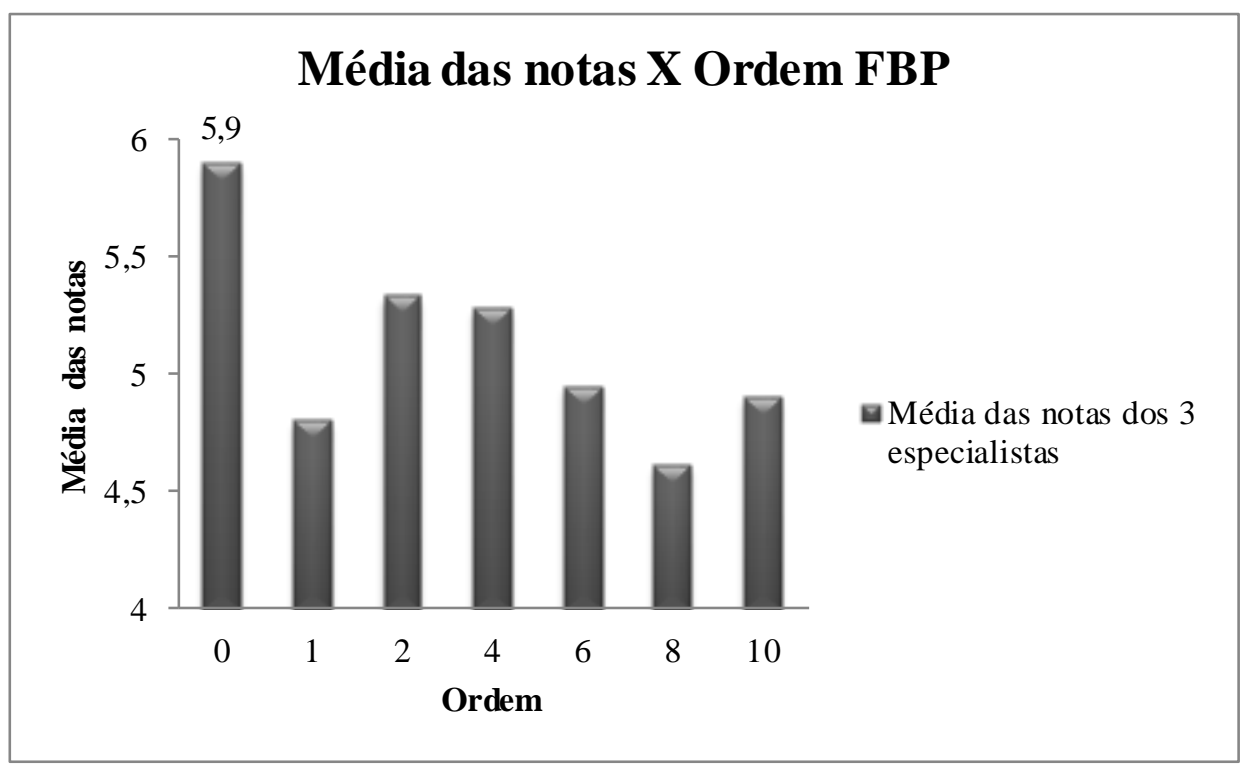

Figura 20 - Gráfico de barras com as médias das notas dos três especialistas designados e as imagens com diferentes ordens reconstruídas no algoritmo FBP.

4.5 Variáveis ordem e frequência de corte utilizando o algoritmo FBP (Fase 1)

Aplicando o modelo de regressão linear múltipla de segunda ordem (Fórmula 7) e utilizando o algoritmo analítico FBP, obtivemos o seguinte gráfico de contorno (Figura 21) como resultado para encontrar as regiões ótimas (maximização da resposta), na escala Z (Fórmula 5). 


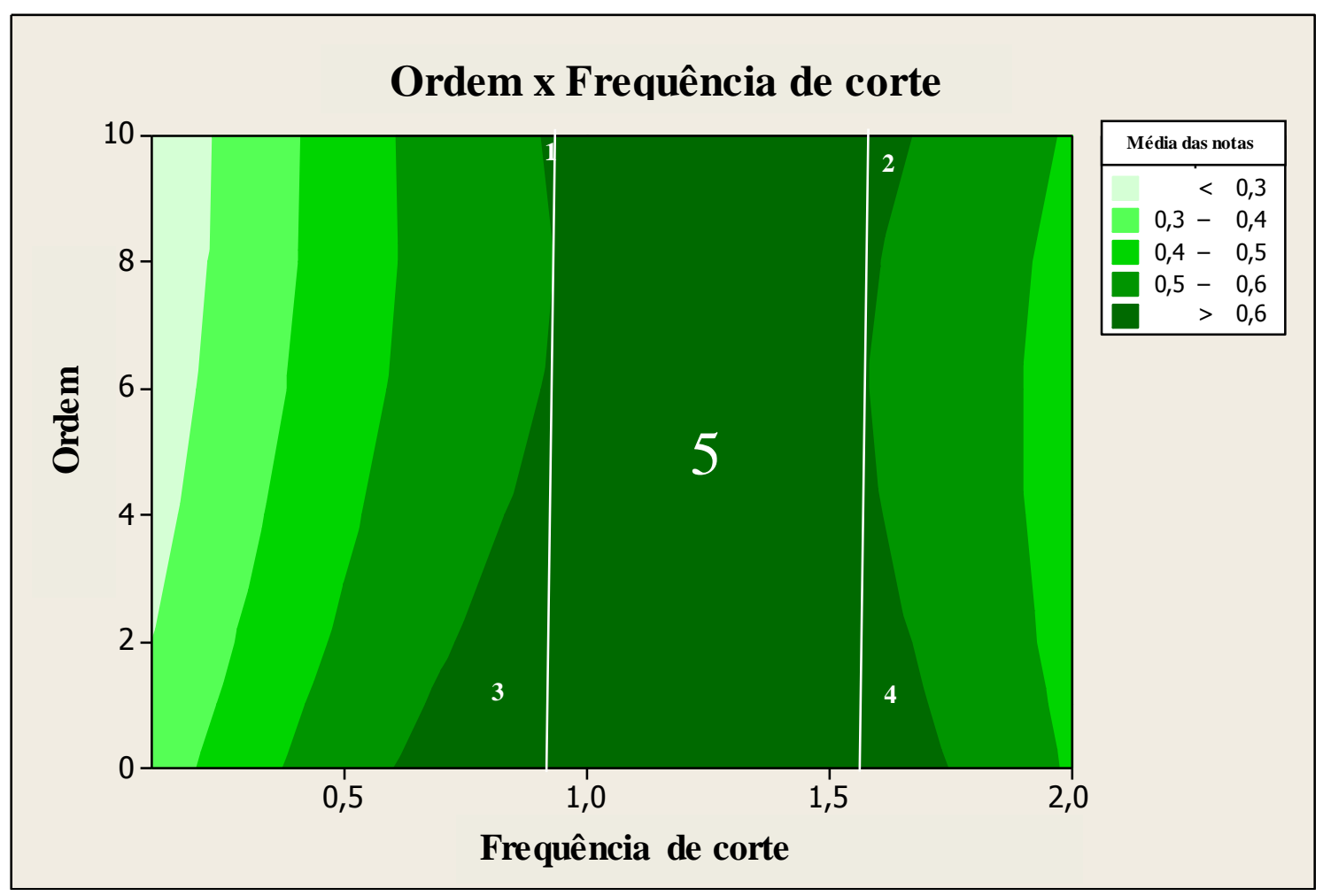

Figura 21 - Gráfico de contorno com as variáveis frequência de corte e ordem. Também composto pelas médias das notas, utilizando o algoritmo FBP.

Conforme a interpretação do gráfico de contorno, sugerimos que na reconstrução FBP, para obter uma imagem de qualidade (média das notas >0,6), é viável utilizar a frequência de corte no intervalo 5 da Figura 21, aproximadamente 0,9 a 1,6 e a ordem livre para a escolha do profissional que irá reconstruir (intervalo de $0-10$ ). As imagens do intervalo sugerido estão demonstradas na Figura 22. 


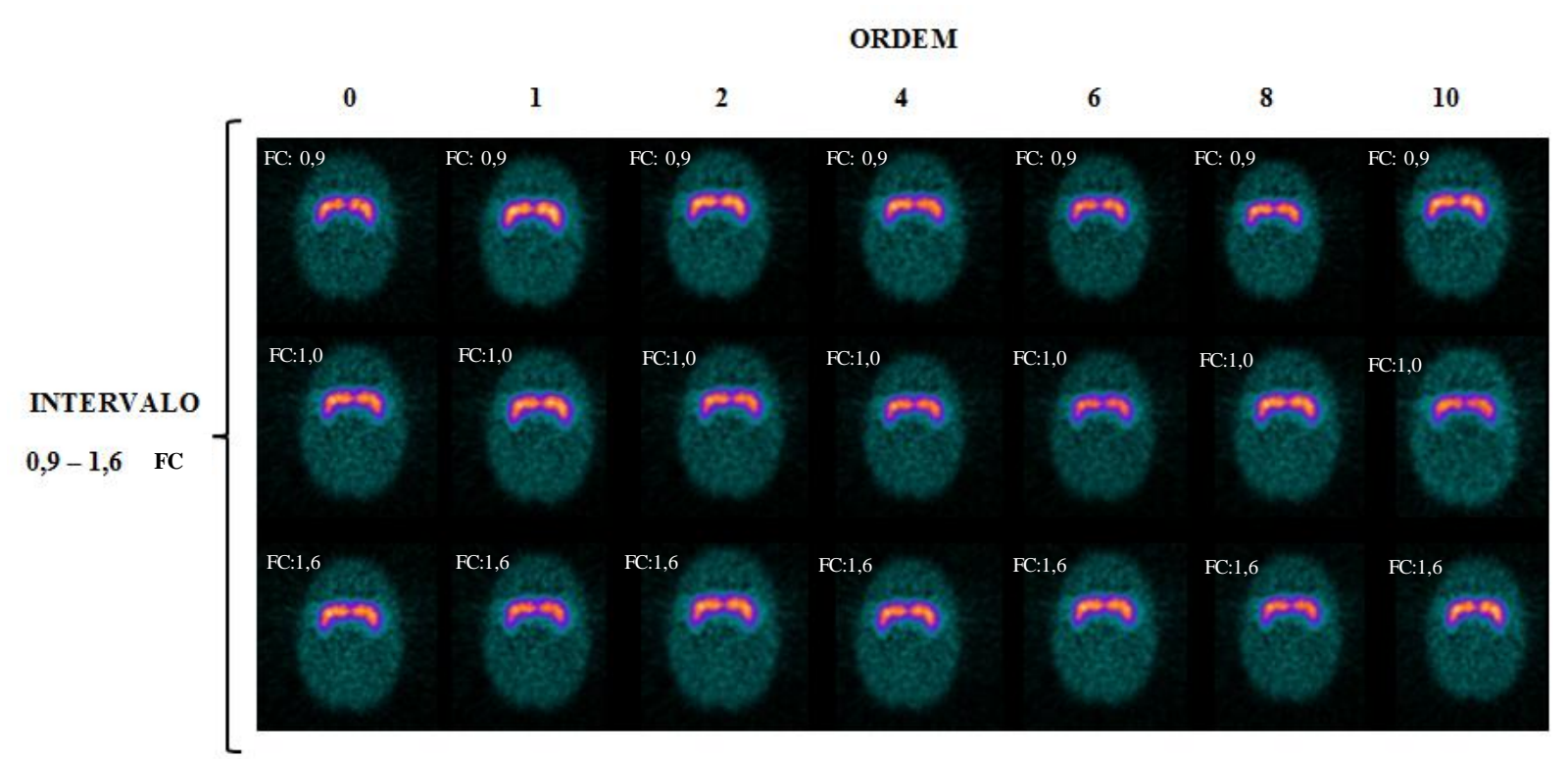

Figura 22 - Imagens de SPECT cerebral com fantoma antropomórfico estriatal reconstruída com algoritmo analítico FBP no intervalo de 0,9 a 1,6 de frequência de corte, variando a ordem de 0 a 10 . Este intervalo proposto fornece 21 maneiras que categorizam padrão de qualidade na análise visual das imagens.

Notamos que outros intervalos (1, 2, 3 e 4 da Figura 21) também apresentaram imagens de qualidade (média das notas $>0,6$ ), mas havendo a necessidade de variar a covariável Ordem. São eles:

1- Frequência de corte $0,85-0,89$ e Ordem variando de 8 - 10 gradualmente

2- Frequência de corte 1,61 - 1,65 e Ordem variando de 7 - 10 gradualmente

3- Frequência de corte $0,6-0,89$ e Ordem variando de $0-7,5$ gradualmente

4- Frequência de corte 1,61 - 1,7 e Ordem variando de 0 - 5 gradualmente

Além de estimar a região ótima, também foi de interesse verificar a hipótese do estudo. Qual covariável é importante variar os valores na reconstrução da imagem de SPECT cerebral com o algoritmo FBP?

Assim consideramos o teste de hipótese com um nível de significância de 5\%:

$$
\begin{aligned}
& \mathbf{H}_{0}=\boldsymbol{\beta}_{\mathrm{j}}=\mathbf{0} \\
& \mathbf{H}_{\mathbf{l}}=\boldsymbol{\beta}_{\mathrm{j}} \neq \mathbf{0}
\end{aligned}
$$

em que $\mathrm{H}_{0}$ é a hipótese de nulidade (parâmetro de regressão $\beta_{\mathrm{j}}$ associado à j-ésima covariável ser igual a zero) e $\mathrm{H}_{1}$ é a hipótese alternativa (parâmetro de regressão $\beta_{\mathrm{j}}$ associado à j-ésima covariável ser diferente de zero). 
Nos resultados a seguir, utilizamos a análise estatística de regressão para verificar qual covariável apresentou a necessidade de variação dos dados para uma imagem reconstruída com qualidade (Figura 23).

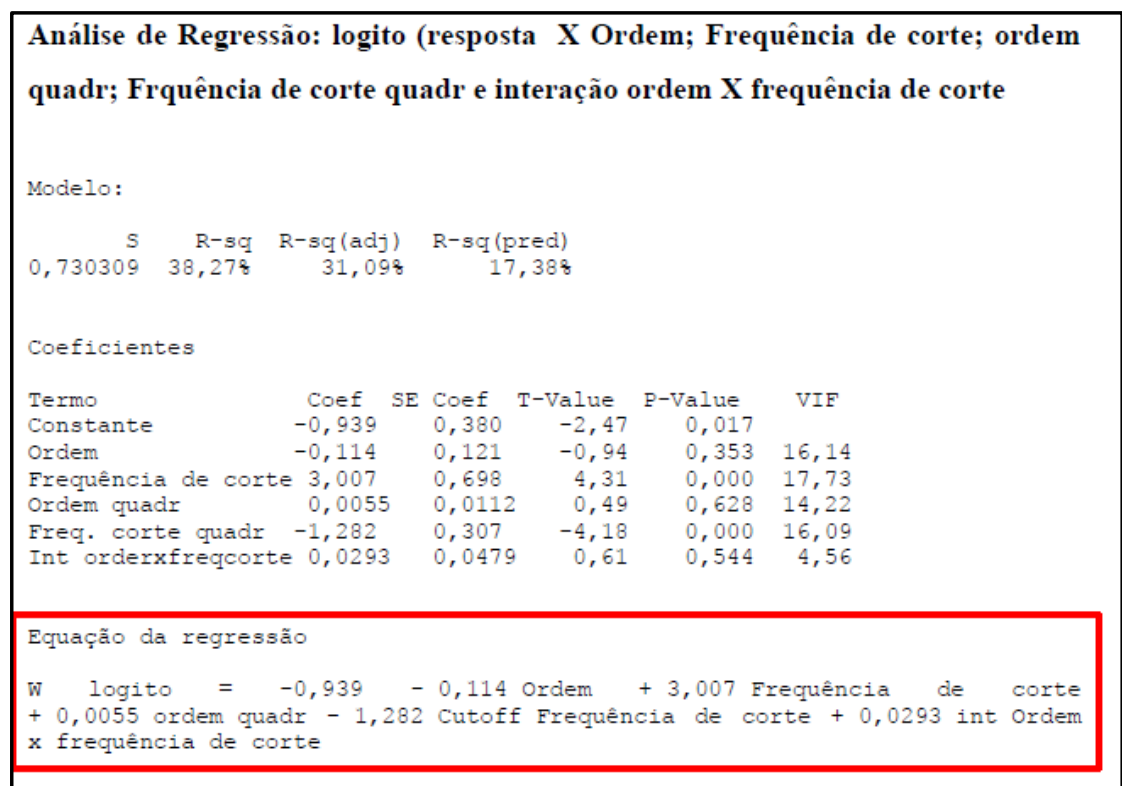

Figura 23 - Análise de regressão, mostrando o p-valor de cada covariável do estudo.

A partir da análise estatística da Figura 23, observamos que a covariável frequência de corte apresentou evidência de efeito linear e de efeito quadrático na resposta de interesse, ou seja, tiveram p-valor <0,05. Da mesma forma, observamos que a covariável ordem (efeito linear e quadrático) não apresentou efeito significativo na resposta de interesse, pois p-valor >0,05. A interação OrderXfreqcorte também não apresentou efeito significativo na resposta.

Assim, conseguimos evidenciar que a covariável que necessita de ajuste e controle, durante a reconstrução de imagem com algoritmo analítico FBP, é a covariável frequência de corte. Já a covariável ordem, dentro do intervalo controlado de frequência de corte, pode variar de 0 a 10, uma vez que não irá apresentar decremento na qualidade da imagem (efeitos não significativos). 


\subsection{Número de iterações e de subsets utilizando o OSEM (Fase 2)}

Através da análise cega de um especialista independente em medicina nuclear, foram aplicadas notas, plotadas em um gráfico de barras (Figura 24), para as 30 imagens reconstruídas (Figura 26).

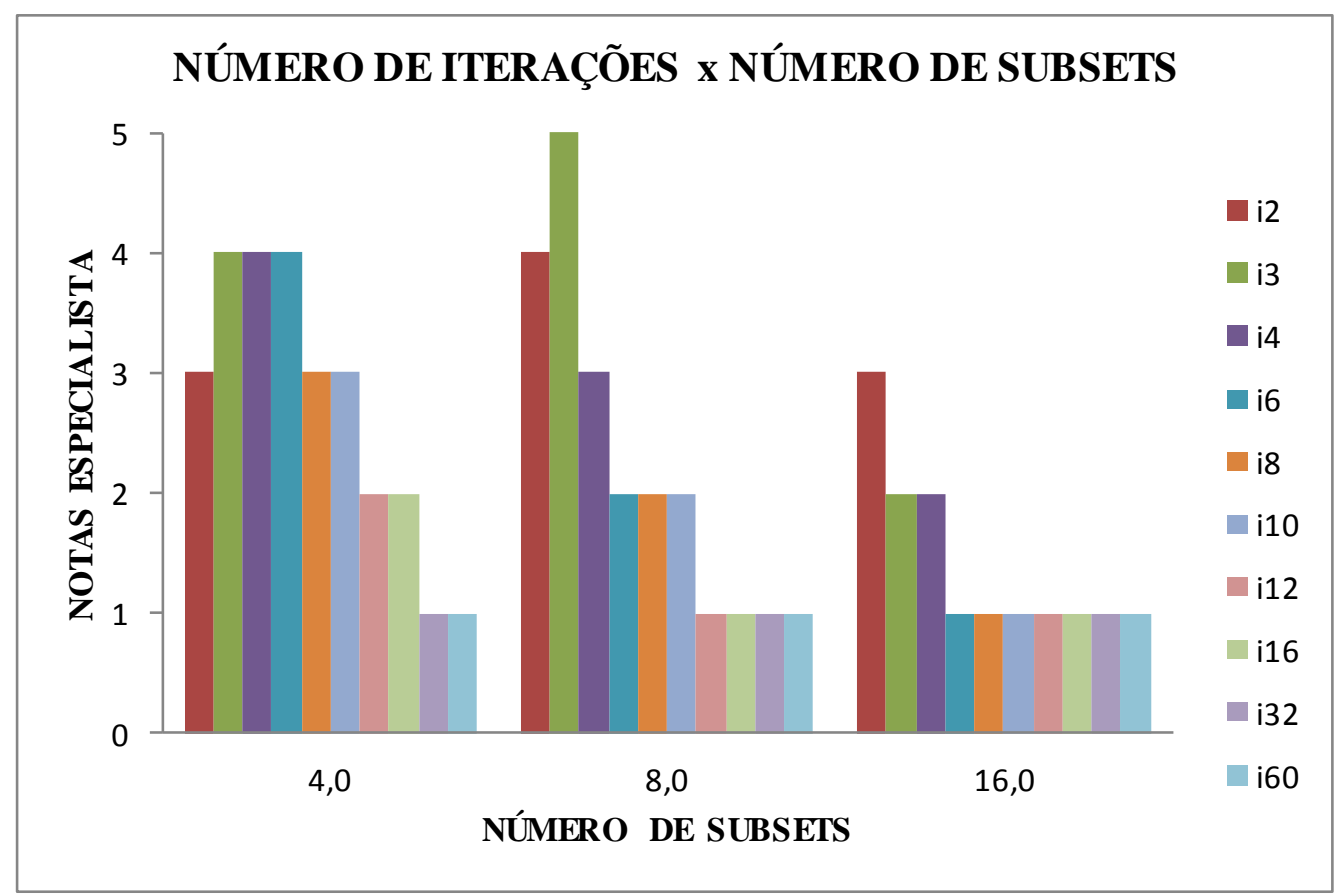

Figura 24 - Gráfico de barras entre as categorias (número de iterações e número de subsets) através de notas $(0-5)$, por um especialista independente em medicina nuclear.

Dessa análise, apenas uma imagem sobressaiu com a melhor nota, a imagem reconstruída com 3i e 8s (Figura 25). 


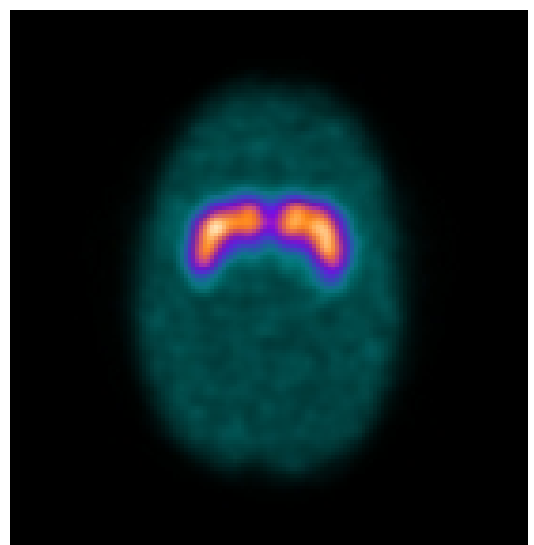

Figura 25 - Imagem de SPECT cerebral adquirido com fantoma antropomórfico estriatal reconstruído com algoritmo iterativo OSEM da gama-câmara PHILIPS, utilizando três iterações e oito subsets. Intervalo que garante qualidade da imagem na primeira etapa da reconstrução OSEM. 


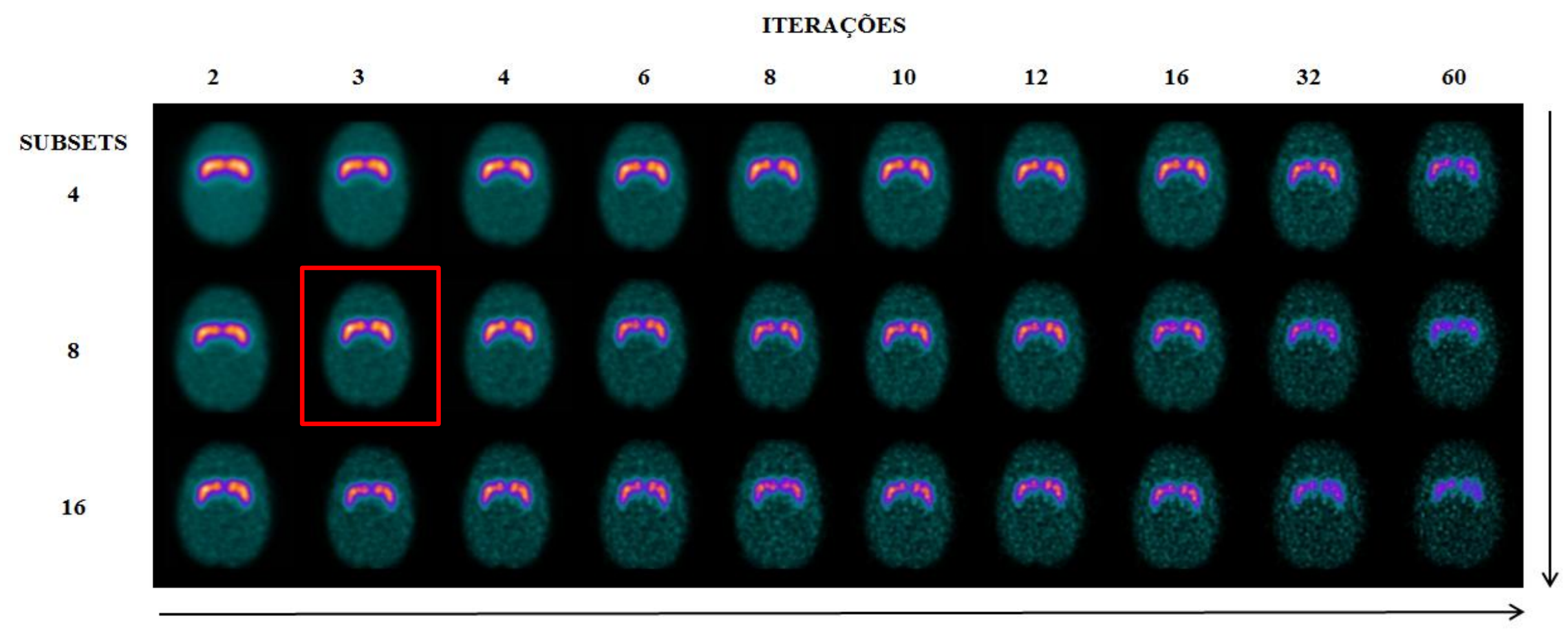

Figura 26 - Imagens reconstruídas com o algoritmo iterativo OSEM, variando as covariáveis iterações (2 a 60) e número de subsets (4, 8 e 16), totalizando 30 imagens. 
A imagem 3i8s foi a que garantiu a maior qualidade de imagem, diferenciando o putâmen e a cabeça do núcleo caudado. Também encontramos que as iterações mais baixas e mais altas resultaram em menores notas para a qualidade da imagem. Estes dados estão apresentados na Tabela 2. Em particular, a partir de 12 iterações, houve um incremento no ruído com consequente redução da resolução espacial.

Pelas notas do especialista em medicina nuclear independente, as imagens com $4 \mathrm{~s}$, a partir de $12 \mathrm{i}$, apresentaram as menores notas para a qualidade das imagens. Com 4i8s, a nota foi média e com os demais valores de iterações, todas as notas foram menores.

Já com o maior número de subsets (16s), as imagens a partir de 3i até 60i foram classificadas com baixas notas, exceto a imagem com i2 que teve uma nota intermediária.

\subsection{Frequência de corte utilizando o algoritmo OSEM}

A Figura 27 apresenta as notas designadas pelos três especialistas para as imagens processadas com OSEM, variando-se as frequências de corte de 0,1 a 2,0. No gráfico de barras, observa-se que a melhor frequência de corte avaliada (nota 7,71) é a de 1,0 ciclos/pixel.

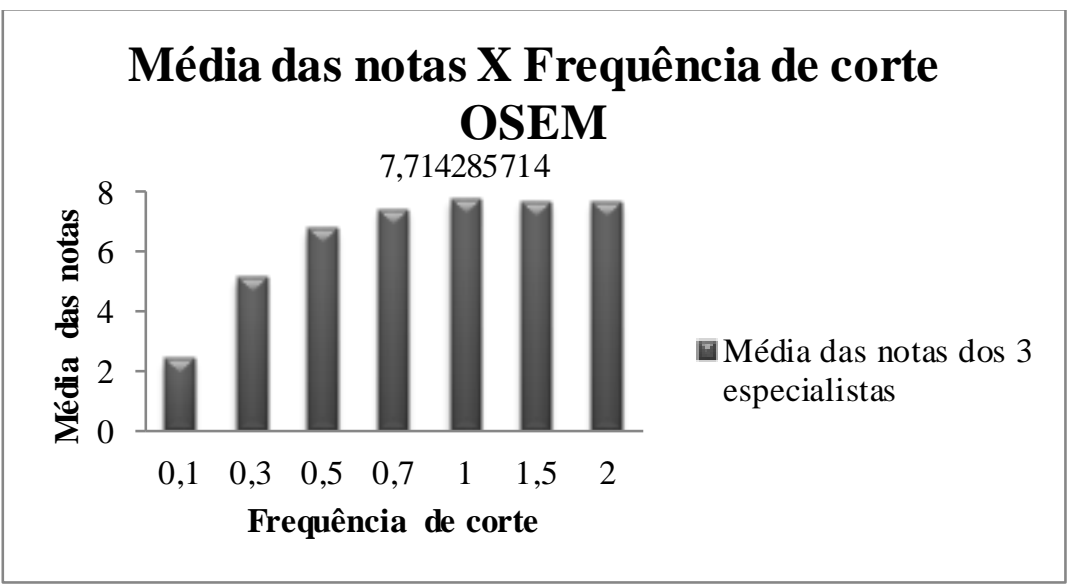

Figura 27 - Gráfico de barras com as médias das notas dos três especialistas, designadas as imagens com diferentes frequências de corte reconstruídas no algoritmo OSEM. 


\subsection{Ordem utilizando o algoritmo OSEM}

A Figura 28 apresenta as médias das notas designadas pelos três especialistas para as imagens processadas com OSEM e variando-se as ordens de 0 a 10 . No gráfico de barras, observamos que a melhor ordem avaliada (nota 7,76) é a ordem 0.

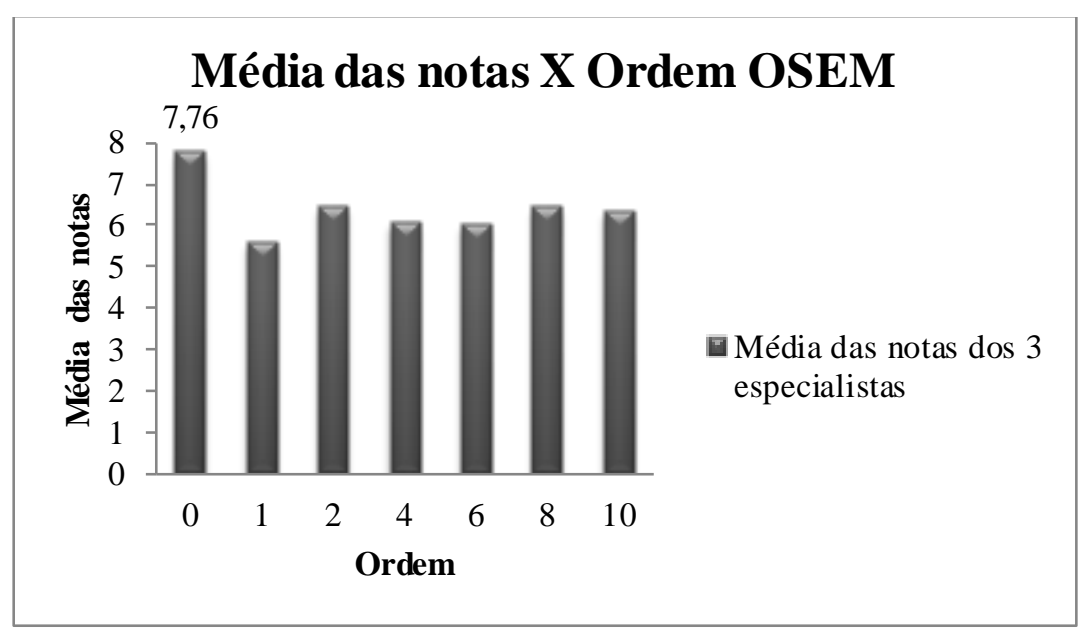

Figura 28 - Gráfico de barras com as médias das notas dos três especialistas, designadas as imagens com diferentes ordens reconstruídas no algoritmo OSEM.

\subsection{Ordem e frequência de corte utilizando o algoritmo OSEM (Fase 3)}

Aplicando o modelo de regressão linear múltipla de segunda ordem (Fórmula 7) e utilizando o algoritmo iterativo OSEM, obtivemos o seguinte gráfico de contorno (Figura 29) como resultado para encontrar as regiões ótimas (maximização da resposta), na escala Z (Fórmula 5). 


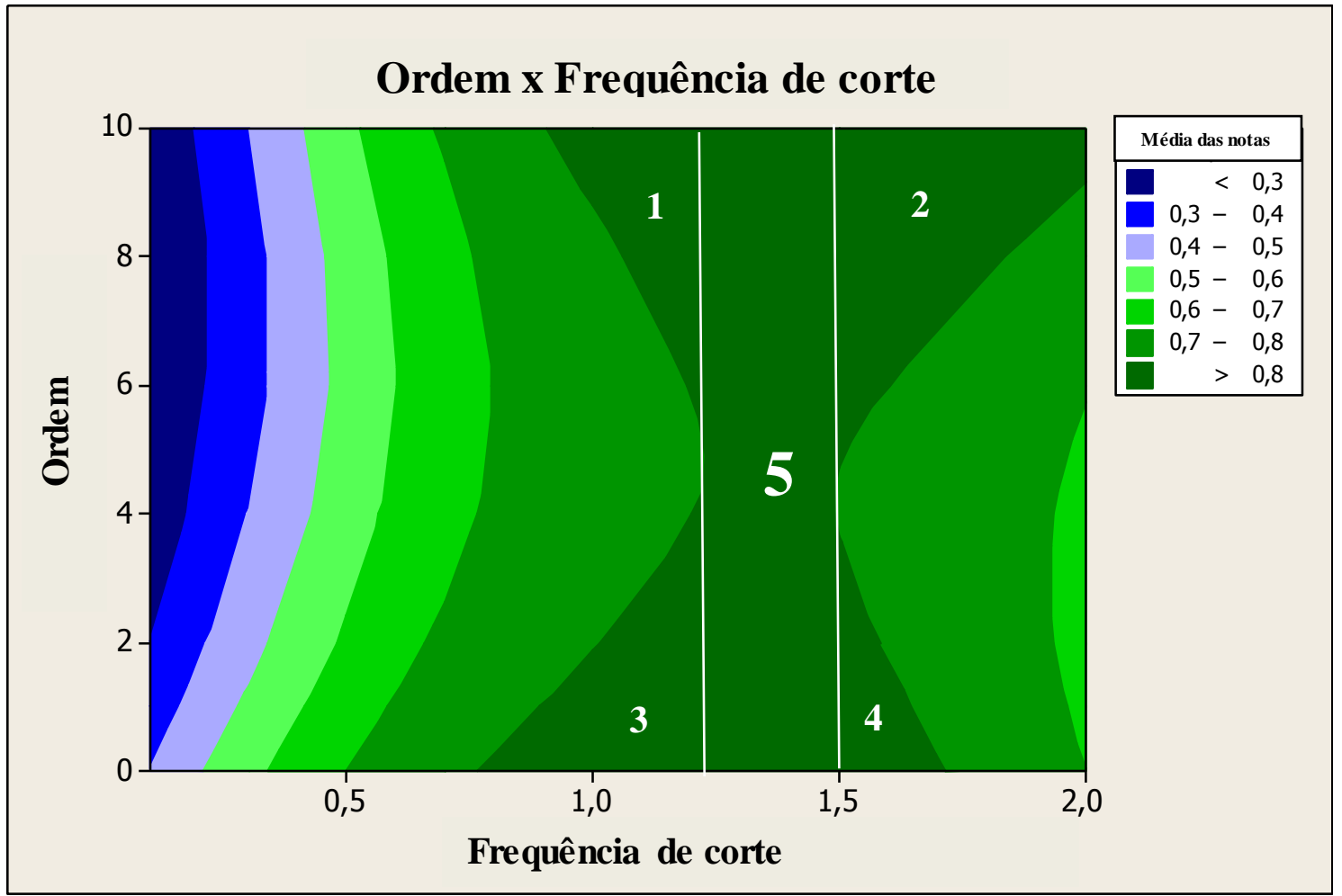

Figura 29 - Gráfico de contorno com as variáveis frequência de corte, ordem e médias das notas, utilizando o algoritmo OSEM.

Conforme a interpretação do gráfico de contorno, sugerimos que na reconstrução OSEM, para obter imagem de qualidade (média das notas >0,8), é viável utilizar a frequência de corte (FC) no intervalo 5 da Figura 29 (1,2 a 1,5) e a ordem livre para a escolha do profissional que irá reconstruir (intervalo de 0 a 10). As imagens do intervalo sugerido estão demonstradas na Figura 30. 


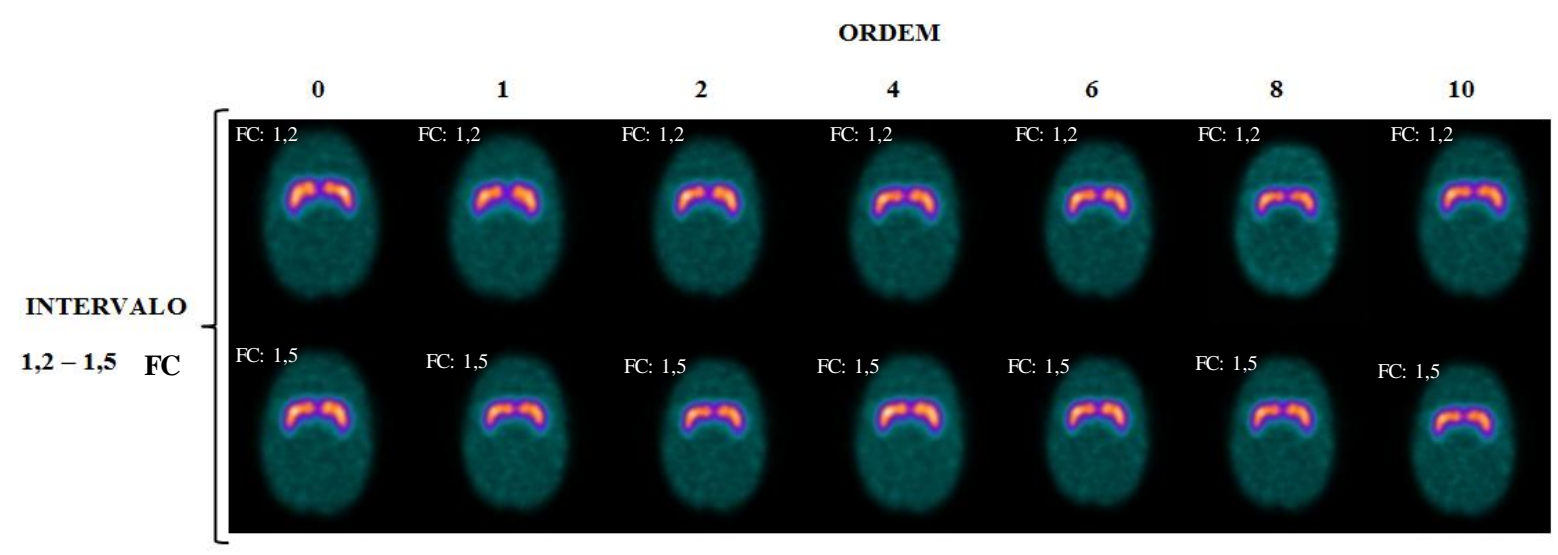

Figura 30 - Imagens de SPECT cerebral com fantoma antropomórfico estriatal reconstruída com algoritmo iterativo OSEM no intervalo de 1,2 a 1,5 frequência de corte, variando a ordem de 0,0 a 10,0. Este intervalo proposto fornece 14 maneiras que categorizam padrão de qualidade nos laudos médicos.

Mas, se utilizarmos o intervalo de frequência de corte de 0,8 a 1,2 e 1,5 a 1,7 e qualquer nível da covariável Ordem, corre-se o risco de diminuir a qualidade da imagem final. Sendo assim, sugerimos os intervalos 1, 2, 3 e 4 da Figura 29:

1- Frequência de corte 0,95 - 1,25 e Ordem 5,0 - 10,0 gradualmente

2- Frequência de corte 1,51-2,0 e Ordem 5,0 - 10,0 gradualmente

3- Frequência de corte $0,8-1,2$ e Ordem $0,0-5,0$ gradualmente

4- Frequência de corte 1,5-1,7 e Ordem 0,0 - 5,0 gradualmente

Nos resultados a seguir, utilizamos a análise estatística de regressão para verificar qual covariável apresentou a necessidade de variação dos dados para uma imagem reconstruída com qualidade (Figura 31): 


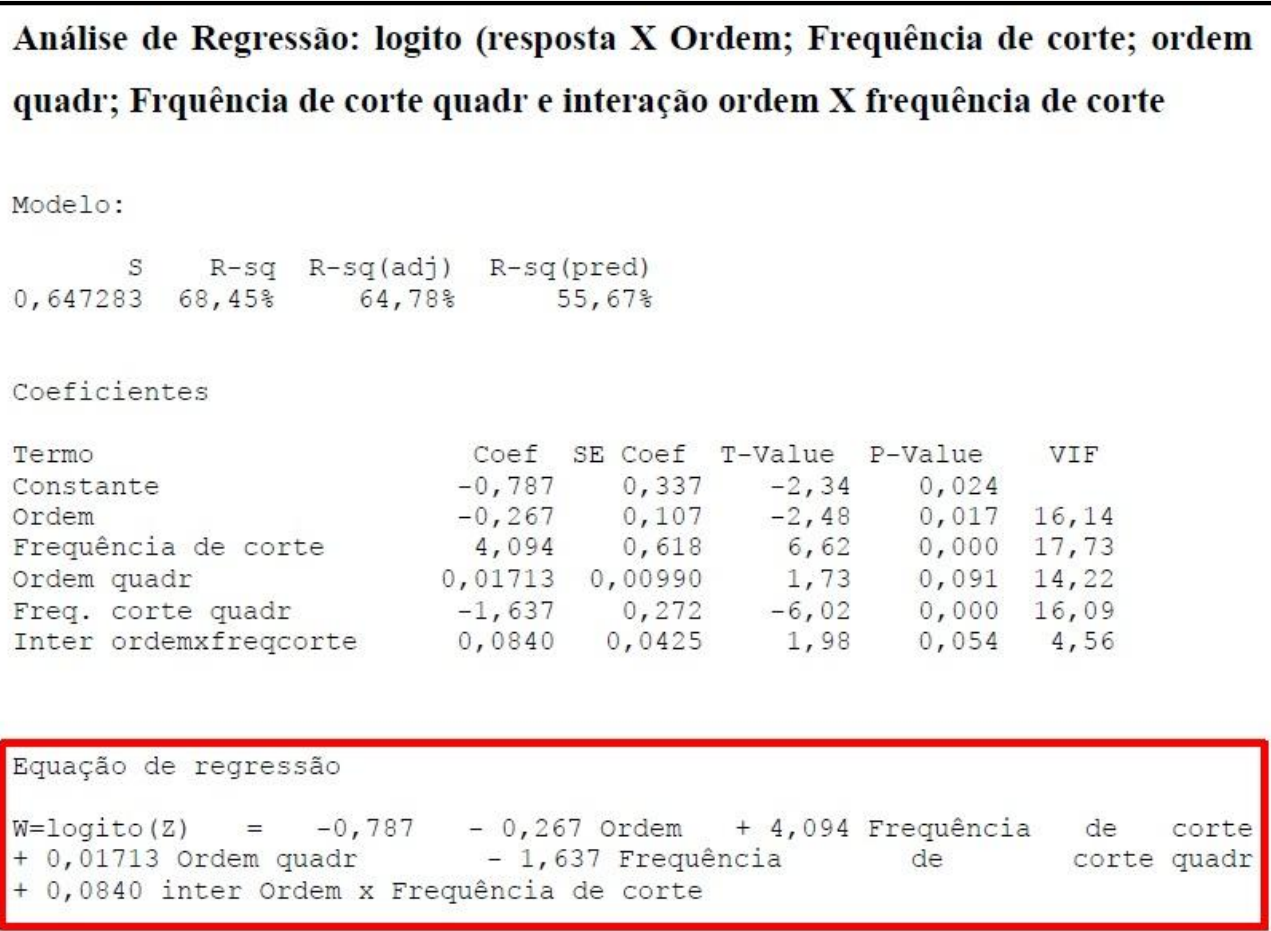

Figura 31 - Análise de regressão, mostrando o p-valor de cada covariável do estudo.

Considerando as observações da Figura 31, o resultado foi interessante, pois todas as covariáveis exceto a ordem quadr foram significantes no estudo, ou seja, pvalor $<0,05$. Já a ordem quadr obteve p-valor >0,05, mas <0,1, sendo ainda aceitável um efeito significativo, considerando um nível de significância igual a $10 \%$.

Desses resultados devemos controlar com cuidado a covariável frequência de corte, mas em certo intervalo de FC, também devemos controlar a ordem.

\subsection{Avaliação comparativa da qualidade das imagens com o algoritmo FBP e} OSEM

\subsubsection{Teste T-Student Pareado com a técnica FBP versus OSEM}

Na Tabela 8, apresentamos as médias das notas, o desvio-padrão e o intervalo de confiança (IC 95\%) de uma amostra de 49 imagens processadas com FBP e OSEM. A 
análise comparativa, entre as médias das notas observadas para os dois métodos e procedente de três especialistas, será apresentada nas seções seguintes.

Tabela 8 - Valores estatísticos que o teste t-student pareado proporcional para a análise entre os três especialistas em medicina nuclear.

\begin{tabular}{ccccccc}
\hline & \multicolumn{2}{c}{ Especialista 1 } & \multicolumn{2}{c}{ Especialista 2 } & \multicolumn{2}{c}{ Especialista 3 } \\
\hline & FBP & OSEM & FBP & OSEM & FBP & OSEM \\
\hline $\mathbf{N}$ & 49 & 49 & 49 & 49 & 49 & 49 \\
Média & 4,51 & 5,79 & 5,44 & 6,87 & 5,38 & 6,42 \\
Desvio-padrão & 1,59 & 2,22 & 1,83 & 2,15 & 2,37 & 2,54 \\
Valor p & $5,94.10^{-9}$ & $3,64.10^{-8}$ & 0,005831 \\
IC 95\% & {$[-1,65 ;-0,91]$} & {$[-1,86 ;-0,98]$} & {$[-1,76 ;-0,31]$} \\
\hline
\end{tabular}

\subsubsection{Especialista 1}

O intervalo de confiança (IC 95\%) do teste entre as duas técnicas (OSEM e FBP) pelo especialista 1 foi de $[-1.65 ;-0.91]$. Utilizando um nível de significância de $5 \%$, o valor $\mathrm{p}=5,94^{-9}$ foi menor que $0,05(\mathrm{p}<0,05)$. Assim, com a hipótese $\mathrm{H}_{0}$ de nulidade (Não há evidências de que as médias das notas da técnica OSEM e FBP diferem), $\mathrm{H}_{1}$ é a hipótese alternativa do estudo (Há evidências de que as médias das notas da técnica OSEM e FBP diferem). Portanto, rejeita $\mathrm{H}_{0}$ e têm-se evidências de que a média das notas na técnica OSEM pelo especialista 1 difere da média das notas da técnica FBP.

Podemos notar a diferença das notas na Tabela 4 pelo especialista 1 entre as técnicas. A média das notas representada pelo ponto preto na Figura 32 demonstra que a média das notas da técnica OSEM foi maior $(5,79)$. As barras horizontais mostram que a técnica OSEM foi a moda, com notas a partir de 6,0. Enquanto FBP obteve grande quantidade de nota 5,0, sendo a média 4,51. 


\section{Especialista 1}

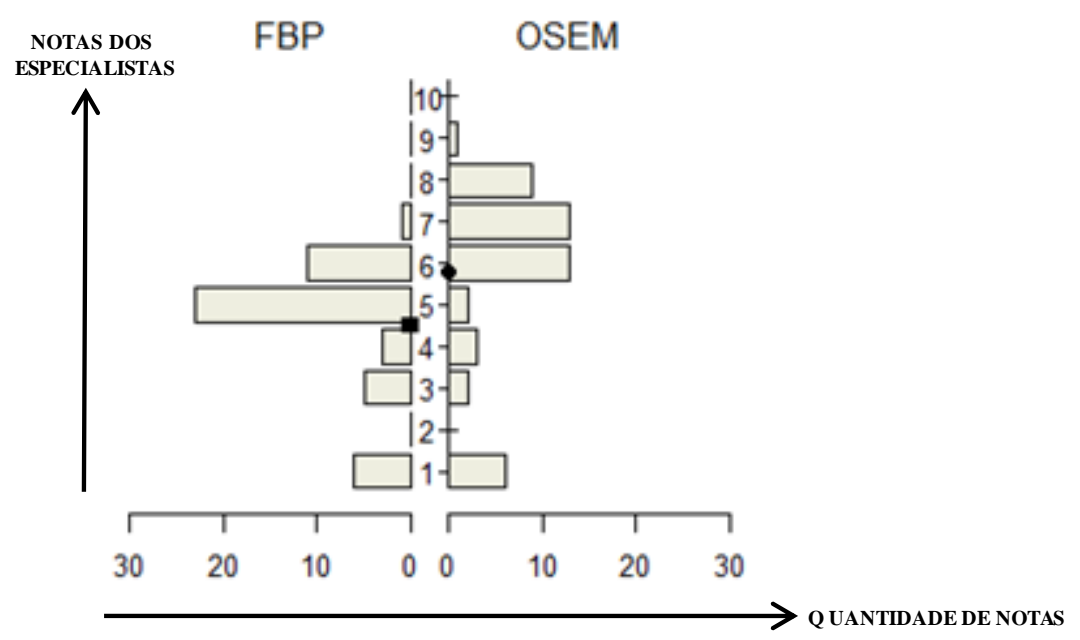

Figura 32 - Gráfico de barras demonstrando as notas e quantidade de notas atribuídas pelo especialista em medicina nuclear 1, tanto para técnica FBP quanto OSEM.

\subsubsection{Especialista 2}

O intervalo de confiança (IC 95\%) do teste entre as duas técnicas (OSEM e FBP) pelo especialista 2 foi de $[-1.86 ;-0.98]$. Utilizando um nível de significância de $5 \%$, o valor $\mathrm{p}=3,64^{-8}$ foi menor que $0,05(\mathrm{p}<0,05)$. Assim, com a mesma hipótese, rejeita $\mathrm{H}_{0}$ e têm-se evidências de que a média das notas na técnica OSEM pelo especialista 2 difere da média das notas da técnica FBP.

Podemos notar a diferença das notas na Tabela 4 pelo especialista 2 entre as técnicas. A média das notas representada pelo ponto preto na Figura 33 já demonstra que a média das notas da técnica OSEM $(6,87)$ foi maior. As barras horizontais mostram que a técnica OSEM foi a moda, com a grande maioria das notas 8,0. Enquanto FBP obteve grande quantidade de nota 6,0, sendo a média 5,44. 


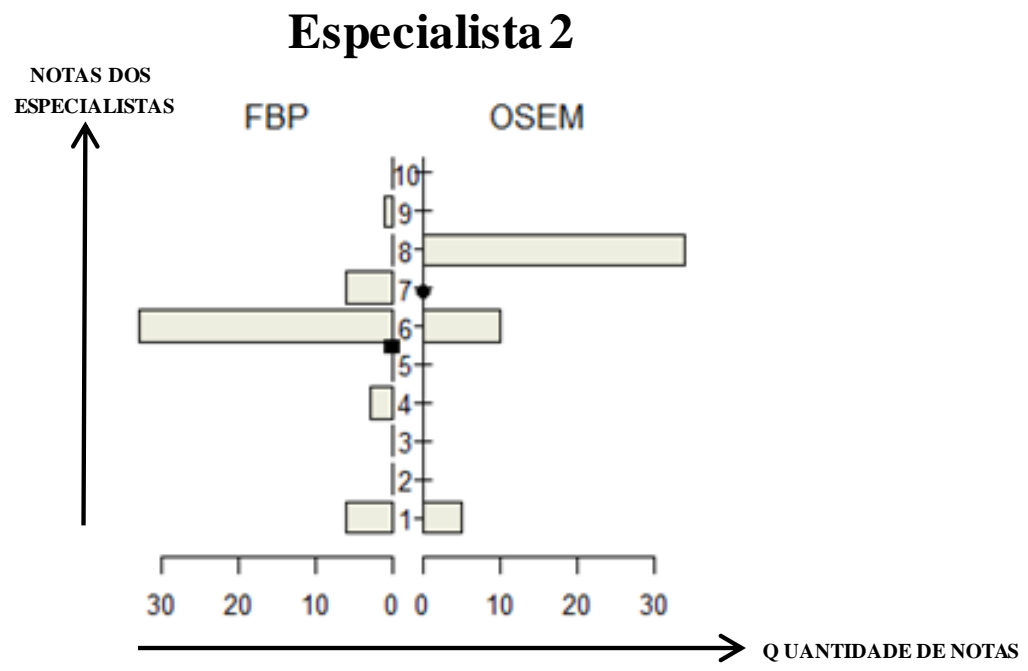

Figura 33 - Gráfico de barras demonstrando as notas e quantidade de notas atribuídas pelo especialista em medicina nuclear 2, tanto para técnica FBP quanto OSEM.

\subsubsection{Especialista 3}

O intervalo de confiança (IC 95\%) do teste entre as duas técnicas (OSEM e FBP) pelo especialista 3 foi de $[-1.76 ;-0.31]$. Utilizando um nível de significância de $5 \%$, o valor $\mathrm{p}=0.005831$ foi menor que $0,05(\mathrm{p}<0,05)$. Assim, com a mesma hipótese, rejeita $\mathrm{H}_{0}$ e têm-se evidências de que as médias de notas na técnica OSEM pelo especialista 3 diferem da média das notas da técnica FBP.

Podemos notar a diferença das notas na Tabela 4 pelo especialista 3 entre as técnicas. A média das notas representada pelo ponto preto na Figura 34 já demonstra que a média das notas da técnica $\operatorname{OSEM}(6,42)$ foi maior. As barras horizontais mostram que a técnica OSEM foi a moda, recebeu maiores quantidades de notas como 7,0, 8,0 e 9,0. Embora a técnica FBP tenha sido bem conceituada pelo especialista 3, com média 5,38, a técnica OSEM mostrou superioridade. 


\section{Especialista 3}

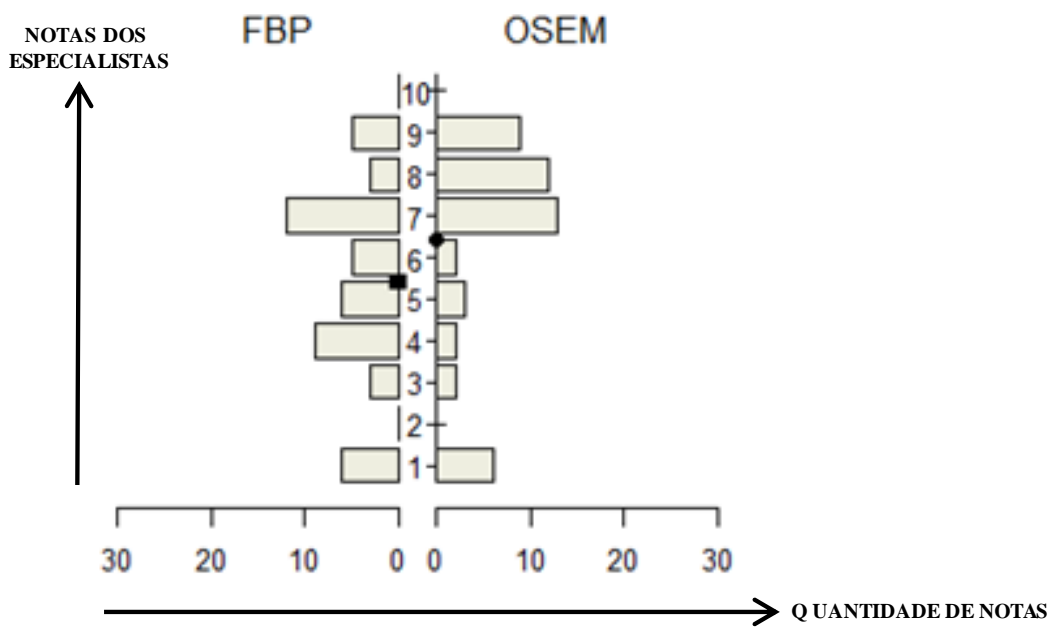

Figura 34 - Gráfico de barras demonstrando as notas e quantidade de notas atribuídas pelo especialista em medicina nuclear 3, tanto para técnica FBP quanto OSEM. 
5. DISCUSSÃO 


\section{DISCUSSÃO}

Este estudo visou avaliar o melhor uso dos algoritmos da gama-câmara Philips BrightView XCT no processamento do SPECT cerebral, primeiramente com o fantoma antropomórfico estriatal, para em futuros estudos, aplicar nas imagens de pacientes que se submeterão ao SPECT cerebral com radiofármaco ${ }^{99 \mathrm{~m}}$ Tc-TRODAT-1.

Existem poucos estudos com o objetivo de avaliar a qualidade da imagem do corpo estriado (putâmen e núcleo caudado) sob o parâmetro visual. Também, dentre os poucos estudos que avaliaram a reconstrução analítica, iterativa e filtro butterworth passa-baixa, a maioria realizou apenas uma avaliação comparativa. Mesmo assim, nenhum estudo investigou uma variedade de valores das covariáveis como o presente estudo.

Conforme Burkhart, Dunning e Andrews (2011), o impacto de iniciar uma pesquisa com estruturas biológicas requer muitas precauções, principalmente quando a pesquisa envolve radionuclídeos. Assim, destacam que a experimentação in vitro em fantomas é muito importante, pois contribui para a obtenção de dados reais, úteis para a realização correta dos exames de SPECT cerebral, na prática clínica. O presente estudo iniciou-se com o fantoma adequado, analisando a estrutura desejada.

Vines et al. (2003) também enfatizam que o verdadeiro método de protocolar estudos com distribuições radioativas é pela utilização de um fantoma, que apresenta cavidades com tamanhos reais do cérebro. Em pacientes não existem as cavidades na projeção dos núcleos da base, mas sim a estrutura anatômica sólida do corpo estriado, podendo haver variações anatômicas entre os sujeitos. Por este motivo, os fantomas são tidos como ferramentas mais confiáveis nas experimentações em medicina nuclear, permitindo avaliar parâmetros importantes tanto para reconstrução de imagens quanto para controle de qualidade das gâma-câmaras (LEONG; O'CONNOR; MARAGANORE, 1999; PARETO et al, 2003; BULLICH et al., 2010; ERLANDSSON; HUTTON, 2010; ISHII et al., 2012).

$\mathrm{O}$ fato é que existem muito poucos estudos que tenham utilizado o fantoma antropomórfico estriatal com o objetivo de avaliar no SPECT cerebral as diferentes técnicas de reconstrução e processamento das imagens do corpo estriado, também são raros os estudos que tenham avaliado o processamento de imagens com humanos e 
utilizando o radiofármaco ${ }^{99 \mathrm{~m}} \mathrm{Tc}$-TRODAT-1. Esta foi uma das razões para a condução do presente estudo.

Para a primeira fase, foram testados 49 valores do filtro butterworth passabaixa, divididos em sete valores de ordem e sete valores de frequência de corte, na reconstrução analítica FBP, para eliminar ruído e baixa resolução espacial. Conforme Alessio, Kinahan (1959), a qualidade da imagem de uma análise visual é a avaliação de um especialista capacitado que consegue observar o desempenho que a imagem proporciona. Bieńkiewicz et al. (2009) confirmam que a análise visual de SPECT cerebral é extremamente importante quanto à avaliação quantitativa. No entanto, nenhum dos trabalhos que visaram a analisar a qualidade da imagem de uma maneira qualitativa utilizou esta vasta quantidade de valores das covariáveis.

Koch et al. (2005) avaliaram visualmente os mesmos quesitos da qualidade da imagem que este estudo. $\mathrm{O}$ intervalo proposto foi com a $\mathrm{FC}=0,6$ e 1,0 e ordem 5 e 7. Este intervalo apresentado por Koch et al. (2005) não foi totalmente aceitável, comparando com o resultado deste estudo. Em nossos resultados, as imagens com FC = 0,6 e ordem 5 e 7 também apresentaram qualidade intermediária, e a imagem com FC = 1,0 e ordem 5 e 7 também nos garantiram imagem de extrema qualidade. Embora o contexto da aplicação das notas dos especialistas tenha sido diferente, um dos intervalos propostos por Koch et al. (2005) garantiu a mesma eficiência da imagem.

Seret e Forthomme (2009) analisaram quantitativamente diferentes valores de ordem (3 e 6) e de frequência de corte $(0,1 ; 0,2 ; 0,35 ; 0,5)$ através da utilização de dois fantomas, em diferentes marcas de gama-câmara, totalizando oito imagens cada. Nem todos os algoritmos permitiam a utilização destes valores, indicando menos imagens para a análise. Já o algoritmo da Philips Jetstream possibilitou apenas o uso de ordem (6) e frequência de corte $(0,1 ; 0,2 ; 0,35 ; 0,5)$, totalizando quatro imagens. Isto difere da Philips Jetstream em que realizamos as pesquisas. Mesmo assim, nestes intervalos propostos, as imagens demonstraram clareza nos dados, sendo compatíveis com o intervalo da ordem deste estudo ( 0 a 10$)$, variando a frequência de corte, principalmente no intervalo de 0,9 a 1,6 .

Também com uma análise quantitativa dos valores de frequência de corte no filtro butterworth passa-baixa, Winz et al. (2012) reconstruíram apenas duas imagens com um fantoma, utilizando ordem (7) e frequência de corte $(0,36$ e 0,45$)$. Notamos que estes valores classificaram a imagem com uma delineação ótima das estruturas do corpo estriado, mas apresentando ruído. Concluíram que o ruído neste intervalo, não 
impossibilita o médico de realizar uma análise visual adequada. $O$ equipamento utilizado era de outra marca, e também utilizaram o radionuclídeo Iodo-131 ( $\left.{ }^{131} \mathrm{I}\right)$, podendo alterar os resultados quando comparado a este estudo com ${ }^{99 \mathrm{~m}} \mathrm{Tc}$.

Nesses parâmetros, nossos resultados apresentaram imagens com notas baixas, bastante presença de ruído, bordas não delimitadas e sem diferenciação do putâmen e núcleo caudado. Com os nossos resultados, o intervalo sugerido foi diferente, mas Winz et al. (2012) afirmam que todas as imagens apresentaram qualidade na diferenciação do putâmen e cabeça do núcleo caudado, mesmo com a presença de ruído, concluindo que a imagem ainda é capaz de proporcionar resultados satisfatórios, mesmo apresentando alto grau de ruído (WINZ et al., 2012). Talvez com o radionuclídeo diferente, as contagens foram captadas de uma forma mais eficaz.

Knoll et al. (2012) resolveram testar gama-câmaras da GE, Philips e Siemens, também com uma análise quantitativa, classificando a resolução espacial, contraste e ruído das imagens. Pelo algoritmo FBP dos três equipamentos, utilizaram ordem (10) e frequência de corte $(0,48)$. Neste intervalo, Knoll et al. (2012) garantiram uma imagem com boa resolução espacial, contraste aceitável e apresentando baixo nível de ruído nos três equipamentos. Conforme nossos resultados, este intervalo apresentou uma classificação intermediária, ou seja, não foi descartada para a aquisição de uma análise visual satisfatória, sendo possível utilizar o intervalo proposto nos nossos resultados, este proporcionará uma imagem muito melhor, focando na diferenciação do putâmen e núcleo caudado, menos ruído e levemente amaciada.

Além da principal hipótese, percebemos a necessidade de analisar as covariáveis de cada técnica separadamente. A covariável ordem na reconstrução FBP apresentou como melhor ordem $n=0$. Embora a teoria de Gonzalez; Woods (2002) e Saha (2010) afirme que quanto maior a ordem, melhor a imagem, o resultado encontrado foi diferente. Notamos que a imagem reconstruída com ordem $n=0$ não barra as baixas e altas frequências, deixando todas as frequências acometerem a imagem. A imagem final apresentou diferenciação no putâmen e cabeça do núcleo caudado, com bordas distinguíveis, onde as altas frequências atuam. Também apresentou um leve amaciamento, onde as baixas frequências agem. Assim, seguindo o formulário (ANEXO 2), estes dados caracterizaram boas notas dos três especialistas. Mas como a ordem atua na rapidez da atenuação das amplitudes, a ordem 0 se apresenta muito rápida, atenuando as frequências críticas, mas mesmo assim caracterizando em pouco ruído (SAHA, 2010). Embora as imagens apresentem ruído, em uma análise 
quantitativa, as estruturas do corpo estriado são viáveis para uma reconstrução momentânea, para uma análise visual após o término do exame.

Já para a análise da covariável frequência de corte na reconstrução FBP, a melhor frequência de corte foi 0,5. Já no intervalo proposto com frequência de corte versus ordem, este intervalo ficou entre imagens boas (média 0,5 a 0,6 ) e não no intervalo entre imagens muito boas (médias >0,6). Mesmo com as notas separadas, os valores ficaram em um intervalo qualificado para a reconstrução das imagens, como afirma Winz et al. (2012), Knoll et al. (2012) e Forthomme e Seret (2009).

Com relação à segunda fase, também foram testados demais valores de iterações (i) e números de subsets (s) com análise qualitativa para confirmar a proposta da empresa. Segundo o Software NM Aplication Suite através do aplicativo AutoSPECT Pro, da Estação de Trabalho EBW (Extended Brilliance TM Workspace) Philips Healthcare, os valores-padrões de (i) e (s) para o processamento de imagens cerebrais são $3 \mathrm{i}$ e $8 \mathrm{~s}$. Alguns trabalhos realizaram esta análise utilizando os valores padronizados por várias marcas de gama-câmara, e os testes de reconstruções de imagens captadas pela gama-câmara da Philips foram aplicados $3 \mathrm{i}$ e 8s, confiando no conselho da empresa (KOCH et al., 2011; KNOLL et al., 2012).

Os valores de iterações e números de subsets testados foram determinados, conforme demais análises de artigos científicos, apenas modificando os valores mínimos e máximos disponíveis pelo Software NM Aplication Suite (CATAFAU, 2008; SERET; FORTHOMME, 2009; CERIANI et al., 2010; DUARTE et al., 2012).

Segundo a avaliação das variáveis, concordamos com a sugestão da Philips que o uso de $3 \mathrm{i}$ e 8 s para a reconstrução iterativa OSEM em imagens cerebrais foi o que apresentou melhor qualidade. Conforme a literatura, quanto maior o número de iterações, melhora a estrutura anatômica analisada, mas que com este valor muito alto, também apresenta alto índice de ruído, o qual pode causar consequências no laudo, além de aumentar o tempo de processamento, não sendo viável para a rotina clínica (MARQUES DA SILVA, 1998; FRIDA, 2006; KOCH et al., 2011; KNOLL et al., 2012, POWSNER; POWSNER, 2013). Concordamos com isto, onde as imagens com alto índice de iteração, apresentaram sinais críticos de ruído, bordas não muito definidas e sem diferenciação de putâmen e núcleo caudado. Isto acontece pelo fato de cada iteração corrigir os dados dos subconjuntos. Com muitas correções, há a possibilidade de ocasionar ruídos e prejudicar a imagem. 
Com a reconstrução de maior número de subsets (16), notamos que as imagens não tiveram qualidade (imagem ruidosa, acometendo a estrutura do corpo estriado), apresentando apenas uma nota intermediária e as demais baixas. Assim, concordando com a literatura, quanto maior o número de subsets, os mesmos podem causar perdas significativas na estrutura analisada (KNOLL et al., 2012; MOREY e KADRMAS, 2013).

Winz et al. (2012) avaliaram as imagens de SPECT cerebral reconstruídas em dois grupos (8i 8s) e (6i 16s). Por uma avaliação quantitativa, seu melhor resultado foi a reconstrução com (6i 16s), com o radionuclídeo ${ }^{123}$ I. Isto difere dos nossos resultados, em que, com 16s, as imagens apresentaram péssima qualidade visualmente, mas talvez com outro radionuclídeo e para análise quantitativa este valor seja eficaz.

Alzimani et al. (2008) estudaram os mesmos parâmetros, mas não assumiram o 3i8s, mesmo porque o equipamento do estudo não era da Philips. Com uma análise quantitativa, Alzimani et al. (2008) variaram as reconstruções com 1, 4, 8, 12 e 24 iterações e 2, 4, 8 e 16 subsets. A imagem que apresentou melhor qualidade, através dos mesmos quesitos que propusemos, foi a imagem com 12i8s.

O valor de subset (8) foi o mesmo intervalo que nosso resultado aconselhou e o indicado pela Philips. Já a iteração variou demais, sendo que nosso valor proposto foi de 3i. Isto se deve ao fator correção de cada algoritmo (DUARTE et al., 2012). Em nosso algoritmo, a imagem demonstrou ser ligeiramente ruidosa, e com perda de estrutura do putâmen, comparado à imagem de 3i8s. Assim, notamos a clara diferença da qualidade com imagens reconstruídas em diferentes algoritmos.

Para a terceira fase, com a reconstrução utilizando os parâmetros confirmados pela segunda hipótese ( $3 \mathrm{i}$ e $8 \mathrm{~s}$ ), o intervalo proposto de frequência de corte e ordem da reconstrução OSEM garantiu qualidade da imagem em uma análise qualitativa, como Koch et al. (2005) também garantiram. As imagens demonstraram ótimas delineações do putâmen e cabeça do núcleo caudado e mais livres de ruído, sem problemas importantes de ruído. No estudo de Koch et al. (2005), as imagens com o mesmo fantoma antropomórfico estriatal, também, foram analisadas por três especialistas, mas variou a frequência de corte apenas em 0,6 e 1,0 e ordem apenas em 5 e 7 do filtro butterworth passa-baixa. A diferença para este estudo foi que as notas foram dadas por três quesitos (melhor delineação do corpo estriado em geral, melhor diferenciação do putâmen e núcleo caudado e imagem mais homogênea) e nossos especialistas analisaram todos estes quesitos em apenas uma nota. 
Este intervalo apresentado por Koch et al. (2005) garantiu melhor qualidade da imagem para OSEM em comparação ao FBP, diferenciando desta fase do estudo (fase 3), onde encontramos um melhor intervalo apenas na reconstrução OSEM. Embora o contexto tenha sido diferente, o intervalo proposto por Koch et al. (2005) não garantiu eficiência da imagem como em nossos resultados. Para a FC $=0,6$ e ordem 5 e 7, nossos resultados foram imagens intermediárias e para $\mathrm{FC}=1,0$ e ordem 5 e 7 , as imagens também se apresentaram intermediárias. Mas para $\mathrm{FC}=1,0$, se variar a ordem de 0 a 2 , a imagem fica com extrema qualidade.

Kock; Suessmair; Tatsch (2011) fizeram uma avaliação visual em várias reconstruções com SPECT cerebral, com diferentes algoritmos, inclusive com a reconstrução OSEM. Sem mencionar a marca da gama-câmara, as imagens foram avaliadas por apenas um especialista em medicina nuclear que mencionava a qualidade da imagem. Na reconstrução OSEM, os parâmetros utilizados foram 3i8s e FC = 1,2 e ordem $=7,0$. Por este especialista, esta imagem não apresentou artefatos e garantiu extrema qualidade das estruturas do corpo estriado. A radiação ficou visualmente homogênea e particularmente melhor que as demais reconstruções. Em nossos resultados, este intervalo de reconstrução ficou no intervalo de extrema qualidade da imagem (intervalo 5 da Figura 29), garantindo as estruturas bem delineadas, bordas perfeitas, incluindo a eficiência da resolução espacial, contraste e ruído.

Knoll et al. (2011) testaram três algoritmos diferentes, e um deles era da Philips. Utilizou o recomendado 3i8s e um valor aleatório de $\mathrm{FC}=0,48$ e ordem $=10$. Através de uma análise quantitativa, avaliaram contraste, resolução espacial e nível de ruído. Com a imagem reconstruída no algoritmo da Philips, a resolução espacial demonstrou eficiência comparada às reconstruções das outras marcas. A diferenciação do putâmen e do núcleo caudado ficou em segundo lugar, não garantindo total eficiência. Isto concorda com nossos resultados, onde este intervalo foi avaliado como intermediário, ou seja, garantiu qualidade em alguns aspectos, mas falhou na parte de diferenciação das estruturas, que é extremamente importante.

Para a análise individual de cada covariável, a covariável ordem na reconstrução OSEM também apresentou como melhor ordem, $\mathrm{n}=0$, da mesma forma que a reconstrução FBP. Pelos mesmos motivos que a reconstrução FBP, a ordem no algoritmo OSEM atua da mesma maneira, assim a ordem 0 não barrou as baixas e altas frequências, deixando todas as frequências acometerem a imagem. A imagem final apresentou diferenciação no putâmen e cabeça do núcleo caudado, com bordas 
distinguíveis, onde as altas frequências atuam e também apresentou um leve amaciamento, onde as baixas frequências agem. Assim, seguindo o formulário (ANEXO 2), estes dados caracterizaram boas notas dos três especialistas, embora as imagens apresentem ruído em uma análise quantitativa, as estruturas do corpo estriado são viáveis para uma reconstrução momentânea, para uma análise visual após o término do exame.

Já para a análise da covariável frequência de corte na reconstrução OSEM, a melhor frequência de corte foi 1,0. No intervalo proposto com frequência de corte vs. ordem, este intervalo ficou entre imagens muito boas (médias $>0,8$ ), conforme visto no intervalo 3 da Figura 29. Mesmo com as notas separadas, os valores ficaram em um intervalo qualificado para a reconstrução das imagens, tal como afirma Winz et al. (2012), Knoll et al. (2012) e Forthomme e Seret (2009).

Para a quarta fase, das três análises realizadas, os resultados foram satisfatórios para a técnica de reconstrução iterativa OSEM. Houve evidências de que a técnica OSEM difere das médias das notas da técnica FBP. Esta diferença demonstrou um intervalo significativo, e as médias das notas foram maiores para a reconstrução OSEM. Em todos os estudos com esta mesma hipótese, a técnica OSEM sobressaiu nos quesitos resolução espacial, contraste e ruído. Conforme Koch et al. (2005), com apenas análise visual, os dados também mostraram evidências de que a técnica OSEM difere para melhor, comparando-a com a técnica FBP. Para os três especialistas em medicina nuclear, a estrutura do corpo estriado na reconstrução OSEM apresentou melhor distinção das estruturas.

Nas análises quantitativas de Alzimami; Sand; NM (2008), os resultados também apresentaram a mesma resposta. As comparações foram com cada quesito da qualidade da imagem separadamente, diferenciando da comparação deste estudo. Segundo Alzimami; Sand; NM (2008), a técnica OSEM também sobressaiu nos três quesitos avaliados pelo teste t-student pareado. Já Liu, et al. (2010) reconstruíram as imagens do corpo estriado utilizando ${ }^{99 \mathrm{~m}}$ Tc TRODAT-1, apenas com o algoritmo analítico OSEM, pois Koch et al. (2005) confirmaram que a técnica OSEM comparada com FBP apresentou melhor qualidade na imagem, principalmente na distinção do putâmen e cabeça do núcleo caudado. O resultado deste estudo concorda que a técnica OSEM demonstrou evidências de melhor qualidade, mas a técnica FBP, no intervalo proposto, também demonstrou a distinção das estruturas com certa qualidade. A preferência pelo OSEM é pelo fato de a imagem apresentar menos ruído e menos 
radiação espalhada. Mas, caso o serviço de medicina nuclear não trabalhe ainda com o algoritmo iterativo OSEM de reconstrução de imagens, com a técnica analítica FBP, na medida do possível, o serviço também obterá imagens de qualidade.

Al-Lehyani (2009) comparou as duas técnicas de reconstrução com fantoma ósseo, através de pequenas esferas. Embora a análise não seja com regiões cerebrais, o estudo demonstrou que OSEM apresentou imagens com bordas mais definidas, e a técnica FBP não conseguiu distinguir todas as esferas, acometendo a resolução espacial e contraste da imagem. Al-Lehyani (2009) também concluiu que as imagens das esferas na técnica FBP apresentaram mais ruído. Assim, garantiu que utilizar OSEM para reconstrução das imagens de cintilografia é mais confiável.

Winz et al. (2012) afirmam que a reconstrução do corpo estriado no SPECT cerebral era feita apenas com FBP, comparado ao MLEM. Mas com a chegada do OSEM, o algoritmo iterativo mais robusto que MLEM, esta técnica está proporcionando melhorias relevantes na imagem. Winz et al. (2012) reconstruíram as imagens com algumas variações e analisaram quantitativamente, pelas contagens das regiões separadamente (putâmen, núcleo caudado e background), e as compararam. Através dos três grupos formados, em todos, a técnica OSEM se mostrou superior ao FBP, apresentando maiores contagens e consequentemente melhor resolução espacial. Assim, os resultados de Winz et al. (2012) confirmaram os resultados deste estudo, onde a utilização de FBP é eficaz, mas com a nova técnica OSEM, o algoritmo iterativo vem mostrando melhores qualidades da imagem.

Conforme, Koch et al. (2005), Powsner; Powsner (2006) e Cherry; Sorenson; Phelps (2012), o algoritmo iterativo tem muito mais correções durante a reconstrução, o que caracteriza os nossos resultados.

Desse modo, o presente estudo propôs reconstruir as imagens de SPECT cerebral com ${ }^{99 \mathrm{~m}}$ Tc-TRODAT-1, através da reconstrução iterativa OSEM, no intervalo proposto e com os valores de iterações e números de subsets que a Philips sugere. 


\section{CONCLUSÕES}

1. Para a reconstrução analítica FBP do SPECT cerebral utilizando o fantoma antropomórfico estriatal, a melhor representatividade anatômica do corpo estriado foi obtida utilizando-se a ordem no intervalo de 0 a 10 e a frequência de corte no intervalo de 0,9 a 1,6;

2. Para a reconstrução iterativa OSEM do SPECT cerebral utilizando o fantoma antropomórfico estriatal, a melhor representatividade anatômica do corpo estriado foi obtida utilizando-se a três iterações e oito número de subsets;

3. Para a reconstrução iterativa OSEM do SPECT cerebral utilizando o fantoma antropomórfico estriatal, a melhor representatividade anatômica do corpo estriado foi obtida utilizando-se a ordem no intervalo de 0 a 10 e a frequência de corte no intervalo 1,2 a 1,5;

4. O método de reconstrução iterativa OSEM resultou na melhor qualidade visual e na melhor representatividade anatômica do corpo estriado em um SPECT cerebral utilizando um fantoma antropomórfico estriatal. 


\section{REFERÊNCIAS}

ALESSIO, A.; KINAHAN, P. PET Image Reconstruction. v. 1, n. figure 1, p. 1-22, Sattle, 1959.

ALEXANDRE, D.; FARIA, B. Segmentação, Reconstrução e Quantificação 3D de Estruturas em Imagens Médicas - Aplicação em Imagem Funcional e Metabólica. Dissertação de mestrado em Engenharia Biomédica, Porto, 2013.

ALZIMAMI, K.; SAND, S.; NM, S. An Evaluation of 3D OSEM , and a Comparison with FBP in 99m TC SPECT Images. World Congress on Engineering, London, 2008.

ANDRADE, M. A. Desenvolvimento de um plugin java para reconstrução tomográfica em SPECT. Dissertação de mestrado em Engenharia Elétrica, Pontifícia Universidade do Rio Grande do Sul, Porto Alegre. 2007.

ANDRADE, W. G.; LIMA, F. F. Avaliação da qualidade dos eluatos de geradores de 99Mo-99mTc. Scientia Plena. v. 6, p. 1-9, Recife, 2010.

AZEVEDO, B. L. de SÁ. Reconstrução / Processamento de Imagem Médica com GPU em Tomossíntese. Dissertação de mestrado. Universidade Novoa de Lisboa. 2011.

BIEŃKIEWICZ, M. et al. Impact of CT based attenuation correction on quantitative assessment of DaTSCAN ((123)I-Ioflupane) imaging in diagnosis of extrapyramidal diseases. Nuclear medicine review. Central \& Eastem Europe, Lodz, v. 11, n. 2, p. 53-8, jan., 2008.

BOERMAN, O.C.; OYEN, W. J. G.; CORSTENS, F. H. M. Radio-labeled receptorbinding peptides: a new class of radiopharmaceuticals. Seminars in Nuclear Medicine, Rotterdam, v. 30, n. 3, p. 195-208, 2000.

BOR-SENG-SHU, E. et al. Substantia nigra echogenicity and imaging of striatal dopamine transporters in Parkinson's disease: A cross-sectional study. Parkinsonism \& related disorders, Rostock, v. 20, n. 5, p. 477-81, maio, 2014.

BOURNE, R. Fundamentals of Digital Imaging in Medicine. London: SpringerVerlag, v. 1, Vienna, 2010. 
BRASIL. Ministério da Ciência e Tecnologia. Comissão Nacional de Energia Nuclear. CNEN-NN.3.05- Requisitos de Radioproteção e Segurança para Serviços de Medicina Nuclear. Rio de Janeiro, 2013.

BRUYANT, P. P. Analytic and Iterative Reconstruction Algorithms in SPECT. The journal of nuclear medicine, 43:1343-1358, 2002.

BULLICH, S. et al. Impact of scatter correction on D2 receptor occupancy measurements using 123I-IBZM SPECT: comparison to 11C-Raclopride PET. NeuroImage, Barcelona, v. 50, n. 4, p. 1511-8, 1 maio, 2010.

BURKHART, T. A; DUNNING, C. E.; ANDREWS, D. M. Determining the optimal system-specific cut-off frequencies for filtering in-vitro upper extremity impact force and acceleration data by residual analysis. Journal of biomechanics, Windsor, v. 44, n. 15, p. 2728-31, 13 out., 2011.

BUSEMANN-SOKOLE, E. IAEA Quality Control Atlas for Scintillation Camera Systems. IAEA, Vienna, ISBN 92-0-101303-5, 2003.

BUSHBERG, J. T. et al, The essential physics of medical imaging. 2. ed. Philadelphia, PA: Lippincott Willians \& Wilkins, 2002.

CAO, Z. et al, Comparison of Continuous Step-and-Shoot versus Step-and-Shoot Acquisition SPECT. Journal of nuclear medicine, 37:20137-2040, Reston, 1996

CASSOLA, V. F. Acoplamento dos Fantomas Tomográficos Fax06 e Max06 ao Código Monte Carlo Geant4. Dissertação de mestrado. Departamento de Energia Nuclear, Universidade Federal de Pernambuco, Pernambuco, 2007.

CERIANI, L. et al. Three-dimensional ordered-subset expectation maximization iterative protocol for evaluation of left ventricular volumes and function by quantitative gated SPECT: a dynamic phantom study. Journal of nuclear medicine technology, Bellinzona, v. 38, n. 1, p. 18-23, mar., 2010.

CHERRY, S. R; SORENSON, J. A.; PHELPS, M. E. Physics in nuclear medicine. 4th ed. Philadelphia: Saunders/Elsevier. 2012. p. 523.

CREPALDI, M. R. et al. Potencial hidrogeniônico de antimicrobianos, segundo os fatores ambientais temperatura e luminosidade ${ }^{1}$. Rev. Lat-Am de enfermagem. v. 18, n. $2,2010$. 
DASH, A.; KNAPP, F. F. R.; PILLAI, M. R. A. 99Mo/(99m)Tc separation: an assessment of technology options. Nuclear medicine and biology. Mumbai, v. 40, n. 2, p. 167-76, fev., 2013.

DUARTE, D. D. et al. Influence of reconstruction parameters during filtered backprojection and ordered-subset expectation maximization in the measurement of the left-ventricular volumes and function during gated SPECT. Journal of nuclear medicine technology, Lausanne, v. 40, n. 1, p. 29-36, mar., 2012.

ERLANDSSON, K.; HUTTON, B. F. Partial Volume Correction in SPECT Using Anatomical Information and Iterative FBP. Tsinghua Science \& Technology, London, v. 15 , n. 1 , p. 50-55, fev., 2010.

FERREIRA, A.; PETERLINI, S.; GON, L. Ambientais: ensaio preliminar. Revista Esc. Enf. USP, v. 46, n. 2, p. 311-319, São Paulo, 2012.

FICHNA, J.; JANECKA, A. Synthesis of Target-Specific Radiolabeled Peptides for Diagnostic Imaging. Bioconjugate Chemistry, v. 14, p. 3-17, 2003.

GENG, Y. et al. Investigating the role of 99mTc-TRODAT-1 SPECT imaging in idiopathic Parkinson's disease. Journal of Zhejiang University. Science. B, v. 6, n. 1, p. 22-7, Zhejiang, jan. 2005.

GONZALEZ, R. C.; WOODS, R. E. Digital image processing. Second Edition, prentice Hall, London, 2002.

HOEXTER, M. Q. et al. Neuroimagem do transportador de dopamina na doença de parkinson Primeiro estudo com [ 99m Tc ] -TRODAT-1 e SPECT no Brasil. Rev. Psychopharmacology, São Paulo, v. 64, p. 628-634, 2006.

HUANG, C.-K. et al. Optimization of Imaging Parameters for SPECT scans of [99mTc]TRODAT-1 Using Taguchi Analysis. Psychiatry Research: Neuroimaging, Taiwan, v. 10, n. 3, p. e0113817, jan. 2015.

INTERNATIONAL ATOMIC ENERGY AGENCY (IAEA). Human health series $n^{o}$ 1: Quality Assurance for PET and PET/CT System. Vienna: IAEA. Press; 2009.

ISHII, K. et al. Impact of CT attenuation correction by SPECT/CT in brain perfusion images. Annals of nuclear medicine, Osaka, v. 26, n. 3, p. 241-7, abr.,2012. 
KNOLL, P. et al. Comparison of advanced iterative reconstruction methods for SPECT/CT. Zeitschrift für medizinische Physik, Vienna, v. 22, n. 1, p. 58-69, mar., 2012.

$\mathrm{KOCH}, \mathrm{W}$. et al. Iterative reconstruction or filtered backprojection for semi-quantitative assessment of dopamine $D_{2}$ receptor SPECT studies? European journal of nuclear medicine and molecular imaging, Munich, v. 38, n. 6, p. 1095-103, jun., 2011.

KORDE, A. et al. Single vial freeze-dried TRODAT-1 kit: preparation and demonstration of clinical efficacy of $[(99 \mathrm{~m})$ Tc]TRODAT-1 in Indian scenario. Rev. Applied radiation and isotopes, Mumbai, v. 96, p. 57-62, fev., 2015.

KRAEMMER, J. et al. Correlation of striatal dopamine transporter imaging with post mortem substantia nigra cell counts. Movement disorders: official journal of the Movement Disorder Society, Vienna, p. 1-7, 22 jul. 2014.

KUNG, H. F. et al. Short communication Imaging of dopamine transporters in humans with technetium-99m TRODAT-1. European Journal Nuclear Medicine, Philadelphia, v. 23, n. 11, p. 8-11, 1996.

LARSSON, A. et al. Dopamine D2 receptor SPECT with (123)I-IBZM: evaluation of collimator and post-filtering when using model-based compensation-a Monte Carlo study. Physics in medicine and biology, Umeâ, v. 55, n. 7, p. 1971-88, 7 abr. 2010.

LEONG, L. K.; CONNOR, M. K. O.; MARAGANORE, D. M. Quantitation of Iodine123-CIT Dopamine Receptor Uptake. Journal of Nuclear Medicine Thecnology, Minessota, v. 27, n. 2, p. 117-123, 2015.

LIU, H. et al. Evaluation of Tourette's syndrome by (99m)Tc-TRODAT-1 SPECT/CT imaging. Annals of nuclear medicine, Shanghai, v. 24, n. 7, p. 515-21, ago., 2010.

LOPES, P. C. R. Estudo de Diferentes Materiais Adsorvedores para o Preparo de Sistemas Geradores de ${ }^{99} \mathrm{Mo}-{ }^{\mathbf{9 9}}{ }^{\text {Tc e e }}{ }^{188} \mathbf{W}-{ }^{188}$ Re. São Paulo, 2009.

MACCALLUM, J. K. et al. Effects of low-pass filtering on acoustic analysis of voice. Journal of voice : official journal of the Voice Foundation, Wisconsin, v. 25, n. 1, p. 15-20, jan., 2011. 
MARQUES DA SILVA, A. M. Reconstrução Quantitativa de SPECT: Avaliação de Correções. 1998. 134 f. Tese (Doutorado em Física) - Faculdade de Física, USP, São Paulo, 1998.

MARQUES, F. L. N. et al. ALGUNS ASPECTOS SOBRE GERADORES E RADIOFÁRMACOS DE TECNÉCIO-99m E SEUS CONTROLES DE QUALIDADE *. Rev. raiol. Bras., São Paulo, v. 34, n. 4, p. 233-239, 2001.

MARTINO, G. et al. Dopamine transporter single-photon emission computerized tomography supports diagnosis of akinetic crisis of parkinsonism and of neuroleptic malignant syndrome. Medicine, Italy, v. 94, n. 13, p. e649, abr., 2015.

MOZLEY, P. D. et al. Binding of [ 99mTc ] TRODAT @ 1 to Dopamine Transporters in Patients with Parkinson's Disease and in Healthy Volunteers. Phys. Med. Biol. Philadelphia, 2014.

NEMA NU-1: Performance measurements of scintillation cameras. National Electrical Manufacturers Association, 1300 North 17th Street, Suite 1752, Rosslyn, Virginia, USA. 2001. http://www.nema.org/stds/nul.cfm

PARETO, D. et al. Iterative reconstruction with correction of the spatially variant fanbeam collimator response in neurotransmission SPET imaging. European journal of nuclear medicine and molecular imaging, Barcelona, v. 30, n. 10, p. 1322-9, out. 2003.

PARK, M. A. et al. Performance of a high-sensitivity dedicated cardiac SPECT scanner for striatal uptake quantification in the brain based on analysis of projection data. Medical physics, Boston, v. 40, n. 4, p. 042504, abr. 2013.

PATTERSON, H.E., HUTTON, B. F. Distance Assisted Training Programme for Nuclear Medicine Technologists. IAEA, Vienna, 2003.

PELLECCHIA, M. T. et al. Cognitive performances and DAT imaging in early Parkinson's disease with mild cognitive impairment: a preliminary study. Acta neurologica Scandinavica, Salerno, v. 131, n. 5, p. 275-81, maio, 2015.

POWSNER, R. A.; POWSNER, E. R. Essential Nuclear Medicine Physics. 2a Ed. Boston: Blackwell Publishing, 2006.

SAHA, G. B. Fundamentals of nuclear Pharmacy. 6a ed. EUA: Springer, 2010. 
SANTOS, R. L. S. R. Marcação de análogo da timidina com complexo organometálico de tecnécio-99m para diagnóstico de câncer: avaliação radioquímica e biológica. Dissertação de mestrado. Instituto de pesquisas energéticas e nucleares - USP. São Paulo. 2007.

SCHERFLER, C; POEWE. W, Dopaminergic Imaging in Parkinson's Disease: SPECT. Oxford University Press. Sep. 2011.

SERET, A.; FORTHOMME, J. Comparison of different types of commercial filtered backprojection and ordered-subset expectation maximization SPECT reconstruction software. Journal of nuclear medicine technology, Liége, v. 37, n. 3, p. 179-87, set., 2009.

SOWA-STASZCZAK, A. et al. Optimization of image reconstruction method for SPECT studies performed using $\left[{ }^{99} \mathrm{mTc}-\mathrm{EDDA} / \mathrm{HYNIC}\right]$ octreotate in patients with neuroendocrine tumors. Nuclear medicine review. Central \& Eastern Europe, Krakow, v. 16, n. 1, p. 9-16, jan., 2013.

SPRENGER, F. S. et al. Nonmotor Symptoms in Subjects Without Evidence of Dopaminergic Deficits. Movement disorders: official journal of the Movement Disorder Society, Austria, p. 1-6, 15 mar. 2015.

STEVES, A. M. Review of nuclear medicine technology. Society of Nuclear Medicine Inc., Reston, ISBN 0-032004-45-8, 1996.

STODILKA, R. Z. et al. SPECT quantification The relative contributions of scatter and attenuation corrections toward improved brain SPECT quantification. Phys. Med. Biol, v. 43, p. 2991-3008, 1998.

VALLABHAJOSULA, S. Molecular Imaging: Radiopharmaceuticals for PET and SPECT. Springer. p. 392, Sep. 2009.

VINES, D. C. et al. Evaluation of 2 scatter correction methods using a striatal phantom for quantitative brain SPECT. Journal of Nuclear Medicine Technology, Maryland, v. 31, n. 3, p. 157-160, 2003.

WENG, Y. et al. Sensitivity and Specificity of 99m Tc-TRODAT-1 SPECT Imaging in Differentiating Patients with Idiopathic Parkinson's Disease from Healthy Subjects. Clin. Nucl. Med, Kaohsiung, 2014. 
WINZ, O. H. et al. Image quality and data quantification in dopamine transporter SPECT: advantage of 3-dimensional OSEM reconstruction? Clinical nuclear medicine, Aachen, v. 37, n. 9, p. 866-71, set., 2012.

XU, L.; CHEN, H. An Improved Ordered Subsets Expectation Maximization Reconstruction. [s.d.].

YIN, T. K. et al. Differences of various region-of-interest methods for measuring dopamine transporter availability using 99mTc-TRODAT-1 SPECT. The Scientific World Journal, p. 837439, jan., 2014.

ZENG, G. L. Medical Image Reconstruction: A Conceptual Tutorial. Department of Radiology. University of Utah, USA, 2009.

ZOLLE, I. Technetium-99m Pharmaceuticals: Preparation and Quality Control in Nuclear Medicine. Department of Medicinal/pharmaceutical Chemistry. University of Vienna. Austria Springer. 2007. 
ANEXOS 


\section{ANEXOS}

ANEXO 1 - Anatomia do corpo estriado contendo a estrutura do putâmen e núcleo caudado.

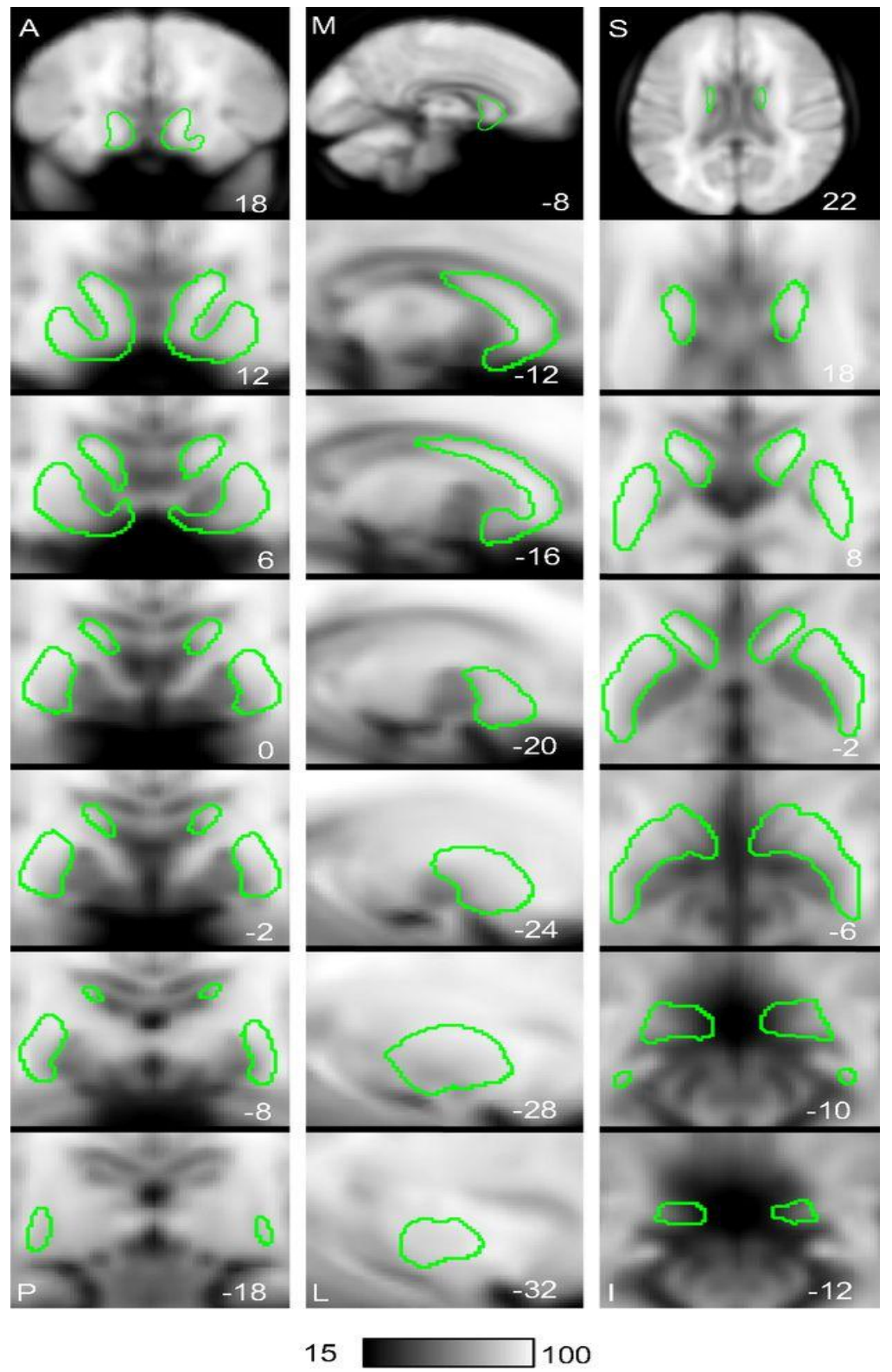

Fonte: CHOI; YEO; BUCKNER, 2012. 
ANEXO 2 - Formulário explicativo para aplicação das notas pelos especialistas em medicina nuclear.

\section{FORMULÁRIO - ANÁLISE DAS IMAGENS}

Informação clínica da imagem:

( ) Distinção das estruturas do corpo estriado (Putâmen e cabeça do Núcleo Caudado)

( ) Resolução Espacial da imagem

- Retratar distintamente dois objetos (diferentes tamanhos) e bem próximos um do outro

- Blurring: amaciamento das imagens e desfoque das estruturas

( ) Contraste da imagem

- Diferença na escala de cinza da imagem em regiões adjacentes

( ) Ruído da imagem

- Diferentes intensidades ou flutuações de contagem que dificultam analisar a estrutura desejada 